Portland State University

PDXScholar

$1-1-1984$

\title{
State policy for multicultural education: an inquiry into policy status and administration, 1968-1984
}

Thomas G. Greene

Portland State University

Follow this and additional works at: https://pdxscholar.library.pdx.edu/open_access_etds Let us know how access to this document benefits you.

\section{Recommended Citation}

Greene, Thomas G., "State policy for multicultural education: an inquiry into policy status and administration, 1968-1984" (1984). Dissertations and Theses. Paper 776.

https://doi.org/10.15760/etd.776

This Dissertation is brought to you for free and open access. It has been accepted for inclusion in Dissertations and Theses by an authorized administrator of PDXScholar. Please contact us if we can make this document more accessible: pdxscholar@pdx.edu. 


\section{STATE POLICY FOR MULTICULTURAL \\ FDUCATION: AN INQUIRY INTO \\ POLICY STATUS AND ADMINISTRATION \\ $1968-1984$}

By

Thomas G. Greene

A dissertation submitted in partial fulfillment of the requirements for the degree of

\section{DOCTOR OF EDUCATION}

in

PUBLIC SCHOOL ADMINISTRATION AND SUPERVISION

Portland State University

The University of Oregon

1984 
TO THE OFFICE OF GRADUATE STUDIES AND RESEARCH:

The members of the Committee approve the dissertation of Thomas G. Greene presented July 12, 1984.


John D. Lind 2 PSU


Ronald Petrie - PSU


APPROYED :

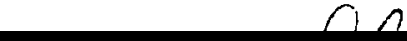

George V. GuÝ, Bi-Universit Program Coordinator (PortlanäSt,ate university)

Max Abbott, Bi-University Program Coordinator (University Oregon)

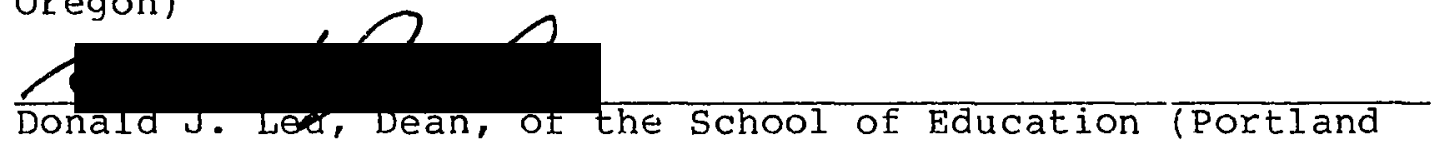
State University)

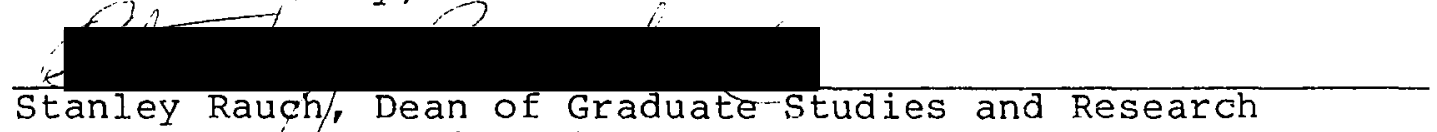
(Portland state University) 
AN ABSTRACT OF THE DISSERTATION OF Thomas G. Greene for the Doctor of Education in Public School Administration and Supervision presented July 12,1984 .

Title: State Polidy for Multicultural Education: An Inquiry into Policy Status and Administration: 1968-1984 APPROVED BY MEMBERS OF THE DISSERTATION COMMITTEE:

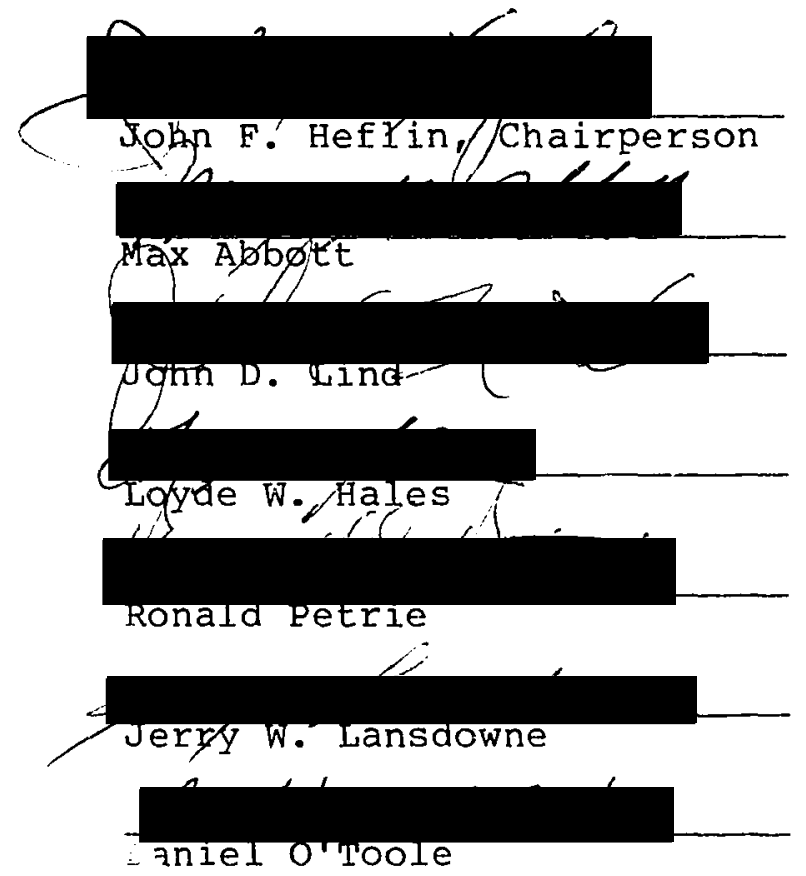

America's population is diverse in ethnic and cultural composition. This wealth of diversity has been viewed as a positive attribute, but has also resulted in prejudice, discrimination and intergroup tension. Efforts to deal with this social problem have ranged from philosophical rhetoric to government funded programs. One recent phenomena has 
been the rise of the multicultural sduration movement. This study addresses the growth of this movement through a policy analysis paradigm. Policy analysis has been viewed by Boyan (1981) as a conceptual framework for examining the practice of educational administration. This study focuses on the growth of multicultural education through policy formation, the administration of multicultural education through policy implementation and the effects of multiculutral education through policy impact.

The focus of the study centers around three basic questions related to the policy analysis paradigms presented by Jones (1977) and Heflin (1981):

1) What is the current status of multicultural education programming policy mandates at the state level?

2) Have certain administrative practices been employed by the state education agencies in implementing muiticultural programming?

3) What are the perceptions of chief state school officers (CSSOs) as to the effectiveness and status of multicultural programming in their state?

To obtain data in response to those questions, a survey was mailed to all fifty chief state school officers inquiring about policy mandates and administrative practices 
and responses were solicited from CSSO's regarding perceptual statements about the impact of multicultural education. The results of this descriptive study are summarized in the remaining paragraphs.

In reference to the status of multicultural programming policy mandates, the findings reveal that each of 33 states have at least one mandated multicultural program in the areas of multicultural education, bilingual education, ethnic studies, affirmative action, textbook adoption process or inservice education and technical assistance. The frequency of policies across the states mandating these programs has decreased since 1980.

Policy and program implementation were examined by inquiring about the frequency of usage of nine common administrative practices in the areas of: 1)planning/assessment, 2) organization/development, 3) supervision/technical assistance and 4) evaluation/review. Findings indicate the most commonly used administrative practices in implementing multicultural education are: 1) involvement of students, teachers, administrators and community members in planning at the state level, 2) a reflection of multicultural education in the SEA's organization structure and 3 ) personnel assignment and specific personnel have responsibility for multicultural education. Practices in the category of evaluation and review were the leastfrequently used practices. 
The impact of multicultural education was assessed by asking cssos to respond to ten statements about the impact of multicultural education in their state. cssos viewed multicultural education as a positive force, however, it has not been implemented evenly within or across the states, nor has it been a major focus for most states. Multicultural education is supported by various ethnic communities and state education agencies are actively involved in implementation. A chi square test with Yate's correction was used to determine if CSSOs with mandated multicultural education policies responded differently from those without mandated policies to ten perceptual statements on a likert scale. The two categories of cssos responded differently to six of ten items. Those cSSOs with mandated policies responded more positively to the impact of multicultural education.

Scholars have indicated that multicultural education may be at educational crossroads where one turn results in continued survival and success and another turn results in an educational grave. This study suggests that this premise may be true. CSSOs are very divided about the future of multicultural education in their respective states. 


\section{ACKNOWLEDGEMENTS}

I wish to express gratitude to Dr. John Heflir, chairperson of my doctoral committee: and to the other members of the committee who also gave of their time, expertise, and support, Dr. Loyde Hales, Dr. John Lind, Dr. Max Abbott, Dr. Jerry Lansdowne, Dr. Ron Petrie and Dr. Daniel O'Toole.

I am also deeply indebted to Barbara Wiegele and Doris Anderson for their excellent technical assistance.

I further acknowledge the support of my parents, George and Norma Greene, and for clerical assistance I thank Arlie Smith. Thanks must also go to Audrey Smith Richter, an educator devoted to the cause of equal education for all who sparked my interest in this field and academe.

To my wife, Shannon, I thank for encouragement, sacrifice, patience, love, prayers and forgiveness. To Brittany, my three-year old daughter, I thank for the encouraqina words, "When you are a doctor, can you be a daddy?", and for playing "study" and discussing dissertation to placate her father. 
ACKNOWLEDGEMENTS . . . . . . . . . . . . . . . . i i

LIST OF TABLES • • • • . • . . • . • . • • . . vi vi

CHAPTER

I INTRODUCTION • . . . . . . . . . . . 1

Background . . . . . . . . . . 3

Statement of the Research Problem . . . 10

Conceptual Framework . . . . . . . 12

Importance of the study. . . . . . . . 19

Contribution to Educational Practice. 20

Contribution to status of Policy

Development . . . . . . . . 21

Methodology . . . . . . . . . . . 22

Assumptions and Limitations . . . . . 23

Operational Definitions... . . . . . 24

Organization of the Study . . . . . . 27

II. REVIEW OF THE LITERATURE. . . . . . . . 29

Introduction and Scope of the Review. . . 29

Multicultural Education . . . . . . . 30

Philosophical Foundations . . . . . 31

Philosophical Conclusions . . . . . 34

Issues and Questions Related to Multicultural Education. . . . . . . . 34

Is Multicultural Education Divisive?. . 35

Is Multicultural Education Another

Attempt to Placate Minorities, Another

Attempt at Assimilation, or An Effort

to Address the Educational Needs of

America's Diverse Population?. . . 36

How Should Multicultural Education $\mathrm{Be}$

Implemented?. . . . . . . . . . . 40

Practices in Multicultural Education with

an Empirical Research Base . . . . 50

Teacher Preservice and Inservice

Education School and Classroom

Implementation. . . . . . . . 59

State Policy studies for Multicultural

Education............. . . 66

Summary, Findings, Conclusions. . . . . 79 
CHAPTER

III. METHODOLOGY AND PROCEDURES • • . • • . • . . 84

Introduction . . . . . . . . . . . 84

Survey Research Methodology. . . . . . . 84

The Survey Instrument. . . . . . . . 87

The Population . . . . . . . . . . 89

Data Collection. . . . . . . . . . . 89

Data Analysis. . . . . . . . . . . . . 90

Slimary. • . • . . . . . . . • . . 91

IV. PRESENTATION AND ANALYSIS OF THE DATA. • • . 92

Introduction . . . . . . . . . . . 92

State Level Mandates Regarding Multi-

cultural Programs. . . . . . . . . 92

Multicultural/Multiethnic Education. . 93

Bilingual Education. . . . . . . . . 99

Ethnic Studies . . . . . . . . . 103

Affirmative Action Plans . . . . . 105

Textbook Selection Process . . . . . 108

Inservice Training/Technical

Assistance. . . . . . . . . . . 111

Multicultural Programs Across the States . 114

Chief State School officers' Perception

of the Impact of Multicultural Education. 116

Analysis of the Data . . . . . . . . 124

Summary. •. . . . . . . . • . . . 131

V. SUMMARY, CONCLUSIONS, RECOMMENDATIONS. • • 133

Introduction . . . . . . . . . . . . 133

Summary of the Study . . . . . . . . . 133

Policy Formation Conclusions . . . . . . 136

Policy Implementation Conclusions. . . . 138

Policy Impact Conclusions. . . . . . . 140

Suggested Further Research . . . . . . 143

Summary. . . . . . . . . . . . . 145

Bibliography . • . . . . . . . . . . . . • . 147

Appendix :

Appendix A . . . . . . . . . . . . . 156

Appendix B . . . . . . . . . . . . . . . . 159

Appendix C . • . . . . . . . . . . . . . 163 
Table

I The Policy Process. . . . . . . . 16

II Multicultural Education and Aspects of Education Addressed in Those provisions. . . . . . . . . . 69

II Statutory Provision Mandating Multicultural Programs, 1980. . . . . . 75

IV Mandated Multicultural/Multiethnic Education Policy, 1984. . . . . . . 94

$V$ Administrative Practices of State Education Agencies with Mandated Policies for Muicicultural/Multiethnic Education. . . . . . . . .

VI Admiristrative Practices Employed by State Education Agencies Implementing Mandated Multicultural/Multiethinic Policies. . . . . . . . . . . 98

VII Mandated Bilingual Education Policy,



VIII Manäated Ethnic Studies Policy, 1984. . . 103

IX Mandated Affirmative Action Policy, 1984. 106

X Mandated Textbook Selection Policy, 1984. 110

XI Mandated Inservice Training or Technical Assistance in Multicultural/Multiethnic Education, 1984. . . . . . . 112

XII Mandated Multicultural Programming, 1984. 115

XIII Frequencies of states With/Without Multicultural Programming, 1984. • . . 116 
Table

XIV Chief state School Officer's Perceptions of the Impact of Multicultural sducation at the Statewide Level. . . . . 117

$\bar{X} \bar{V} \quad$ A Comparison of the CsSo's Perceptual Response ana the Policy Mandate Variable . . . . . . . . . . 125

XVI Multicultural Programming Policy Mandates, 1980-1984. . . . . . . . . . . 128

X̃VII Comparative Growth of State Mandated Programs, 1974-1984......... 130

XVIII Percent of States with at Least one Mandated Multicultural Program, 1968-1984. . . . . . . . . . . . 
CHAPTER I

\section{INTRODUCTION}

Multicultural education has become an important focus in education over the last three decades. Although, for many educators, it appears to be yet another "buzzword," or a confusing term which can mean anything from an attempt to foster ethnic revolt to a possible panacea for world peace. Various interest groups, politicians, and educators have defined it, implemented it and promoted it, and government monies and the endorsements of professional educational organizations continue to strengthen it. However, this relatively new thrust in education needs continued observation and study to determine exactly what it is. However, it is being implemented, and eventually, what are the results.

America and cultural diversity are nearly synonymous. Americans are a diverse mixture of various races, cultural and ethnic groups. Even prior to early European exploration of the New World, the natives of this land were diverse in every regard and with the immigrations of people from all corners of the world, America's population became and is becoming increasingly diverse. It is from 
this diversity that the thrust for multicultural education has arisen. "Since the 1960's, with varying degrees of success and reflection, the nation's schools and other educational institutions have responded to the unique educational problems of the nation's growing ethnic population" (Banks, 1981, p. 11). The impact of the efforts of these educational institutions has been documented, but Banks makes the following observations.

The degree of impact is difficult to determine. Almost any educator who has recently visited schools in different parts of the nation would probably agree, however, that the teaching strategies, culture, norms, and other aspects of the schools indicate that many of the nation's educators have been little if at all influenced by the myriad developments and publications in multiethnic education.

The rise of neoconservatism, the so-called 'back to the basics' movement, and the recent upsurge of racial incidents in the nation suggest that the national commitment to equality for excluded groups which emerged during the 1960's is rapidly waning and that many leaders would like to see the nation return to the 'good old days' of doing business as usual, with little attention devoted to the problems and promises of ethnic group life in the United States. (Banks, 1981, p. 12)

With this confusion and conflict in the air, this research begins to probe and document the status of multicultural education policies, and to examine the role of state governments in facilitating multicultural education. 


\section{Background of the Froblem}

Since very early times people have been moving to "greener pastures." The shifting of groups of people from one place to another has caused religious, social, economic and political problems both for the immigrant and those occupying the territory. "Every nation has had its immigration and emigration problems. But, the mass immigration that took place to the United States is unmatched elsewhere" (Epps, 1974, p. 38).

Historically, immigration to America has been cyclical and each cycle has been dominated by different ethnic groups from different geographic locations. Cycles of heavy immigration have been followed by a rise in restrictionism and nativism. As new immigrants arrived, they were thought to be inferior.

The immigrants who arrived after 1880 struck the American immigrant as a dark, swarthy, inferior race; they were drawn into the orbit of the associations linked to 'black.' (Novack, 1973, p. 95)

The Civil rights of these new immigrants, as well as those of Blacks Americans were continually violated.

Because Blacks were more numerous, more aware of the hostility of whites, and more distinctively colored, they were the most overtly harrassed and oppressed. (Baptiste, 1979, p. 5)

An attempt to right this wrong was the Civil Rights Act of 1875, but it was circumvented by Jim Crow laws and the 
sanctioning of the practice of "separate, but equal" which was codified in the Plessy $v$ Ferguson (1896) decision.

In 1909, Israel Zangwills' play, "The Melting Pot," gave to Americans the conceptual label for the social dynamics of the time. America was to represent the fusion of all races. Americanization of all immigrants was the goal. This notion was consistent with the rise of nativism. Commanger states that "It was the public school which proved itself the most efficacious of all agencies of Americanization -- Americanization not only of the children but, through them, of the parents as well" $(1969$, p. 6). While the melting pot concept was the popular guiding socialization theory, the early years of the twentieth century did not bring about its practice. During the immigration of the 1900's, Kallen (1924) wrote about the concept of cultural pluralism. But, Kallen's theories were buried under the dominance of the "melting pot theory" and would not resurface until the mid-1950's (Banks, 1981).

According to Epps, "The melting pot theory is as old as the republic" (1974, p. 45). Thus, the eradication of such a theory was no small task for the early proponents of pluralism, such as Horace Rallen, John Dewey and Julius Drachsler. The melting pot theory became firmly rooted and was based on the central theme that all Americans, re- 
gardless of cultural orientation, should fuse and melt together values and customs, creating a superior and uniquely American culture. The metaphor became a myth. The ingredients did not melt together as many had hoped.

The reality of American society today is that while many ethnics have been acculturated -- that is have adopted the mainstream cultural tastes in music, clothes, entertainment, food, the WASP ethic, and so forth -- all have not been totally assimilated into the mainstream social system. Many disparate ethnic groups are at different stages of the assimilative process. (Pratte, 1973 , p. 32)

In the 1950's, the cultural dynamics of American society began prođucing strong ethnic groups of all types and a rekindled interest in the theories of cultural pluralism.

The combined forces of rising expectations and discrimination in employment, housing and education caused Afro-Americans to lead an unprecedented fight for their rights which became known as the Black Revolt. (Banks, 1977, p. 12)

Black Americans set the pace for the advancement of ethnicity. "In a sense, the black civil rights movement legitimized ethnicity and other alienated ethnic groups began to demand more group and human rights" (Banks, p. 13). The rise of ethnicity coincided with the waning of enthusiasm and support for the melting pot theory.

Novak describes the rise of ethnicity and hope for cultural pluralism, stating that

Millions of Americans, who for a long time tried desperately even if unconsciously to become "Americanized," are delighted to discover that they no longer have to pay that price; are grate- 
ful that they were born among the people destiny placed them in; are pleased to discover the possibilities and the limits inherent in being who they are... (and can see that) there is a creativity and new release, there is liberation, and there is hope. (Novack, 1971, p. 29i:

of course, not all have caught Novack's dream, but ethnic priàe will eventually give rise to cultural pluralism.

With the re-emergence of cultural plualism as a perceived viable plan for American society, has also come a refinement of its definition and application. When Kallen and others first wrote about cultural pluralism, it was in reference to the wave of immigration taking place. Now, the ideology of cultural pluralism is being espoused by contemporary thinkers such as Moynihan, Itzkoff, Heflin, Hilliard, Banks, Baker, Valverde, and others and is being applied to the emergence of the "unmelted melting pot," as well as to a new wave of Asian immigrants.

The concept of cultural pluralism as defined today is represented by this statement from The Commission on Multicultural Education:

Cultural pluralism is to understand and appreciate the differences that exist among the nation's citizens. It is to see the differences as a positive force in the continuing development of a society which professes a wholesome respect for the intrinsic worth of every individual. Cultural plutalism is more than a temporary accommodation to placate racial and ethnic minorities. It is a concept that aims toward the heiahtened sense of being and of wholeness of the entire society based on the unique strengths of each of its parts 


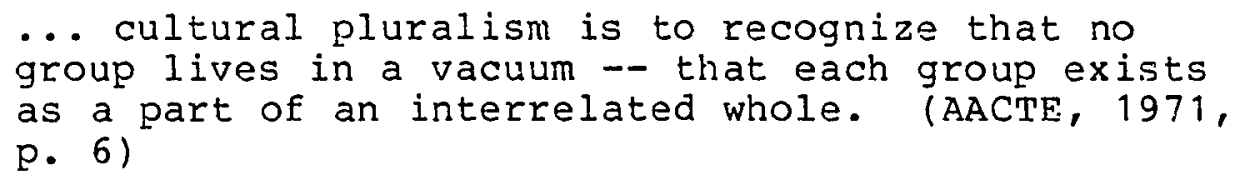

Throughout history, education has been a primary force in the passing of cultural heritage from generation to generation. This has been a crucial issue in the history of American education. But, how is America's public education system controlled?

In the early years of education in the united states, schools were primarily the function of local parent groups, enterprises sponsored by individuals, or an arm of the church (Campbell and Sroufe, 1965). Thus, the local control of schools became a firmly rooted American tradition. Control remained at the local level through much of the development of U.S., public schools, even though state constitutions provided for the establishment and control of public schools. The constitution of the United States does not expressly mention the issue of education or schools but, through the Tenth Amendment, states have reserved all other powers not delegated to the Federal government through Constitutional provision. Hence, each state, except Connecticut, has a constitutional provision for the establishment of a public school system (Bolmeier, 1968). 
The management and control of public education are an ultimate responsibility of the state. Subject to restrictions imposed by federal and state constitutions, state legislatures create, fund, and regulate public schools through various state, intermediate and local agencies. (Hazard, 1978, p. 1)

Historically, even though the state is responsible for education, the local school board has dominated the educational policy realm. But recently, increasing state involvement has been an observable phenomena, (Innaccone, 1967). State legislatures have become more deeply involved in educational policy making through greater involvement in education governance. Categorical programs, accountability laws and increased state funaing illustrate greater statewide involvement. State legislatures also have developed directly or indirectly policies concerning pupils, curriculum, qualifications of teachers and a vast range of management procedures (Hazard, p. 1, 1978). This tendency toward state centralization of educational policy making as been furthered by an increasing concern over the issues of equity in education. Various ethnic minority groups have been the impetus benind the equity movement in education over the last three decades. The quest for educational equity has been an educational issue fought in both the political and judicial arena. Cultural diversity is a by product of the equity movement. 
American society is in the process of change and the value of cultural diversity is being recognized. But, many groups have perceived local educational institutions as unresponsive to their demands for equal educational opportunity.

It may be argued that the principal charge against the Public school Movement (PSM) today has yet to be raised, namely, that it has failed to provide a genuine commitment to the toleration of the lifestyles of the various ethnic, religious and racial subgroups that make up the American social order - . Basic to an understanding of this problem is the recognition that this criticism of the PSM is symptomatic of a rejection of the dominant goal-system ideology of assimilation that has dominated American schooling since the second half of the nineteenth century. Pratte, 1973, p. 121)

Various factions of society have turned to other government levels (federal and state) for assistance in achieving educational reform.

The civil rights movement, for example, resorted to federal courts for relief from segregated schools when local and state officials provided unwilling or unable to address desegregation questions satisfactorily. So, too, other groups (such as American Indians, parents of children with limited English proficiency, the handicapped, and women, have pressed and are continuing to press federal and state governmental agencies to respond to their requests for assistance. (NIE, 1979, p. 8)

The result of such pressue is a new body of educational policy regarding equity, beginning with the Brown decision in 1954. Since that time, and as a result of continued political pressure and additional legal mandates, schools have been directed to foster cultural 
pluralism through multicultural education. This curriculum intervention was designed primarily to reduce inter. racial tension, foster intercultural understanding and contribute to the development of students self-concept. Thus, the new body of law regarding equity has been extended to include law which fosters intercultural understanding through multicultural education, such as Article 3.3 in the California Education Code.

Political pressure on any type of governmental agency in this democratic society generally results in a change of the agency's position (Jones, 1977). Law is the means for advancing various governmental postures and those postures are created through the political process. This trend towards increasing state governmental involvement in educational policy is a relatively new phenomena. Lehne (1983) states,

Twenty years ago there would have been little reason to note this fact; state legislatures seldom became involved in debates about elementary and secondary education policy, nor did they participate often in formulation of policies that governed post secondary institutions. ( $p$. 43)

State governmental initiated educational policy related to multicultural education is the focus of this research.

\section{Statement of the Research Problem}

The research problem is concerned with the documentation of state multicultural policy mandates, state level 
administrative practices related to multicultural programs, and an examination of the perceived effects of such programs as viewed by chief state school officers in each of the fifty states. The problem has three dimensions:

1) What is the current status of multicultural education policy mandates as measured through governmental enactments, i.e. scatutes, agency regulations/guidelines or state board of education policy.

2) Were certain administrative processes a) planning/assessment, b) organizing/developing, c) supervision/technical assistance, and d) evaluation/review) employed by the state education agency (SEA) in the establishment of state level multicultural educational programming?

3) What are the perceptions of chief state school officers relative to the effectiveness of such enactments and related program implementation, strategies and tactics?

Previous studies have explored the status of state governmental mandates requiring multicultural programs. Examples are Buffington (1974), The American Association of Colleges for Teacher Education (AACTE) (1978), and Greene (1980). While the activity of the state government can be observed longitudinally by comparing the data from the 
three studies, occurrences over the last three years are critical in documenting the status of state mandated multicultural programs. Since those studies were conducted, new political, economic and educational climates have evolved. According to Banks (1983), multi-ethnic education is at a critical point. That is to say, the turmoil of the sixties which gave birth to the multicultural emphasis seems far removed from today's society and the nation is moving on to other concerns. For example, global education, educational excellence, advanced technological education and educational finance are just a few issues demanding the attention of educators. In this plethora of educational issues, where does the multicultural education movement stand on the nation's agenda?

\section{Conceptual Framework}

The governance of public education in the United States has been established in an earlier discussion as has a discussion of the dynamics involved therein. Many paradigms exist to facilitate an understanding of that phenomena. This study borrows from the discipline of political science, more specifically, policy analysis provides the framework for this study has evolved.

Policy analysis is best understood by examining the definitions of the two words: policy and analysis. 
"Webster's dictionary describes policy as follows:

1a: prudence or wiscom in the management of affairs: sagacity; $b$ : management or procedure based primarily on material interest; 2 : a definite course or method of action selected from among alternatives and in light of given conditions to guide and determine present and future decisions'

The key to understanding policy analysis is contained in the second definition -- a notion of selecting from a set of alternatives. Add to this policy definition Webster's definition of analysis:

'separation of a whole into its component parts; a: an examination of a complex, its elements and their relations...'

In short, these two dictionary definitions, when combined, capture the essence of the policy science concept advanced by the early theoreticians" (Heflin, 1981, p. 2). Policy analysis is a field with strong applications to the area of educational administration, for "the purpose of policy analysis is to provide data-based guides for educational practice at the national, regional, state or local level" (Heflin, 1981, p. 4).

policy analysis should be of obvious interest to the educational administrator. Boyd and Immegart (1979) see policy research as "the most preferred modality for reducing uncertainty and centrifugal activity in educational administration research" according to Boyan (1981, p. 11). 
The educational policy approach seems pecularly appropriate for an applied and interdisciplinary field such as educational administration. This is so because, with its focus on the consequences of policies, on what makes a difference at the level of educational implementation, educational policy analysis helps to bind together theory and practice and provides a unifying nexus for research from different disciplines and field of study.

Wirt (1979) and Mitchell (1979) also make a strong case for policy analysis in education as a promising area of research.

Therefore, an examination of law and government and education policy is central to this study. The conceptual framework for this study is a systematic inquiry into governmental policy toward education, specifically multicultural education. Policy analysis is a relatively new field, especially educational research.

Policy research in general and educational policy research in particular is in a nascent stage of development; far from a state of being, it is a state of becoming. (Yeakey, 1983, p. 274)

The last three decades have seen federal and state governments become increasingly involved in educational governance, and as this trend continues it becomes important to document and analyze the involvement of 1 aw and government in education. Wirt (1978) points to this increasing government involvement and its effect on the centralization of school governance at the state level. Accountability laws, categorical srants, policies focusing 
on equity issues or any type of educational. law often

oriainate in Washinaton D.C. and impact both state

government and the classroom (NIE, 1979).

This study is, in part, an attempt to merae administrative and policy research. According to Yeakev (1981)

one offering policy/administrative studies provide is the

furthering of reiection of the apolitical approach to

administration. Historically, administration has been

viewed as apolitical.

Political theorists beqinning with Woodrow wilson (1887) have created false distinctions between polj.tics and administration, restrictina politics to deliberate attempts at decision making by the formal aroups to improve educational oractice in the field of multicultural education throuah the compilation of the works of major scholars in the field and a synthesis of the material. The study also provides knowledae about the various types of multicultural programs and which, over time, have become the most or least common, as well as to document the use of various implementation strategies. Educational practitioners will be provided with a current national perspective on the viability and vitality of the multicultural movement. Inferences may be drawn from the data about the movements' future educational impact as a national educational prioritv. Perhaps the last four years have brought other priorities to the forefront and multicultural educational statutory mandates are not continuinq to increase, assiqned such functions. [ ] The real distinction between politics and administration is not to be found in the formal separation of functions nor in titular positions, but in the significance of decisions for organizational functioning. (Yeakey, 1983, p. 3)

Thus the conceptual framework for this study endeavors to link the political entanalements of administra- 
tive practice rather than extricate the political from the administrative.

There is an abundance of policy frameworks, but Jones (1977) provides a policy analysis paradigm which has great ability for analyzing the interaction between law, government and education (See Table I).

TABLE I

THE POLICY PROCESS

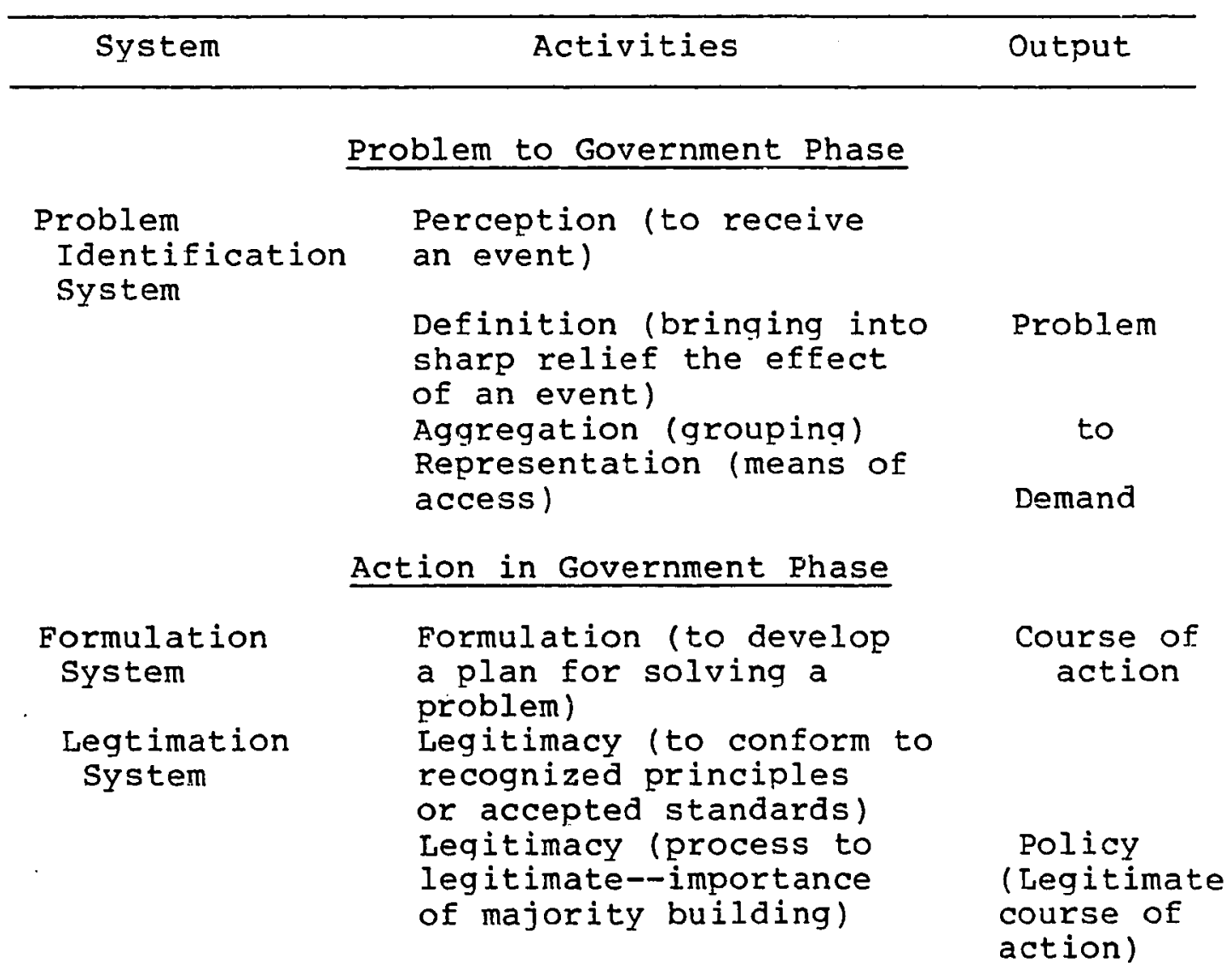


TABLE I continued



(Jones, 1977, p. 149).

Clearly this model has relevance for documenting and analyzing the role of state government in the multicultural education movement. The problem identification activity of the Jones model could refer to recognition of discriminatory practices against minority population, and one can trace the attempts of this problem's resolution through history and see the parallels with the Jones model. Another policy paradigm provides a framework for simplifying the Jones' model. 
Heflin's (1979) model is based on the work of several political scientists and parallels the Jones' model, but is based on three phases in the policy process:

1) The Policy Formulation Phase

2) The Policy Implementation Phase

3) The Policy Impact Phase

These two paradigms applied to the rise of multicultural education policy provide a schematic for reflecting on the background material presented earlier in the chapter, but the following questions can be extrapolated from the policy process models to further refine the conceptual framework and generate research questions for this study. The research questions are:

Policy Formation Phase

1) What is the status of legitimation (i.e., policy mandates) at the state level regarding multicultural programming particularly multicultural education?

2) How widespread is the practice of multicultural programming without policy mandates.

Policy Implementation Phase

3) Are specific administrative processes used in the implementation of multicultural education policy? Policy Impact Phase

4) What has been the impact of mandated multicultural education policy, as perceived by the chief state school officers? 
5) Over time has the status of multicultural program legitimation changed over time if at all?

An academic interest in the role that policy process commancis in the operation of public school systems, as well as a commitment to the development of a culturally pluralistic society are the motivating factors behind this study. Banks (1977) states:

Events of the last decade have dramatically indicated that we live in a world society beset with momentous social and human problems, many of which are related to ethnic hostility and conflict. Effective solutions to these critical problems can be found only by an active, compassionate, and ethnically sensitive citizenry capable of making sound public decisions that will benefit our ethnically diverse world community. (p. 32)

This citizenry may come to pass, in part, as a result of multicultural education; at least that is the desired outcome. That assumption makes multicultural education an imperative.

Multicultural education is imperative for future generations of Americans for a variety of reasons. With a finite amount of world resources, interaction and interdependence among nations are increasing. Also, migration among neighboring and even distant countries is on the rise. (Valverde, 1977, p. 200)

The observations of Banks and Valverde point to the need for multicultural education and this study will document the status of that educational program.

The Importance of the Study

Research in the social sciences centers around theory development, research methodology, and application 
in an effort to establish new knowledge. This study is important for its contribution to both educational practice and policy development.

\section{Contribution to Educational Practice}

Multicultural education is a developing philosophical position from which an educational programing thrust has developed, but little is known about the extent of its adoption, implementation or impact.

This study will provide the educational practitioner with data regarding the location of multicultural programming, some perceptions regarding its effectiveness and some knowledge regarding the use of certain administrative practices utilized for program implementation. This status study may provide valuable data for educational planners in determining trends and programming considerations. James Banks recently observed,

Multiethnic education is indeed at the crossroads. The future of this movement will influence how our children and their children will deal with racial problems and conflict. Without active and strong support from policy makers and opinion leaders in the government, in business, and in the education community, multiethnic education may fail in its central mission, and U.S. institutions, including schools and colleges, will retreat to doing business as usual. If this happens, muted ethnic tensions and frustrations will grow by leaps and bounds. This is a dismal prospect but a distinct possibility. I prefer to believe that American leaders and policy makers will mobilize the resources needed to institutionalize multiethnic education in U.S. schools and universities. (1983, p. 559) 
The importance of this study is magnified by Banks' perspective. The study, to some degree, will provide a data base for inference as to whether multicultural education will weather the eighties.

Iastly, it will provide a foundation for other educators interested in advocacy for policy analysis as a tool in the study of educational administration as suggested by Boyan (1981) and others.

\section{Contribution to Policy Development}

This study has value as a policy reference tool. Lehne (1983) states,

While some work has been done on state legislatures and some on education policy in the states, thus far little research has been devoted to an explicit examination of state legislatures and education. The need for such research has recently become more acute because legislatures have been developing as modern political institutions. ?. 13 !

This research airection adds to the value of the study. It could be used by lawmakers and lobbyists for examining the practices of other states in regard to multicultural education programs and thus play a facilitory role in the adoption, modification or termination of policies. The opinions of the chief state school officers on the implementation and impact of such policies would be valuable to the educational practitioner, policy analyst and legislator.

The study will have value for educators in making inferences about the effectiveness of policy mandated 
curriculum programs versus nonmandated curriculum programs. That data, in turn, may serve to impact the legitimation process as indicated in the Jones' model. For these reasons, the study will serve to advance knowledge in the relatively new fields of multicultural education and educational policy analysis.

\section{Methodology}

The study is a survey research design in nature. The focus of the study is the current status of multicultural programming as related to state government policy, the utilization of certain administrative practices, and the perceived effectiveness of the former.

The development of the survey instrument was based on Buffington's (1974) work and the work of the AACTE (1978) and the instrument was refined to include: 1) data regarding administrative practices and 2 ) the perceived impact of the documentedpolicies and practices.

Data collection began in September, 1983 and continued through February, 1984. Responses to the survey were solicited from each of the fifty chief state school officers through the mail and telephone conversations. The raw data was tabulated and prepared for analysis. The data resulting from the study was analyzed in qualitative and quantitative manners respectively. Conclusions and inferences were drawn based upon the data and 
by comparing the previously cited policy studies, reviewing the current literature, and conducting statistical analysis.

\section{Assumptions and Limitations of the Study}

The assumptions of this research project are:

1) Multicultural education when implemented according to theory will positively impact the development of cultural pluralism.

2) Governmental policies reflect an intention or action and result from a scenario described in theories regarding public development.

3) State education agency personnel and the chief state school officer in each state have some concept of multicultural programming nationally and within their respective states enhancing the validity of their responses to the survey instrument.

The limitations of this study are:

1) The study is dependent on survey response and the knowledge, judgement and interest of the respondent.

2) The examination of the impact of policy is limited to perceptual responses of chief state school officers rather than empirical data. 
3) No further attempt has been made to evaluate the policies or the resulting proqrams that are documented through the research.

4) Comparing statistics from other studies may result in erroneous information due to a differentiation in methodoloay and definitions of terminology.

5) Survey methodology, by its nature, has limitations such as self report dependence on the mail, and low return rates.

\section{Operational Definitions}

\section{Cultural Pluralism}

A state of society in which members of diverse ethnic, racial, reliqious or social groups maintain an autonomous participation iri and development of their traditional culture or special interest within the confines of a common civilization. (Webster, 1965)

\section{$\underline{\text { Policy }}$}

Webster's Dictionary describes policy as follows: Ia: prudence or wisdom in the management of affairs: sagacity; b: management or procedures based primarily on material interest; 2: a definite course or method of action selected from alternatives and in light of given conditions to guide and determine present and future decisions. The key to understanding policy science and analysis is contained in the second definition--a notion of selecting from a set of alternatives (Heflin 1981, p. 2). Yeakey defines policy as "characterized as the culmination of the action and inaction of the social system in response to demands made on it. $(1983$, p. 257$)$

Policy is then summarized for this study as a legitimized course of action taken by a governmental body. (Jones, 1977) 
Multicultural Education

Multicultural education is education for cultural pluralism (AACTE, 1971, p. 6). Multicultural education is education which is culturally pluralistic in content and process. In this study, it is also used to represent all multicultural programs, for in total, they form a process for education which is plualistic.

\section{Multiethnic Education}

Muliciethnic education is a concept which emerged when educators working in ethnic studies realized that the total school environment, and not just the curriculum needed to be reformed in order to increase educational opportunity for ethnic youths. (Banks, 1981, p. 32)

\section{Ethnic Studies}

Ethnic studies is defined for this study as the scientific and humanistic study of the histories, cultures, and experiences of the ethnic groups within a society (Banks, 1983, p. 57). This type of study is more limited than multicultural or multiethnic education. Ethnic studies refers primarily to a course of study, rather than an educational philosophy.

\section{status}

Webster (1965) defines status as:

1: the condition of a person or thing in the eyes of the law, 2a: position or rank in relation to others, b: relative rank in the hierarchy of prestige, 3: state of affairs: situation. (Webster, 1965, p. 856)

\section{Administration}

Administration is: 1: the act or process of administering 2: performance of executive duties: management 3: the execution of public affairs as distinguished from policy making, $4 a$ : a body of 
persons who administer... (Webster, 1965, p. 12). These definitions are applicable to the concerns of this study.

\section{Administrative Processes}

Planning is collecting information, utilizing decision-making techniques, developing plans, both short and long range, formulating objectives, assessing possible difficulties in an attempt to balance stability with flexibility. (Buchele, 1977)

Organizing is the development of a structure, vehicle for the implementation of objectives and goals. (Buchele, 1977)

Controlling is the process of measuring actual results, comparing those results to plans (or some stahdard), diagnosing the reason for deviations of actual from desired result, and taking corrective action when necessary. (Buchele, 1977, p. 125)

Evaluation, according to webster is the act of examining and judging. Evaluation can then be applied to all other administrative practices to determine effectiveness. Evaluation techniques can also be applied to programs and personnel. $(1965$, p. 287)

\section{Multicultural Programs}

Multicultural programs is used in this study to reflect any practice designed to promote cultural pluralism.

\section{Bilingual Education}

Bilingual education is education offered in two languages. Basically, there are three types of bilingual education. Those categories are:

1) Transitional

Transitional language programs are targeted for non-English speaking students and are designed to provide students with the opportunity to gain 
a fundamental knowledge of Eng̣lish to facilitate assimilation into the majority culture. Once a student attains a certain level of competency in English, he is generally dropped from such programs as he has made the transition linguistically. Many English-as-a-Second-Language programs fit into this category.

2) Maintenance

Maintenance language programs are designed to help the bilingual student continue to develop a mastery of two or more languages, generally English and one other language in U.S. public

schools. Frequently, the other language is the student's native tongue. Throughout the student's school program, instruction is received in both languages and the student is encouraged to utilize both languages. Thus, the ultimate goal of a maintenance language program is the mastery of two languages.

3) Enrichment

Enriciment language programs are those programs designed to help a student gain competency in the use of a foreign language. These classes have been fairly typical in U.S. public schools for many years and have focused primarily on the classical languages of Europe, i.e. French, German, Latin and Spanish. (AACTE, 1978, p. 13-14)

The Organization of the study

The study is divided into four remaining sections:

review of the literature, methodology and procedures, presentation and analysis of the data and summary and conclusions. A brief description of each section follows:

\section{Chapter II: Review of Literature}

Chapter II describes the scope of the literature review. The review focuses on the following topics: 1) Multicultural Education, 2) Issues and Questions related 
to Multicultural Education, 3) Practices in Multicultural Education with an Empirical Data Base and 4) state Policy Studies for Multicultural Education. Finally, the results of the review are presented.

\section{Chapter III: Methdology and Procedures}

Chapter III explains the methodology used in the study with a discussion of the survey instrument, population, data collection and analysis procedures.

\section{Chapter IV: Presentation and Analysis of the Data}

The data is presented in a narrative form with support from numerous tables. The data is presented around the framework of the research problem statement. Statistical analysis supports the raw data and is used in examining cross categorical relationships.

\section{Chapter V: Summary and Conclusions}

Chapter $V$ provides a summary of the study, conclusions and recommendations for further research. 
CHAPTER II

REVIEW OF THE LITERATURE

This review focuses on two bodies of literature. Those foci are as follows: 1) multicultural education: philisophy, issues, practices, plus empirical research, and 2) state level governmental involvement in multicultural education.

\section{Introduction and Scope of the Review}

While multicultural education is relatively a new field, the major portion of the literature in this field is currently philosophical and theoretical in nature resulting in a dearth of empirical research (Washington, 1981). Therefore, this review will begin by examining the conceptual base in the field and then progress to an examination of the limited empirical studies in multicultural educational implementation.

Following the multicultural education discussion, the author will present the findings of state level policy studies relating to multicultural education. The studies presented have some similarities with this study, and therefore provide an historical perspective for the reader. 


\section{Multicultural Education}

Philosophical Foundations

When one attempts to define multicultural education, the literature reflects three basic perceptions (Payne, 1983). The first of these views is expressed with multicultural education as tine product. The emphasis is on ethnicity. The second view of multicultural education emphasizes the civil rights turmoil of the $1950^{\prime} \mathrm{s}$ and $60^{\circ} \mathrm{s}$ and is targeted for oppressed minorities and amelioration of their conditions. This practice causes people to view multicultural education as a program for minorities only. The third view of multicultural education is that it is a process. This approach includes the first two perceptions, but goes beyond and focuses on the total process of teaching. One might express this view of multicultural education as proposing not multicultural education, but rather education that is multicultural. Payne (1983) states that "...this view of multicultural education is simply good teaching and good education" (p. 99). This perception of mulicicultural education is generally the one accepted by many prominent scholars in the field, but unfortunately, it is the most infrequently implemented (Payne, 1983).

Gibson (1976) provides another system of categorizing various multicultural education definitions and 
approaches. She identifies five major approaches to multicultural education: 1) education for the culturally different aimed at equalizing educational opportunity, 2) education about cultural differences facilitating cultural understanding. 3 ) education to preserve cultural pluralism, 4) education to help students function in two or more cultures, 5) education to develop competencies in multiple systems. While this schematic is more specific, most of her descriptors are integrated into Payne's broader third category.

Banks (1983) has stated that it would be easier to tell what multicultural education isn't rather than what it is. Every scholar in the field has his own definition, but, by 1970, Banks had emerged as the nation's foremost authority on multicultural education (Hollins, 1982). Banks prefers the term multiethnic education as opposed to multicultural education. He differentiates between the two concepts by stating that multicultural education focuses on various cultures in the U.S. and multiethnic focuses on U.S. ethnic groups only. In general, he espouses that multicultural/multiethnic education both involve the total school environment and both are philosophical bases rather than just curriculum reform or disjointed ethnic studies. It is multicultural education that demystifies the myths about one another and it is the 
process of reform for changing the whole school environment (Banks, 1983).

There is not at this point a scholarly concensus or universally understood or accepted definition of multicultural education, but most statements that attempt to delineate its nature and purpose have as central tenets ethnic legitimacy and cultural diversity. (Baptiste, $1979 \mathrm{p} .10$ )

While Banks is widely recoanized as the foremost authority and his latest writings may very well represent "the scholarly consensus" missing in 1979, his thoughts are built on the foundations of other scholars in the field such as Baker (1983), Gay (1983), Payne (1983), Gibson (1976), Grant (1975), Baptiste (1979) and others.

Both Baker (1983) and Gay (1975) present definitions of multicultural education which categorically seem to agree with Payne's third perception. Baker (1983) states,

Multicultural education is a process that builds on the cultural backgrounds and experiences of the learner and fosters growth and development in that which is familiar to the student. It is a process that helps expose the individual to diversity and encourages an understanding and appreciation for differences. (p. 45)

Gay defines multicultural education as:

Materials, activities and experiences that are authentic, interdisciplinary, multi-dimensional, comprehensive, integrative, and that employ both cognitive and affective skills should be used to help students understand ethnic differences and cultural diversity. (Gay, 1973, p. 27)

Grant (1977), writing for the Association for Supervision and Curriculum Development (ASCD), states

Multicultural education is a continuous, systematic process that will broaden and diversify as it develops. It views a culturally pluralistic 
society as a positive force that welcomes different as vehicles for understanding. It includes programs that are systematic in nature; that enhance and preserve cultural distinctions, diversities, and similarities; and that provide individuals with a wide variety of options and alternatives.

Multicultural education goes beyond an understariaing and acceptance of different cultures. It recognizes the right of different cultures to exist, as separate and distinct entities, and acknowledge their contribution to the societal entity. It evolves from fundamental understanding of the interaction of diverent cultures within the culture of the United States. (p. 3)

The ASCD definition also fits well into Payne's third category.

According to Baptiste (1979), the American Association of Colleges of Teacher Education has one of the "more definitive" definitions of multicultural education. This definition also is in agreement with Payne's third category.

Multicultural education is education which values cultural pluralism. Multicultural education rejects the view that schools should seek to melt away cultural differences or the view that schools merely tolerate cultural pluralism. Instead, multicultural education affirms that schools should be oriented toward the cultural enrichment of all children and youth through programs rooted to the preservation and extension of cultural alternatives. Multicultural education recognizes cultural diversity as a fact of life in American society, and it affirms that this cultural diversity is a valuable resource that should be preserved and extended. It affirms that major education institutions should strive to preserve cultural pluralism. (Baptiste, 1979, p. 16)

The authors of Teaching in a Multicultural Society offer this very broad view of multicultural education: 
Thus, a multicultural concept is an inevitable reality in any society where there are people of various cultural backgrounds who are changing, moving about, and learning. The multicultural concept implies a view of life in which we recognize and cherish the differences among groups of people and search for ways to help such traits to be cositive influences on both the individuals who possess them and all others with whome they associate in our society. (Cross, Baker, stiles, 1977, p. 5)

\section{Philosophical Conclusion}

Through the reading of these widely recognized conceptualizations on multicultural education, one can draw together the commonality of all the definitions. These definitions include either directly or implied the following premise: multicultural education is education for cultural pluralism.

Multicultural education is process oriented, encompassing the total educational environment and fosters the basic tenets of cultural pluralism. The definitions reviewed herein reflect the thinking of major scholars and in part, are in agreement regarding many issues. Yet, as Payne (1983) points out, the implementation of multicultural education is far from the optimum and there are many issues to be resolved before implementation will reach the desired stage.

Issues and Questions Related to Multicultural Education

The literature is replete with questions and issues regarding multicultural education. This author found 
literature addressing these major concerns related to multicultural education:

1) Is multicultural education divisive?

2) Is multicultural education just an attempt to placate minorities, another attempt at assimilation or an effort to address the educationa? needs of America's diverse population?

3) How should multicultural education be implemented?

These questions plus the empirical and state policy research reflect literature relating to multicultural education. The citations supporting conclusions to these questions are basically nonempirical, but assisted this researcher in forming a conceptual base.

\section{Is Multicultural Education Divisive?}

Specifically, an issue that has surfaced from the literature regarding multicultural education is related to the short and long term affects of multicultural programming's possible divisiveness. Whether multicultural education is a divisive factor or not depends greatly on the type of multicultural programming implemented. Some philosophical bases behind some multicultural programs naturally foster division. Therefore, the question remains difficult to answer. But, several scholars have written about this potential danger in multicultural education. Freedman (1977) warns against implementing multi- 
cultural education because of its divisiveness and Dolce (1973) questions how schools can foster unity and diversity at the same time.

Banks (1977) retorts to Freedman by pointing out that "when excluded minorities are allowed to take part in various institutions in society, the thrust will change from alientation to national cohesion and mutual interests" (Geze, 1981, p. 7).

This author concludes that when multicultural programming is established from Payne's (1983) third philosophical base as expressed earlier, then it will serve to unify. Multicultural education is the process of educating all people (majority and minority) in the skills of human relations. Improved relations between various ethnic and cultural groups is the precursor to human unity and peace. Is the focus then on unity and acculturation?

Is Multicultural Education Just an Attempt to Placate Minorities, Another Attempt at Assimilation or an Effort to Address the Eductional Needs of America's Diverse PopuIation?

Historically speaking, Eree public education has been viewed as the fire under the melting pot or as Newman puts it "the assimilative glue for integrating a society of increasingly diverse peoples (1977, p. 46). However, Neuman (1977) makes the point that this has been a theoretical viewpoint. In practice, the ideology of individual 
freedom and social mobility for which the schools were to have been the vehicle, never was achieved. Thus, a disparity existed between theory and practice. Neuman (1977) makes the point that "the standard textbook view that public education was designed to promote assimilation ignores an enormous conflict between ideology and practice in American public education" (1977, p. 47). He contends that there were probably never any actual attempts to acculurate. Social practices throughout American history served to limit rather than advance the well-being of ethnic groups. Based on this dismal track record, Newman pessimistically suggests that to argue whether multicultural education is another attempt to acculturate is moot. It may well be the first attempt to deal with the needs of American's culturally diverse population, but again the theory and practice are miles apart for Newman. He bases this impression on his observation of current implementation difficulties.

One such difficulty could be related to the origin of the multicultural education movement. Many scholars have observed that the onset of the multicultural movement was simply an attempt to placate minorities involved in ethnic revival. The response to minority pressure was the establishment of ethnic studies programs which were in themselves generally very ethnocentric. Capitulation as 
opposed to education was often the end result of this reactive programming.

Originating largely as a pallative to minority student demands, they were designed basically to pacify rather than educate. Excellent programs do not originate over night. It is the nature of colleges and universities to establish priorities when handling programmatic thrusts. Usually this is done in response either to powerful pressure interest groups, or to a powerful white knight. Proponents of ethnic studies goals definitely could not follow the white knight model. Unfortunately, ethnic group ethnocentrism, along with narcissism, led to hostility between ethnic groups that prevented them from forming strong coalitions to exert pressure on the university, college, or school district. Subsequently, temporal reactive plans instead of permanent proactive plans were implemented. Therefore, in most cases, anemic separate ethnic studies programs were set up. (Baptise, 1979, p. 27)

Cuban (1972) refers to these anemic type programs as "educational enclaves without introducing substantive changes" (p. 273). This dubious beginning resulted in some negative reactions to this programming and thus the number of Black studies programs found in the 70 's had declined compared with the 60's (Obalata, 1974). This phenomena could be accounted for by some ethnic programs being absorbed into the regular curriculum under a multicultural education label or perhaps it was a result of a weakening of the pressure which caused such courses to come into existence earlier. At any rate, there is little doubt that the beginnings of multicultural education were formed in a crisis reactive mode, rather than well designed and based on a sound theoretical foundation. 
Because of the nature of multicultural education's origin, it follows that its early funding and in many instances, its continued funding was or is dependent on "sofi" money. Baptiste (1979) responds to this:

It is almost a truisin in eüuciuiun history that a course of study cannot become a viable and stable - part of curricular structures until its support is based on regular or hard money allocations and the agencies charged with the responsibility of legitimating programs have given it their approval.

(p. 29)

Thus we have the focus of this state governmental policy research study -- to determine a degree of legitimation. But, recent cutbacks in federal and state budgets, cast an ominus shadow on expansion of multicultural education.

Many multicultural programs are not adequately

funded when they are conceived. Inadequate personnel and budget tend to limit the effectiveness of the program.

For instance, the California state Board of Education policy on multicultural education is not a mandate and hence cannot generate reimbursable costs. School districts are merely encouraged to implement the various guidelines on multicultural education for all students without the appropriate financial support to do so from the state or the federal government. (Gezi, 1981, p. 11)

The funding question is an issue which must face resolution if multicultural education is to become an effective program of national concern.

From the literature, the author concludes that historically the public schools have served the cause of assimilation and early attempts at addressing the needs of 
the minority student were focused on placation, but as the equal opportunity movement grew the focus changed to conflict resolution. This phenomena was due in part to the evolutionary process involved in becoming multiculturally literate. The muiticulicural education movement began as ego centric ethnic awareness and evolved to a more global perspective. The motivation behind the various stages of multicultural evolution probably parallel the development process. Thus, this author believes that we currently find individuals and organizations at all stages of the developmental process. So, for some it maybe another attempt at assimilation and for others a serious attempt to address the needs of America's pluralistic society. Funding and policy maybe an indicator of commitment to this program.

How Should Multicultural Education Be Implemented?

Beyond funding and the other issues and questions raised herein, why does the implementation of multicultural education pose such difficulty? This researcher finds much of the difficulty is a result of implementor's lack of understanding that multicultural education is a process as well as a product. Multicultural education is not a new curriculum guide, program or position. Multicultural education is education that is multicultural or as Payne states, "simply good teaching and good education" 
(1983 p. 99). It is broad and all encompassing. Hollins (1983) indicated that, "the next stage in the development of multicultural education appears to be the development of a theory of learning.

A good theory of multicultural education will organize existing knowledge and present a framework for the prediction of what is not yet known about learning and culture.

A new multicultural theory of learning must explain whether learning can be culture-free and/or culture-specific. The learning theory needs to establish a culture-free or culture-specific framework for predicting the potential effectiveness of specific curriculum and instructional strategies for specific groups of pupils. The theorists must provide general principles concerning the relationships between culture and learning that are testable. (Hollins, 1983, p. 47)

The continued existence of multicultural education rests on the development of such a theory, according to Hollins; otherwise, multicultural education will fund its way to the catacombs of educational fads. Certainly, Hollins points beyond the product of multicultural education and perhaps its continued existence is dependent upon a race between educational technology and a societal priorities. While Hollin's arguments may be cause for stunted implementation, other factors are at work.

Banks (1981) suggests a typology for examining the development of multiethnic competency. Much is to be gained from examining this theory, especially an understanding for some of the problems in implementing a process approach to multicultural education. Banks typology 
is a continuum showing six stages of development in reaching a state of globalism or global competency. Therefore, before a person can become globalistic, growth is required through the following stages:

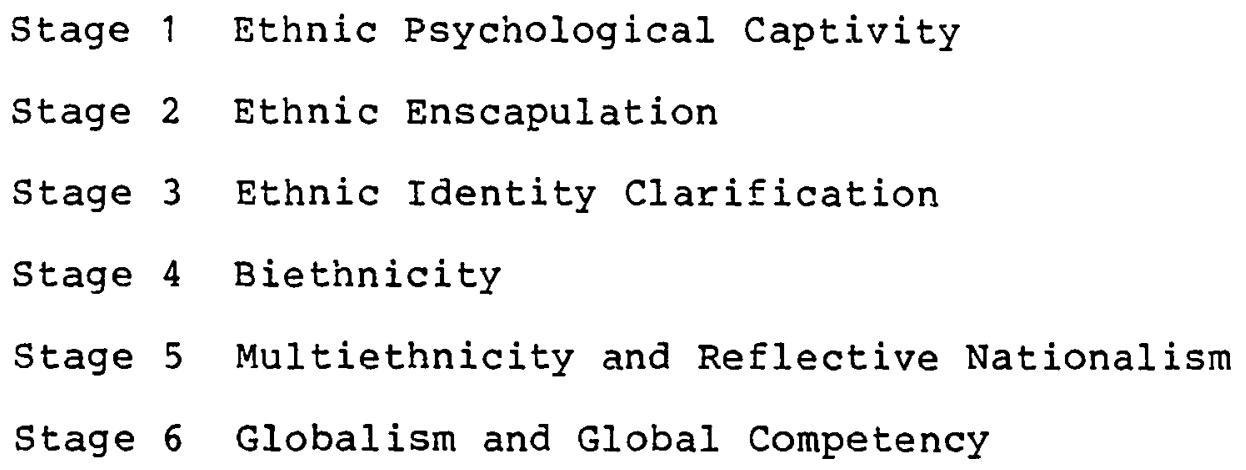


ing through the various stages of development. The Obalata (1974) study points the changing status of multicultural education programming as do, to some extent, the policy studies of Buffington (1974), the AACTE (1978) and Greene (1980). But, the evolution of multicultural education is difficult to convincingly document due to the lack of research and the confusion regarding its nature and practice.

Implementation strategies in multicultural education are as numerous as the definitions of multicultural education. Some implement it as an "add on," others as a series of topics in social sciences and still others infuse it into the entire school environment.

The National Council for Accreditation of Teacher Education has some specific guidelines used in implementing an evaluating multicultural education in teacher education programs. The guidelines address the following concerns:

1) The need for community involvement and support is crucial

2) Institutional support is needed

3) A needs assessment should be conducted

4) Multicultural education content should be integrated through the curriculum

5) Field experiences in culturally diverse settings are imperative 
6) Long and short range goals are important. (Gollnick, 1983)

The California state Board of Education (1979) has a policy stating, "Multicultural education is an interdisciplinary process rather than a single program or a series of activities" (p. 23). It further suggests that multicultural education should be:

1) cross cultural

2) appropriate to instructional level

3) utilizing the community as a resource

4) staffed by cultural diverse personnel

5) encouraged through staff development

Banks states multiethnic education programs should strive to meet the following twenty-three criteria:

1) Ethnic pluralism should permeate the total school environment.

2) School policies and procedures should foster positive multiethnic, interactions and understandings among students, teachers and the supportive staff.

3) The school staff should reflect the ethnic pluralism within American society.

4) Schools should have systematia, comprehensive, mandatory, and continuing staff development programs.

5) The curriculum should reflect the ethnic learning styles of the students within the school community.

6) The multiethnic curriculum should provide students with continuous opportunities to develop a better sense of self. 
7) The curriculum should help students to understand the totality of the experiences of American ethnic groups.

8) The multiethnic curriculum should help students understand that there is always a conflict between ideals and realities in human societies.

9) The multiethnic curriculum should explre and clarify ethnic alternatives and options within American society.

10) The multiethnic curriculum should promote values, attitudes, and behaviors that support ethnic plualism.

11) The multiethnic curriculum should help students develop their decision-making abilities, social-participation skills, and sense of political efficacy as necessary bases for effective citizenship in an ethnically pluralistic nation.

12) The multiethnic curriculum should help students develop the skills necessary for effective interpersonal and interethnic group interactions.

13) The multiethnic curriculum should be comprehensive in scope and sequence, should present holistic views of ethnic groups, and should be an integral part of the total school curriculum.

14) The multiethnic curriculum should include the continuous study of the cultures, historical experiences, social realities, and existential conditions of ethnic groups, including a variety of racial compositions.

15) Interdisciplinary and multidisciplinary approaches should be used in designing and implementing the multiethnic curriculum.

16) The curriculum should use comparative approaches in the study of ethnic groups and ethnicity.

17) The curriculum should help students to view and interpret events, situations, and conflict from diverse ethnic perspectives and points of view. 
18) The curriculum should conceptualize and describe the development of the United States as a Multidirectional society.

19) The school should provide opportunities for students to participate in the aesthetic experiences of various ethnic groups.

20) Schools should foster the study of ethnic group languages as legitimate communication systems.

21) The curriculum should make maximum use of local community resources.

22) The assessment procedures used with students should reflect their ethnic cultures.

23) Schools should conduct ongoing, systematic evaluations of the goals, methods, and instructional materials used in teaching about ethnicity. (Banks, 1981, p. 257-278)

Arciniega sites these specific changes in organization and practices for the successful implementation of multicultural education. The five goals are:

Goal 1: Recognition of the appropriateness, worth, and status of minority languges and dialects as bona fide media of instruction in the classroom.

Goal 2: Adequate treatment and presentation in the curriculum of the historical, cultural, and economic contributions made by minorities to American society.

Goal 3: Adequate representation of ethnic minorities in school district staffing pattersn (teachers, administrators, counselors, etc.).

Goal 4: Full and representative participation by the minority communities in the decision making structures of the school system.

Goal 5: Development of a testing, counseling, and guidance system based on a noncultural deficit perspective of ethnic minority student needs. (Banks, 1981, p. 58) 
Blumenberg suggests the foliowing action agenda for implementation:

1. Clearcut articulation of policy that cuts across all levels, divisions, and individual responsibilities, and mandates infusion of plualism through the system.

2. Abandonment of additive and compensatory programs based on a deficit model.

3. Study of staffing and school assignment patterns to determine how they might better reinforce appreciation of diversity.

4. Confrontation with the allocation and delivery systems of the district (including testing and counseling programs) to see how these impact on multiethnic education.

5. Development of new patterns of access and participation in terms of both student and community involvement.

6. Provision of staff development, instructional materials, and individual support systems that faciliate the actual delivery of multicultural education to students. (Banks, 1981, p. 177)

Morrison (1981) points to the following activities

as necessary in implementation of multicultural education.

(1) Identifying and acquiring pertinent materials (audio and printed) that reflect the dignity and worth of all people.

(2) Assisting beginning teachers in the development of professional skills and attitudes for working in a multicultural classroom. This includes skill development in evaluating instructional material relative to ethnic and sexual bias.

(3) Involvement and cooperating in activities such as informal experimentation (action research), writing proposals, developing curriculum materials and testing out new approache that promote the concept of cui ural pluralism. 
(4) Developing a resource bank. This involves listing community resource persons with their specific competencies to obtain a roster of potential consultants capable of providing assistance in translating, rapping with students, etc. Also keep a Eile on suggestions, questions and needs that merit further refinement.

(5) Planning, organizing and coordinating a continuing series of seminars, displays, $\in t c$. for the purpose of exchanging ideas that reflect the pluralistic nature of our society. Implied in this activity is the opportunity for an open discussion of the ideas expressed.

(6) Communicating with resource people and experts in the field. This opens up channels of communication with specialized personnel.

(7) Providing experienced teachers with learning experiences that enable them to improve their teaching performance in a multicultural classroom.

(8) Dissemination of information and materials. This activity includes sharing expertise and the results of research and approaches in the application of cultural pluralism to the classroom situation.

(9) Communicating with superiors so they understand the rationale of multicultural education and why new materials, workshops, etc. must be budgeted for.

(10) Fighting prejudice aginst culturally different students on a professional basis (value clarification techniques) whatever or whenever it is encountered in individuals or institutions.

(11) Supporting a balanced teacher representation of cultural groups when asked for assistance in the selection of new teaching assignments.

(12) Continuously evaluating innovations to provide direction of changes and further developments.

(13) Being aware of the malpractice (validity and reliability) of using measurement devices inappropriate for the intent and purposes for which they were developed. (p. 88) 
The previous citations regarding implementation strategies

focus on an infused or integrated model. This type of model is the most recent form of implementation touted by the major scholars in the field. Gay (1983) has these summative comments to make regarding the history and potential of the infusion model and various implementation strategies.

The history (albeit a relatively short one) of multicultural education suggests that the articulation of and commitment to the concept are developmental. That is, the idea continues to grow in clarity, comprehensiveness and complexity. Similarly, as individuals become more and more involved with and committed to multicultural education, their understanding of its meanings and potentials broaden over time. Thus, one who has "grown up" with multicultural education from its inception is better able to understand and appreciate its recent wholistic, infusion, systemic and multidimensional features than one who has recently joined the cause. The more recent recruits may be misled by the apparent surface simplicity of suggestions that multicultural education be infused or integrated into other aspects of schools. They may assume that this is an easy task to accomplish, or that interest in and concern about ethnicity are fading. Quite the contrary is true on both points. Infusing multicultural education into other aspects of schooling requires a sophisticated understanding of the concept, mastery from a wide variety of leaders, curriculum change and pedagogical skills and a wealth of cognitive knowledge and values clarification about ethnic pluralism and related cultural diversity.

Finally, the infusion model for implementing multicultural education has both potentials and pitfalls. Its greatest potential is its pedagogical soundness and pragmatism. Such an approach could facilitate the institutionalization 
and permanence of the concept. The most disturbing element of this idea is the inadequate preparation of teachers and other school leaders. Without sufficient professional preparation, integrated multicultural education, or any qualatitative ethnic programs regardless of their conceptual framework, is impossible.

These are times for pragmatic planning, systematic evaluation of prior efforts, and ideological reflection. We are at a crossroads. Multicultural education was conceived in an era very different from the tenor of these times. The conservatism and regimental re-entrenchment which now pervade society and schools are serious threats to the healthy survival and prosperity of multicultural education. Our challenge is to make the concept vital and pliable enough to survive these threats without dissipating or distorting its validity. This will require both critical reflection on what we have accomplished to date, and the charting of new direction that are viable and plausible. (Gay, 1983, p. 7)

Practices in Multicultural Education with an Empirical Research Base

What empirical research exists in the field multicultural education revolves around two topics: 1) teacher preservice and inservice education and 2) school and classroom implementation. The following paragraphs present a discussion of empirical research related to topics under consideration.

Teacher Preservice and Inservice Education

Certainly one aspect of implementation is to examine the role of implementors and the primary implementor is the classroom teacher. A major issue related to multicultural education has been the preparation of teachers. 
Krueger and Parish (1983) point to the importance of teachers in effecting school change. It seems reasonable then that teachers would need to move through the various developmental phases Banks suggests to become multiculturally or globally literate. Therefore, their preservice and inservice training comes to focus.

The rationale for preparing teachers for multicultural education is based on, among others, the fact that many have matured in a society that places little positive value on cultural differences. Consequently, they have limited knowledge of ethnic and racial cultures other than their own. (Morrison, 1981, p. 186)

Preservice and inservice education can serve to reduce and or remove the limited knowledge Morrison cites. Sims

(1983) indicates that infusion is most effective strategy

for a preservice program.

The traditional approach to curricular reform is via new courses. While another course seems to be the academic answer to an educational problem, it is not, in most cases, the solution. There are, for instance, universities that have designed special programs for multicultural education which add 15 to 21 semester hours of new courses over and above the regular teacher certification requirements. These programs are generally electives and there is no assurance that students will volunteer to add an additional semester of study emphasizing preparation for teaching in schools with children from culturally diverse backgrounds. The infusion method of curricula reform uses existing courses in the professional education sequence and provides through these courses a variety of multicultural perspectives. Every prospective teacher completing the professional sequence will have the same educational experiences. Each student will leave the program with basic facts, concepts and theories about culturally different people. (p. 44) 
Sims' specific recommendations parallel the traditional professional education curriculum. Most teacher programs address the following five levels of preparation:

Level 1 -- Introduction to Education

Level 2 -- Educational Philosophy and Psychology

Level 3 -- Educationai Specializations: Exceptional Child Early Childhood Education Reaäing, etc.

Level 4 -- Methods and Materials of Instruction Evaluation

Level 5 -- Student Teaching (p. 44)

Sims suggests that teacher education institutions make multicultural education a vital part of each level by infusing the following content into the five levels.

Level 1 Racial-ethnic attitude survey Visibile minorities in schools Inner city schools

Level 2 Cultural influences on children Improving academic performace of culturally different students Materials/Curricula bias Group differences in intelligence

Level 3 Language characeristics of specific groups Programs for Linguistically different Behavior disorders of culturally different

Materials for multicultural classroom

Level 4 Teaching strategies for multicultural classroom Multicultural resource development Assertive discipline for multicultural classroom Prejudicial evaluative instruments

Level 5 Total cultural immersion (p. 44) 
Inservice models for multicultural teacher educatio: are important to train the professionals in the field. Such a model was developed by Heflin (1981) for use in the Portland Public Schools. The model is based on seven instructional modules:

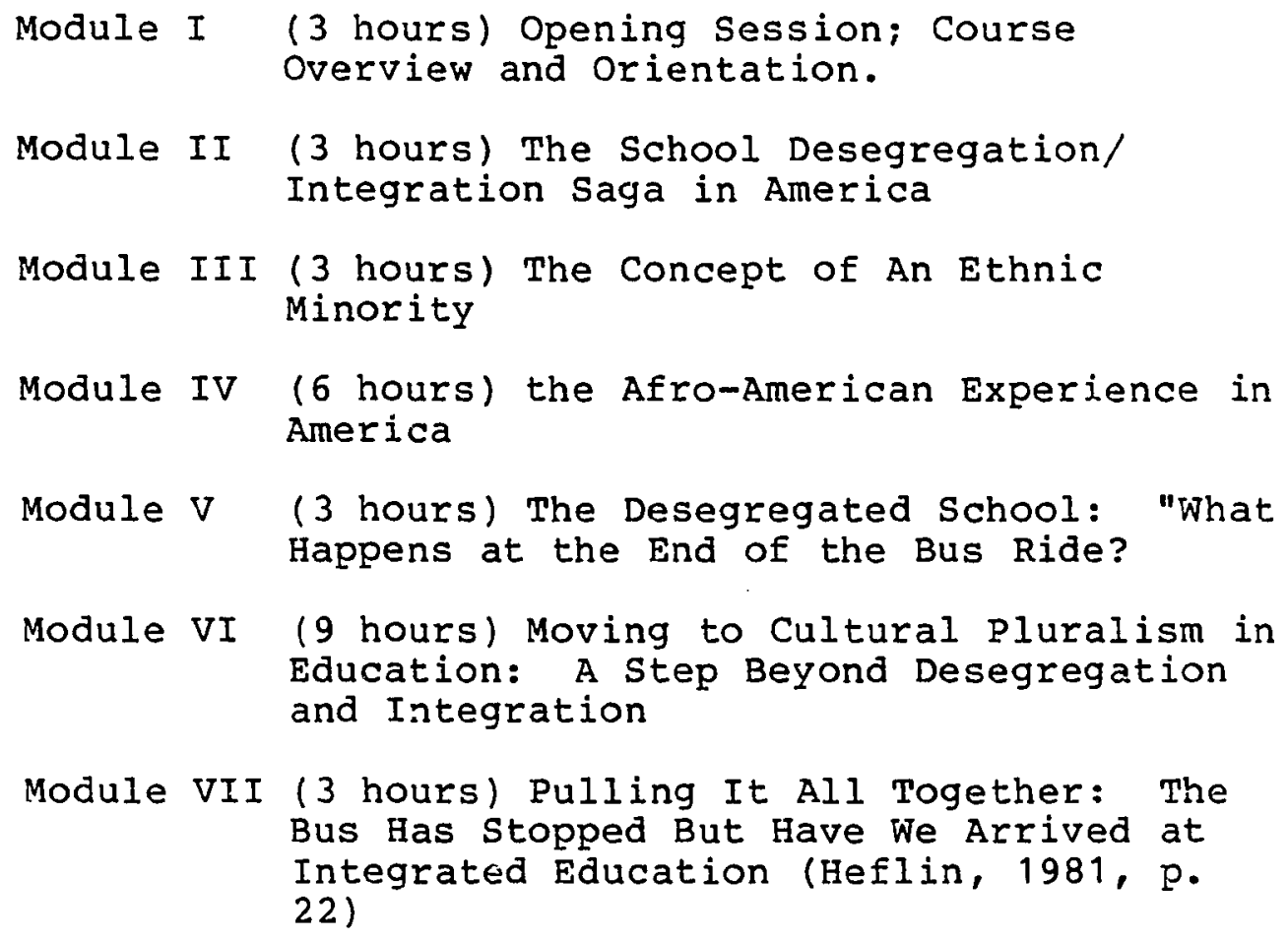

Module V ( 3 hours) The Desegregated School: "What Happens at the End of the Bus Ride?

Module VI ( 9 hours) Moving to Cultural pluralism in Education: A Step Beyond Desegregation and Integration

Module VII ( 3 hours) Pulling It All Together: The Bus Has Stopped But Have We Arrived at Integrated Education (Heflin, 1981, p. 22)

Heflin conducted preassessment and postassessment activities and found that there was an increase in the understanding and knowledge for eight key questions. Heflin sumamrizes:

At the initial and final sessions, participants were asked to respond to a questionnaire. Each questionnaire, although more lengthy, contained eight key items focusing upon knowledge and understandings of its desegregation/integration programming and the elements of education that is multicultural. 
Responses to the Post-Assessment questionnaire showed an increase in understanding and knowledge for each of the eight key questions. Seventy percent indicated that they had a better understanding of PPS District desegregation/integration policy. Forty-eight percent felt that they understood Oregon State Board of Education policy on school desegregation/integration. (Heflin, 1981, p. 22)

Preservice and inservice training in multicultural educa-

tion has received little empirical study.

Part of the difficulty in addressing multicultural education concepts is the lack of material emphasizing program development and implementing strategies. Much of the available information about multicultural education involves theoretical discussion. Many educators respond favorably to the principles of pluralism which state that the existence and expression of differences can improve the quality of life for individuals, for ethnic groups, and for society as a whole and that society should have respect for the individual. Yet many educators are not convinced that multicultural education can effect its desired promises. Rather, multicultural education is viewed as another educational trend, which will make 'no differences' in educational practice. (Washington, 1981, p. 187)

Yet some empirical studies favor the assumption that multicultural education will have positive effects. Baker (1977) found that student teachers' attitudes regarding ethnic groups could be changed as the result of a preservice workshop exposing them to multicultural education materials and cultural diversity and appeciation. 
Baker (1972) designed a study to determine changes in the perception of ethnic groups held by preservice teachers. The study was conducted at the University of Michigan utilizing a workshop format. The hypothesis was that the perceptions of ethnic groups held by preservice student teachers would be altered by participation in a multicultural workshop. The workshop was composed of several program formats, components some of which were lectures, films, discussions and personal contacts. Baker's findings indicated a significant change occurred between pre- and post-testing on the pro-irrational and anti-irrational scales. Baker concludes that perceptions can be changed and that colleges and universities should provide a teacher training program with a multicultural component.

However, Baker (1977) conducted another comparative study using an extended program group versus the workshop group. The hypothesis was there would be no change in the perceptions of workshop or extended program group participants toward ethnic groups. The results indicate that no significant difference was found between the two groups on the total testing instrument, but some subscales were significantly different. In general, the subscale findings indicate that the extended program participants were more rational in their perceptions. Baker concludes: 
Workshops and other less involved approaches to multicultural training have some benefit as indicated by the 1972 study, but when this approach is compared to more comprehensive training, it appears that both time and insensity produce more desirable outcomes. (Baker, 1977, p. 33 )

Washington (1981) found that an inservice workshop

for forty-nine elementary teachers was negligible in impacting teachers' attitudes and behavior. Washington summarizes her study:

The 5-day antiracism/multicultural education training failed to affect these elementary teachers' attitudes or classroom behavior. strong significant differences indicated more favorable outcomes for teachers who were black, who had higher proportions of poor students, and who were more experienced. Yet, these differences appear to have existed prior to, as well as subsequent to, the training experience. Teachers having more positive attitudes and behaviors related to multicultural education continued to feel more positively in relation to other teacher groups. Generally, the attitudinal and behavioral changes were extremely negligible, remainded relatively constant, or declined slightly. (p. 190)

Washington further compared the studies' findings to her interviews with participants. She found teachers requested further training and materials and adininistrators maintained enthusiasm for the training. This stark contrast was attributed to the Hawthorne effect which means that individual's participation in the study skewed the findings.

Washington (1981) also conducted another study in North Carolina. This survey was a statewide assessment 
involving over 478 of the school districts. The study indicates that most teachers apparently agree with the goals of multicultural education, yet lack materials and expertise in using what little materials are available. Over two-thirds of the teachers surveyed indicated "that multicultural failure probably world result because appropriate materials were not available" (Washington 1981 , p. 199).

The Education Committee of the Metropolitan Human Relations Commission (MHREC, Portland, Oregon) prepared a study of multicultural teacher education in Oregon. A survey was sent to the fifteen teacher education institutions in the state and a $94 \%$ response was received. The survey questioned in the areas of policy, program, population profiles and evaluation. In regards to policy, the committee found no institution with a written policy statement. While programatic findings varied greatly from institution to institution, no institution offered a minor or concentration in multicultural education and only one institution had a very ethnically diverse staff.

At all institutions the white student population was the largest. The mean percentage of white students at responding institutions is 85.9 percent of the total student population. Asian-American students comprise the largest minority student group in Oregon Higher Eaucation institutions. In descending order of representation, Asian-Americans were followed by 
Blacks, Hispanics and Native Americans. (Heflin, Broussard and Gudqer, 1983, p. 36)

The evaluation component of the study indicated that some universities evaluated their programs on the basis of criterion referenced tests while others made use of the group participation process.

Other findings as a result of the empirical

literature search in teacher education are summarized below:

1) Good multicultural education teachers utilize certain professional practices, i.e. individualized education, positive, supportive classroom environment. (King and Milan, 1981)

2) Teachers need training in multicultural education to work effectively in newly desegregrated schools. (Beckum and Dasho, 1981)

3) Qualitative research on individual teachers is the key to improving multicultural education instruciion. (Dasho, 1982)

4) Multicultural teacher training is needed and that those possessing such training are successful in seeking employment. (Mahan and Lacefield, 1982)

5) Teacher educators view multicultural education teacher training as important. (Mahan and Boyle, 1981)

6) Teachers feel that multicultural education is important for all students and that it does not 
distract children from learning the basic skills. Multicultural education is helpful to both minority and majority students. (Washington, 1982)

Currie (1978) offers additional guidelines for teacher preparation as do Klassen and Gollnick (1977), Gay (1983) and the others previously cited, but Gay summarizes multicultural education's importance in the teacher preparation role:

The greatest contribution multicultural education has to offer teacher education, regardless of the structural format it takes, is perspective. It brings to conventional teacher education content a different frame of reference, another screen or lens through which to operationalize, interpret, or assign experiential meaning to generic and theoretical concepts and principles of pedagogy.

The educational future of ethnic youth is too precious and precarious for educators, at all levels of the schooling enterprise, to continue to ignore any techniques, strategies, ideologies, and orientations which offer potential for improving the quality of education for these students. Gay, 1983, p. 6)

\section{School and Classroom Implementation}

Classroom studies and studies related to teacherstudent interaction and program effectiveness are few. Earlier studies (HARYOU, Clark, Coleman, etc.) discuss the achievement and behavior of minority students in a minority dominated school and were a part of the plethora of studies reported in connection with the desegregation movement of the 50's, and 60 's. The purpose of this review is not to examine that body of literature, but rather focus on studies related specifically to the multicul- 
tural-multiethnic movement of the $70^{\prime} \mathrm{s}$ and $80^{\prime} \mathrm{s}$ and in the context of the school/classroom.

Pate and Garcia (1981) conducted a study of multicultural programs by surveying the membership of the Social Studies Supervisors Association of the National Council for Social stuaies. The data was based on 150 responses to a two part questionnaire. They found

1) Virtually every possible grade configuration was reported, with the $k-12$ pattern being the most common. Although this finding may appear to be reassuring to proponents of $\mathrm{ME} / \mathrm{MC}$ education, other factors are distracting. Approximately two-thirds of the responding supervisors did not report a grade level or the $\mathrm{k}-12$ pattern, suggesting a less than successful permeation of ME/MC education in the total program. The lack of attention given to this question also indicates what many in the field suspect: The status of $\mathrm{ME} / \mathrm{MC}$ education is indeed poor.

2) MC/ME units were offered in courses in U.S. History, geography or sociology at the high school level and some elementary schools had an integrated program, but no clear pattern existed.

3) That less than one fourth of the responding schools had the reduction of prejudice as a program objective.

4) That of those included in the aforementioned fourth, only approximately sixty percent have some form of assessment plan for measuring performance on the prejudice reduction objective.

In general, Pate and Garcia (1981) state that in regards

to multicultural education:

Clearly, there is no typical program. It is also clear that the reduction of prejudice plays a 
small, if any, role in most schools' programs. The causalness with which prejudice reduction is approached and evaluated reflects a serious lack of commitment to this area. It is disappointing to report that multi-ethnic/multi-cultural education remains a confusion area of study lacking in purpose and direction. (p. 135)

In 1978, Livingston presented a paper at the American Educational Research Association in Toronto, Canada which revealed that "culturally mixed elementary school children in multicultural instruction will result in favorable change in the degree of acceptance of one another, at least on a short term basis" (p. 10). Ijaz (1981), as well, shows that attitudes can be changed toward other ethnic groups when exposed to multicultural instruction. More research needs to be conducted in this area. Pate and Garcia (1981) have pointed out that there is no typical multicultural curriculum. Therefore, it is difficult to empirically evaluate multicultural education because the variables are difficult to control and measure. At this point, one can only evaluate the effectiveness of specific programs until multicultural education programs share more common ground.

Simpson (1981) found that classroom/instructional organization can impact the disparity between major and minority student performance on standardized tests. It appears from the study that a multidimensional classroom structure is better and tends to produce greater performance equality than unidimensional classrooms. King and 
Milan (1981) as a result of their studies in the Denver Public Schools concur with Simpson.

However, it seems appropriate to underscore the crucial nature of the classroom organization in itself, an organization that fosters individualizing providing many alternatives, stimulating active learning approaches as the most effective strategy for teaching ethnically diverse children and for teaching all children. (Milan and King, 1981, p. 24)

Cole (1983) evaluates the educational experiences of today's Black students with mixed review. She states:

There has been a significance increase in school enrollment, with 51 percent of blacks aged 25 or older graduating from high school. Today, more blacks stay in school longer and more blacks go on to college than a quarter of a century ago. ( $p$. 28)

But, it is also observed that black children tend to drop below grade level in their mid-elementary years and stay behind until at age 16 , when $35 \%$ are below their grade level. Achievement test scores are below the norm in inner city schools with $75 \%$ of the student body black. The high school dropout rate for blacks is $28 \%$ as opposed to $17 \%$ for whites. While some indicators point to $90 \%$ improvement for the state of education for blacks, other indicators point to the need for change. It is not possible to draw a correlation between the positive changes for black students and multi-cultural education or any other single variable because of inadequacies in educational research. 
Baptiste, Baptiste and Miott (1977) conducted a study to determine the attitudes of third, fourth, fifth and sixth graders toward selected race related concepts. The study was conducted in four elementary schools with populations of majority amd minority students using a semantic differential model.

Their findings indicated that in general children showed positive attitudes toward race-related concepts with favor towards concepts related to their own ethnic orientation and negativism towards another ethnic orientations. The implications of the results of the study point toward the premise that multiracial schools do not necessarily promote positive racial attitudes nor do monoracial schools promote negative racial attitudes but that school racial composition is one factor involved in the complex school environment and perhaps not the most salient in terms of promoting positive racial relations. As mentioned earlier, the empirical data related to multicultural education centers around the topics of teacher preparation and classroom and school implementation. In the following list, the author provides the summary of the major findings in each of those categories:

\section{Teacher Preparation}

1) Many models exist for preservice and inservice multicultural education programs, but that 
lengthier rather than workshop programs are best at changing attitudes toward ethnic concepts. (Washington, 1981: Baker, 1977)

2) Most teachers agree with the basic goals of multicultural education. (Washington, 198i)

3) There is a shortage of instructional materials in multicultural education in North Carolina. (Washington, 1981)

4) Teacher Education institutions in Oreqon lack policy statements regarding multicultural education and vary greatly in the types of programs offered. (Heflin, Broussard, Gadger, 1983)

5) Teachers need multicultural training to work successfully in newly desegregated schools. (Beckum \& Dasho, 1981)

6) Multicultural education is viewed as important by teachers and a factor in successful employment. (Mahan and Lacefield, 1982; Mahan and Boyle, 1981)

\section{Classroom and School Implementation}

1) Grades $\mathrm{K}-12$ is the most common program configuration for multicultural education. (Pate and Garcia, 1981)

2) No clear pattern exists as to how multicultural education is formated, i.e., separate course 
vs. integrated approach. (Pate and Garcia, 1981)

3) That prejudice reduction is not a common stated objective of multicultural education program and that assessment related to achieving that goal is even less frequent. (Pate and Garcia, 1981)

4) Multicultural education can change student's attitudes toward other ethnic groups. (Livingston, 1978; Ijaz, 1981)

5) Classroom organization can impact the disparity between minority and majority students. Organizational structures which address students' individual needs is the best for minority students. (Simpson, 1981; King and Milan, 1981)

6) Black student retention and graduation frequency is higher than twenty-five years ago. (Cole, 1983)

7) School racial/ethnic composition is one factor of many in planning a successful multicultural program. (Baptiste, Baptiste, Miott, 1977)

This investigator has examined the philosophical and conceptual literature related to multicultural education and examined its implementation theory and practices and to some extent, its effect on teacher and student. It is now appropriate to examine the policy and policy studies 
which govern the implementation of multicultural programming at the state level.

State Policy Studies for Multicultural Education

A literature search reveals there are studies adaressing the role of state government in the fostering of multicultural programs. The studies are summarized and discussed in the following pages. Another study completed in 1968 by George Marconnit documented state legislative mandates in all curriculum areas, not just those pertaining to multicultural education programs.

Marconnit (1968) conducted a survey of the fifty states to determine what curriculum was required by the various state legislatures. He found that no two states had identical legislative requirements and that the subjects required ranged from 43 of the states requiring alcohol and narcotics education to Texas requiring instruction in the grading of cotton. Only one state, New Mexico, had a program which addressed the pluralistic nature of its population. To promote intercultural communication between English-speaking and Spanish-speaking communities, the New Mexico Legislature required Spanish instruction in grades five through eight. No other evidence of a multicultural program can be found in Marconnit's work. 
Buffington (1974) conducted a survey of the fifty states to determine which states had statutory provisions mandating various multicultural programs. The purpose of his research was to document state statutory provisions mandating the following multicultural programs:

a) bilingual programs

b) textbooks properly portraying minorities

c) multicultural concepts contained in courses

d) teacher training in multicultural education. Buffington found that 13 states had statutory provisions regarding bilingual education, eight states had statutory provisions regarding multicultural concepts contained in courses, six had statutory provisions requiring textbooks to properly portray minorities and four had statutory provisions requiring some type of teacher training in multicultural education. Buffington stated, "In conclusion, only 48 per cent of the states surveyed have enacted one or more statutes in respect to multicultural education..." (p. 99)

The Multicultural Education Commission (MEC) of the American Association of Colleges for Teacher Education (AACTE) (1978), under a grant from the National Institute of Education, conducted a survey of state legislatures and state education agencies regarding their laws, regulations, and policies about multicultural education programs. The areas covered in the survey included: 
a) provisions for multicultural education

b) provisions for bilingual education

C) teacher education requirements

d) specific departments or individuals responsible for multicultural education

e) inservice training requirements

f) provisions for curriculum resources. States responding with one or more programs in the aforementioned categories were considered to have multicultural education provisions. Many states had programs in several of the above categories, while some states had only one program (See Table II).

The MEC found that 33 states had some type of multicultural program mandated by legislation, regulation, guidelines or policy as indicated by Table II. Of these states, 23 had provisions for bilingual education, 15 had provisions for the selection of culturally pluralistic instructional materials, and 15 states had requirements including multicultural education as a necessity in teacher certification. The MEC also found that six states have provided resource centers in multiethnic, bilingual or specific ethnic education.

The MEC also analyzed which populations are targeted for multicultural education programs. Those populations are as follows (listed in order from most frequent to least frequent): (a) Spanish-speaking, (b) Black 
TABLE II

Multicultural Education and Aspects of Education Addressed In those Provisions

\begin{tabular}{|c|c|c|c|c|c|c|c|c|}
\hline \multirow[t]{2}{*}{ State } & \multicolumn{3}{|c|}{ State Proyisions } & \multicolumn{5}{|c|}{ Aspects of Education Addressed } \\
\hline & $\begin{array}{l}\text { State } \\
\text { Legis. }\end{array}$ & $\begin{array}{l}\text { State } \\
\text { Board of } \\
\text { Education }\end{array}$ & $\begin{array}{l}\text { State } \\
\text { Educ. } \\
\text { Agency }\end{array}$ & Curri. & $\begin{array}{l}\text { Instr. } \\
\text { Mat. }\end{array}$ & $\begin{array}{l}\text { Teacher } \\
\text { Certif./ } \\
\text { Educ. }\end{array}$ & $\begin{array}{l}\text { Staff } \\
\text { Dev. }\end{array}$ & $\begin{array}{l}\text { Resource } \\
\text { Center }\end{array}$ \\
\hline Alabama & & & & & & & & \\
\hline Alaska & B & B & & B & & & & B \\
\hline $\begin{array}{l}\text { Arizona } \\
\text { Arkansas }\end{array}$ & B & & & B & & $B$ & B & \\
\hline Callfornia & MBI & M & MB & MEI & M & 8 & MB & \\
\hline $\begin{array}{l}\text { Colorado } \\
\text { Connect icut }\end{array}$ & MB & M & $\mathbf{B}$ & MB & & & & \\
\hline Delaware & & M & B & & M & B & & \\
\hline $\begin{array}{l}\text { Flordia } \\
\text { Ceorgla } \\
\text { Hawail } \\
\text { Idaho }\end{array}$ & MBA & & $B$ & B & M & $B$ & & A \\
\hline Illinols & MB & B & M & MB & M & B & & \\
\hline Indlana & & & & & B & B & & \\
\hline Iowa & M & M & M & $M$ & M & M & M & \\
\hline Kansas & M & & & M & & & & \\
\hline Kentucky & & & & & & & & \\
\hline $\begin{array}{l}\text { Louisana } \\
\text { Maine }\end{array}$ & MBAO & B & B & MBAO & & B & & AO \\
\hline Maryland & M & & & M & & & & \\
\hline Massachusetts & MB & & MB & MV & M & B & M & \\
\hline Michigan & MB & & & MB & M & B & 8 & \\
\hline Minnesota & MBI & M & M & MBI & & M & M & M \\
\hline $\begin{array}{l}\text { Mississipp } \\
\text { Missour1 }\end{array}$ & & & & & & & & \\
\hline Montana & & & I & & I & I & I & \\
\hline Nebraska & & M & M & & $M$ & & M & \\
\hline Nevada & & M & MB & 8 & M & M & & \\
\hline New Hampshire & B & & & B & & & & \\
\hline New Jersey & B & & B & B & & B & B & \\
\hline New Mexico & B & MB & MB & MB & M & B & & \\
\hline New York & B & & & B & & & & \\
\hline $\begin{array}{l}\text { North Carolina } \\
\text { North Dakota }\end{array}$ & & M & & $M$ & & & & \\
\hline Ohio & M & M & M & M & M & M & & \\
\hline Oklahoma & & 8 & & $B$ & & & & \\
\hline Oregon & M & & M & M & $M$ & M & & \\
\hline Pennsylvania & M & MB & MB & MB & & $M$ & M & $M$ \\
\hline Rhode Island & $M B$ & A & & MB & A & B & A & \\
\hline
\end{tabular}


TABLE II Continued



Key $A=$ Afro American

$B=$ Bilingual

$I=$ American Indian

$M=$ Multicultural

$0=$ Other Ethnic Group(s)

Reproduced from: State Legislation, Frovisions and Practices Related to Multlcultural Education, AACTE, 1978. 
Americans: (c) Asian Americans, (d) American Indians, (e)

other ethnic groups (French, Italian, etc.), (f)

White-Anglo Americans, and (g) females (AACTE, 1978).

The MEC study also found that most of the

multicultural programs mandated by the various states seemed to support at least one or more of the following basic goals:

1) Cultural and linguistic assimilation

2) Improvement of intergroup relations

3) Assurance of equal educational opportunity for women and minorities

The MEC study was conducted in 1977 and the results were made available in January of 1978 . The study makes current some earlier work done by the AACTE in 1975.

The 1975 work of the AACTE investigated the administration and enforcement of state policies and provisions.

The legislatures of the various states enact all of the educational laws which relate to the rights of people and obligations of the school systems. This is done within the limits of the state constitution. Legislative action alone cannot successfully achieve the intent of the lawmakers. The day to day operations of the state government carried out by administrative agencies results in the development of rules and regulations which have the force of law. Almost every aspect of public education is affected by a municipal, state, or federal agency rule or regulation.

By examining which divisions or department within a state Department of Education is assigned the responsibility for multicultural education, the intent of the provisions can be assessed. The 
AACTE survey of multicultural activities in departments of education found sixteen different divisions and specialists assigned the responsibility for multicultural activities as indicated below:

Bilingual (14)

Foreign Language (10)

Ethnic Studies (7)

Equal Educational Opportunity (5)

Intergroup or Human Relations (4)

Urban Education (3)

Migrant Education (3)

Compensatory Education (2)

Multicultural Education (1)

International Education (1)

Federal Programs (1)

Community Services (1)

Cultural Awareness Specialist (1)

Cross Cultural (1)

Social studies (1)

Instructional Services (1)

The majority of these divisions are concerned with programs for non-English speaking students or for studnts from non-white groups or the lower socioeconomic level. Few of the assigned divisions are concerned primarily with instructional areas. If his can be an indication of the intent of state policies and provisions, it would seem that the major intent of multicultural education at the state level is to protect the rights of cultural and ethnic minorities in an effort to ensure equal educational opportunity. (Klassen and Gollnick, 1977 , p. 153)

Further, the AACTE (1975) found that there are

neither adequate monies or personnel to implement the provisions. For example, in the case of bilingual education in Rhode Island the state legislation read:

Section 16-54-17

This chapter shall take effect only when funds of the federal government are made available to and accepted by the state department of education to carry out the purposes of this chapter on a continuing basis. (Gollnick, Klassen 1977, p. 154) 
From the Minnesota "Guidelines Relating to Quality Intercultural and Non Sex-Biased Education", Section 8, one can examine the guidelines for non-compliance:

If a local board of education fails to conform to these guidelines in any significant respect, the Commissioner shall notify such local board and the State Board of Education, accompanying his report to the state Board with his recommendations. (Gollnick, Klassen, 1977, p. 154)

Chapter 622 of the Massachusetts state Code details a parental complaint procedure which addresses components related to cultural diversity. According to the AACTE "the division of the state department of education assigned the responsibility for the enforcement of Chatper 622 have neither the staff not monies to carry out their duties" (Klassen, Gollnick, 1977, p.155).

The development of policy does not guarantee that satisfactory implementation will occur at the state or local level. The lack of adequate staff and money further impede the development of effective multicultural programs. The AACTE indicated further research on policy effectiveness would be valuable.

Another study conducted by the author in 1980 updated and expanded the 1974 work of Buffington (1974) (Greene, 1980). The survey requested information regarding statutory provisions mandating various multicultural programs. From this survey, the data was classified into six areas: (a) bilingual education, (b) multicultural education, (c) ethnic studies, (d) affirmative action, (e) 
textbook selection, and (f) teacher training. Each office of the chief state school officer was asked to respond as to whether or not his state statutes provided for the previously mentioned six variables, whether or not such statutes were pending legislative action, or if such matters were only standard practice thorughout the state. The survey revealed that 20 states have bilingual education programs mandated by statute. Another eight states responded that bilingual eảuation was a standard practice only and not mandatory.

In the area of multicultural education 10 states have statutory provisions providing for such programs as indicated by Table III. Eleven states provided for ethnic studies.

Although federal regulations mandate affirmative action programs in many school districts, 26 states have reported that they have statutory provisions mandating affirmative action programs. Affirmative action plans are by far the most widespread of all the survey categories and undoubtedly it is because of the federal involvement in employment practices.

Seventeen states have indicated that they have statutory provisions mandating textbook selection processes which require that texts adopted in their state must reflect the diverse cultures in contemporary society. 
Table III

Statutory Provisions Mandating Multicultural Programs, 1980

\begin{tabular}{|c|c|c|c|c|c|c|c|}
\hline State & $\begin{array}{l}\text { Bilingual } \\
\text { Education }\end{array}$ & $\begin{array}{l}\text { Multi- } \\
\text { Cultural } \\
\text { Education }\end{array}$ & $\begin{array}{l}\text { Ethnic } \\
\text { Studies }\end{array}$ & $\begin{array}{l}\text { Affirm. } \\
\text { Action } \\
\text { Programs }\end{array}$ & $\begin{array}{l}\text { Textbook } \\
\text { Selection }\end{array}$ & $\begin{array}{l}\text { Teacher } \\
\text { Training }\end{array}$ & $\begin{array}{l}\text { Dominant } \\
\text { Political } \\
\text { Party in } \\
\text { State } \\
\text { Legislature }\end{array}$ \\
\hline Alabama & & & & $x$ & & & D \\
\hline Alaska & $x$ & $\mathrm{SP}$ & & $x$ & & & $D$ \\
\hline Arizona & & & & & & & $\mathbf{R}$ \\
\hline Arkansas & & & & & & & D. \\
\hline California & $x$ & $x$ & $x$ & $x$ & $x$ & $x$ & D \\
\hline Colorado & $k-3$ & $x$ & & $x$ & & $x$ & $\mathbf{R}$ \\
\hline Connectlcut & $x$ & & & & $x$ & & D \\
\hline Delaware & & & & $x$ & & & D \\
\hline Florida & SP & SP & SP & $x$ & $x$ & SP & D \\
\hline Georgia & & & & $x$ & $x$ & & D \\
\hline Hawail & $x$ & $x$ & $x$ & $x$ & & $x$ & D \\
\hline Idaho & & & & & & & $R$ \\
\hline Illinois & $x$ & & & $x$ & & $x$ & D \\
\hline Indi ana & $x$ & & & $x$ & $x$ & $x$ & $\mathbf{R}$ \\
\hline Iowa & $x$ & $x$ & & & $x$ & $x$ & D \\
\hline Kansas & $x$ & & & $x$ & & & $\mathbf{R}$ \\
\hline Kentucky & & & $x$ & $x$ & $x$ & $x$ & 0 \\
\hline Louisiana & $x$ & SP & $x$ & $\mathrm{SP}$ & $\mathrm{SP}$ & SP & D \\
\hline Maine & & SP & & & $x$ & & $\mathrm{R}$ \\
\hline Maryland & SP & $x$ & $x$ & $x$ & $x$ & $x$ & D \\
\hline Massachusetts & $x$ & & & $x$ & & & D \\
\hline Michigan & $x$ & SP & SP & $x$ & $x$ & SP & D \\
\hline Minnesota & & & & & & $x$ & D \\
\hline Mississippi & & & & & & $x$ & D \\
\hline Missouri & & & & & & & $D$ \\
\hline Montana & & & & & & & D \\
\hline Nebraska & & & & & & & Non-Partisan \\
\hline Nevada & & & & $x$ & $x$ & $x$ & D \\
\hline New Hampshire & SP & SP & SP & SP & SP & SP & $\mathbf{R}$ \\
\hline New Jersey & $x$ & SP & SP & SP & SP & & D \\
\hline New Mexico & $x$ & $x$ & & & & SP & 0 \\
\hline New Yock & $x$ & $x$ & $x$ & $x$ & $x$ & $x$ & $D$ \\
\hline North Carolina & & $x$ & $x$ & $x$ & $x$ & $x$ & D \\
\hline North Dakota & & & & & & & $\mathbf{R}$ \\
\hline Ohio & SP & SP & SP & $x$ & SP & SP & 0 \\
\hline Oklahoma & & & $x$ & $x$ & & $x$ & 0 \\
\hline Oregon & $x$ & & & $x$ & $x$ & $x$ & D \\
\hline Pennsylvania & $x$ & $x$ & $x$ & $x$ & SP & SP & D \\
\hline Rhode Island & & SP & SP & & & & $D$ \\
\hline
\end{tabular}


Table III Continued

\begin{tabular}{|c|c|c|c|c|c|c|c|}
\hline State & $\begin{array}{l}\text { Bilingual } \\
\text { Education }\end{array}$ & $\begin{array}{l}\text { Multi- } \\
\text { Cultural } \\
\text { Education }\end{array}$ & $\begin{array}{l}\text { Ethnic } \\
\text { Studies }\end{array}$ & $\begin{array}{l}\text { Affirm. } \\
\text { Action } \\
\text { Programs }\end{array}$ & $\begin{array}{l}\text { Textbook } \\
\text { Selection }\end{array}$ & $\begin{array}{l}\text { Teacher } \\
\text { Training }\end{array}$ & $\begin{array}{l}\text { Dominant } \\
\text { Political } \\
\text { Party In } \\
\text { State } \\
\text { Legislature }\end{array}$ \\
\hline South Carolina & & & & $x$ & & & D \\
\hline South Dakota & SP & SP & SP & SP & $\mathrm{SP}$ & $x$ & $\mathbf{R}$ \\
\hline Tennessee & SP & SP & $x$ & SP & SP & SP & D \\
\hline Texas & $x$ & $x$ & $x$ & $x$ & $x$ & $x$ & D \\
\hline Utah & SP & SP & SP & $x$ & SP & $x$ & $\mathrm{R}$ \\
\hline Vermont & & & & & & & D \\
\hline Virginia & SP & SP & SP & $S P$ & $x$ & & $D$ \\
\hline Washington & $x$ & & & $x$ & $x$ & & \\
\hline West Virginia & & & & & & & D \\
\hline Wisconsin & $x$ & & & & & & D \\
\hline Wyoming & & & & & & & $R$ \\
\hline
\end{tabular}

SP Indicates Standard Practice

$x$ Indicates the state has statutory provisions mandacing the particular multicultural program. 
A multicultural education component in teacher education is required in 17 states.

The data from Table III was distributed on six outIine maps of the U.S. in an attempt to determine if certain sections of the country seem to be more culturally aware in passng legislation. Each map represented one of the six survey categories.

Certain regions of the country reflect scant support for the multicultural cause. Such is the case with a northwest/central section of the country including Idaho, Montana, Wyoming, North Dakota and Nebraska. These states have no laws which support the vaious aspects of the multicultural programs being questioned in this survey. Arkansas and Missouri represent another area where there seems to be minimal support for the multicultural cause. On the other hand, the Great Lakes states appear to be very supportive of the multicultural movement. These states have positive responses in most of the six areas being questioned in this survey. Three sections of the country which have statutory provisions mandating bilingual education. They are: (a) the Pacific Coast states, (b) a south/central region comprised of Texas, New Mexico, Colorado, Kansas and Louisiana, and (c) the Great Lakes states plus the nearby states of New Jersey, Massachusetts, Connecticut and 
Iowa. These three regions probably reflect areas where bilingual education is a reed.

In general, the previously mentioned three regions seem to be the regions most supportive of multicultural programs, while the midwest and certain sections of the south appear to be areas with little statutory support for such programs.

An attempt was made to determine the correlation between a state's political affiliation and the amount of support for multicultural programs as reflected in theiry statutory provisions. The state of Nebraska was excluded from this statistical investigation due to the nonpartisan nature of its legislature. The correlation figure is . 1462 (rpbi) which was not significant and resulted in acceptance of the null hypothesis. The previously cited studies (Marconnit, 1968; Buffington, 1974; AACTE, 1978; and Greene, 1980) show conclusively that an increase has occurred in the number of states with provisions mandating multicultural programs. In 1968, only two states had one or more laws regarding multicultural programs and by 1980 over $75 \%$ of the states had passed such provisions. At first glance, this growth would seem impressive and it would indicate strong, responsive action on the part of the state legislatures, but when the time span and the urgency of the problem are considered, the response may seem less favorable. While 
these studies document state governmental policy from 1968 through 1979-80, it is important to examine what the last four years have wrought. Thus we have the focus of this current study.

The last four years have brought many changes. Economically, the nation has had to refocus priorities. Unemployment has been high, business failures have been rampant, and overseas' competition has damaged the traditional marketplace for many U.S. firms. Politically, the nation turned to the Republican party for its President and the conservative impact has been forceful in many avenues of American life. The pendulum has also swung educationally. "Many of the new priorities in education -vocationalism, the worship of technology, and an insistence on quantifiable criteria of success -- are antithetical to the essential goals of multiethnic education" (Gay, 1983, p. 562). For example, the Educational Improvement and Consolidation Act of 1981 have blocked up many of the categorical program which formerly supported multicuitural education Teacher corps. The chilly educational climate may impact the multicultural education movement because multicultural education is primarily affective and not easily quantifiable. It may be a fish out of water unless its importance is reemphasized and its status elevated. 


\section{Summary}

The review of 1 iterature has focused on multicultural education and state level involvement in multicultural education. The scope of the review has been limited by these two foci and the resulting data is a product of searches of two university libraries, a computer search, and the use of Educational Resources Information Services, Current Index to Journals in Education, and Education Index. Information was also collected at conferences, workshops, interviews and from unpublished manuscripts. The result of the research has produced the following findings :

1) Major scholars and organizations tend to define multicultural/multiethnic education as a process or education that is multicultural. (Payne, 1983; Banks, 1983; Baker, 1983; Gay, 1975; Grant, 1977; AACTE, 1975)

2) Several issues surrounding multicultural education may have impeded successful national implementation. Those factors are:
a) The issue of divisiveness (Freedman, 1977; Dolce, 1973)
b) The issue of assimilation/acculturation vs. diversity. (Neuman, 1977).
c) The issue of inadequate financial support. (Gezi, 1981). 
d) The issue that the beginning of multicultural education occurred in a crisis reactive mode and really it is viewed as an attempt to placate rather than a serious educational development. (Baptiste, 1979; Cuban, 1972)

3) The confusion regarding what multicultural education is and how to implement it has resulted, in part, because of the nature of its developmental process (Banks, 1983; Gay, 1977).

4) The implementation of multicultural education is complex, but achievable. (Gollnick for NCATE, 1983; California state Board of Education, 1979; Banks, 1983; Arciniega in Banks, 1981; Blumberg in Banks, 1981; Gay, 1983)

5) Teacher education has been the center for many attempts to implement multicultural education because of the important role teachers play in any educational change. (Krueger and Parish, 1983)

6) An integrated, infused, immersed process approach to pre-service teacher training in multicultural cultural education is the preferred model versus short workshops. (Sims, 1983; Baker, 1977)

7) Inservice education is a key factor in the implementation of multicultural education. (Heflin, 1981; Banks, 1981; Sims, 1983; Baker, 1981; Washington, 1981) 
8) Multicultural programming is varied. (Pate and Garcia 1981)

9) The racial/ethnic composition of a school population is one of many factors in facilitating positive racial attitudes in students. (Livingston, 1978; Ijaz, 1981; Baptiste, Baptiste, Miott, 1977)

10) Classrooms organized around individual needs are most effective in teaching ethnically diverse children. (Milan and king, 1981)

11) Black children tend to stay in school longer than 25 years ago. (Cole, 1983)

12) Policy mandates in the area of multicultural education have shown an increase since 1968. (Marconnit, 1968; Buffington, 1974; AACTE, 1978; Greene, 1980)

This researcher concludes that single largest body of literature in multicultural education is primarily conceptual, addressing philosophy and implementation strategies. From that 1 iterature one can find evidence to propose that multicultural education is education for cultural pluralism and that the effective implementation of such programming is dependent on a complex set cf variables ranging from personal development to organizational policy support. Multicultural education has had a developmental history and its implementation tends to be a developmental process dependent on a multitude of variables, rather than a product or program easily implemented 
such as purchasing an additional software program for a computer. From the policy studies, it appears state level involvement in multicultural education has increased since 1968 .

In conclusion, from the literature, it appears that multiculcural education is developing as an important educational issue, that implementation is complex and state involvement in the promotion of multicultural education has increased. 
CHAPTER III

RESEARCH METHODOLOGY AND PROCEDURES

\section{Introduction}

This chapter will provide a brief review of survey research methodology and review the techniques and procedures used in conducting this study. Specifically, the development of the survey instrument will be presented, as well as discussions of the data collection, population, time lines, and data analysis.

\section{Survey Research Methodology}

The problem addressed in this study is national in its perspective and focuses on policy documentation, policy implementation, and to some extent, policy impact. Survey methodology was selected as the research method because of its nature and ability to solicit extensive information from a population in various geographic locations at a relatively nominal cost. survey research, in genral, is defined as an approach in which "we seek to cast light on current problems by a further description and understanding of current conditions" (Fox, 1969, p. 45). This study examines the pre- 
sent conditions and status of state policy for multicultural education and issues related to multicultural education.

The author reviewed several survey research studies that were national in scope. The questionnaire/ survey was the most common research methodology. Weible and Dumas (1982) made use of a questionnaire to examine teacher certification requirements in all fifty states. They also used follow up telephone conversations for all nonresponding states and to clarify confusing information.

Another study similar in format to the Weible and Dumas study was conducted by Kirby and Scales (1981). The objective of their research was to document state quidelines for sex education in the public schools. Their methodology included telephone conversations, surveys, and copies of documents from which the data was compiled.

Buffington (1974), Marconnit (1968) and the AACTE (1978) were also national studies which made use of the survey/questionnaire research methodology. Therefore, the author adopted survey research as methodology for this study.

Survey research is a common methodology in the field of educational administration. Miskel and Sandlin (1981) state that:

Clearly, survey methods represent one area of specialization in educational administration research. In fact, survey procedures have constituted the most frequently used empirical method in educational administraion research. (p. 2) 
Hackett (1981) furthex documents the commonolaceness of survey methoroloay in social science.

While survey research is common, many questions and much confusion surround its effective use (Hackett, 1981). This confusion may be the result of an inadequate, widely accepted definition of survey research (Glock, 1967). According to Hackett (1981), some scholars define survey as a method for data collection or an instrument for such a purpose. This broad definition is inclusive of every type of research involving surveyina. Others focus on survey methodology for the operational meaning focusina on specific types such as personal interview, telephone interview, mailed questionnaire, etc.

Still others posit that, while survev research has much in common with other research methods, particularly at the desiqn and data analysis staqes, there seems to be a special character, a loaic to survey research methods that make them unique and that warrant consideration of survey methods as distinct and leqitimate approach to research (Hackett, 1981, p. 600)

Miskel and Sandlin (1981) conducted an examination of Educational Administration Quarterly (EAQ) and the Journal of Educational Administration (JEA) during the eiaht years of 1972 through 1979. Using six criteria of quality, and a stratified random sampling procedure, the researchers evaluated the survey research in these two iournals. Miskel and Sandin (1981) found evidence to support the position of Boyan (1981) and Boyd and Immeaart (1979) that 
the quality of survey research in educational administration seems to lack quality even though this research methodology appears to be a specialization of the researchers in the educational administration field.

Campbell (1979), on the other hand, finds that the EAQ is achieving its announced purpose to publish only conceptual, empirical and analytical manuscripts. While the confusion over survey methodology and its quality seems to be a question yet unresolved, this researcher attempted to implement the admonitions of the critics and heed the advice of those in praise of the methodology. of particular assistance in this effort were the works of Kerlinger (1973), Boyan (1981), Hackett (1981), Miskel and Sandlin (1981) and Campbell (1979).

\section{The Survey Instrument}

The survey instrument is a questionnaire which evolved over the last five years. Originally, the questionnaire was based on the policy status data categories developed for this researcher's 1980 study which was a replication of the Buffington (1974) study. The areas of inquiry are also similar to the policy study conducted by the AACTE (1978). The questionnaire was divided into two parts. Part I is titled "A Survey: State Level Mandates Regarding Multicultural Programs" and Part II is titled "Chief State School Officers' Perceptions of the Impact of 
Multicultural Education at the Statewide Level." (See Appendix A).

Part I is based on policy status data categories of the studies of Buffington (1974), AACTE (1978), and Greene (1980). Those categories are 1) multicultural/multiethnic education, 2) bilingual education, 3) ethnic studies, 4) affirmative action, 5) textbook adoption and, 6) inservice training of technical assistance. The first three categories are matrixed with grade levels of implementation (elementary, junior high, high school). The basic question of Part I is: Does the state (Oregon, for example) have statutory provisions/administrative rules/regulations mandating the previously mentioned data categories. Besides responding to grade level questions, respondents must indicate whether the policy is mandated, pending governmental action, or if it is not mandated, but a widespread practice. Under the items related to multicultural education, there are nine statements which examine certain administrative practices used in implementing a mandated multicultural program (See Appendix B).

Part II of the survey focuses on the chief state school officers' perceptions of the impact of multicultural education at the statewide level. Chief state school officers are asked to respond on a five point scale from strongly agree to strongly disagree regarding ten statements related to the perceived effectiveness of 
multicultural education. Additional sub-items exist under each statement soliciting specific data (See Appendix C). This tool is designed to solicit data about policy formation, implementaton and impact. The survey instrument went through several revisions under the guidance of the dissertation committee.

\section{The Population}

The population for this study is the 50 state edicational agency (SEA) and chief state school officer for each state. This population was selected to conform to the design of earlier multicultural education policy studies (Buffington 1974, AACTE, 1978 and Greene 1980) thus facilitating some comparisons. Logically, SEA's personnel should have a statewide perspective on educational issues and thus their collective perspectives should give an indication of national perspectives. Since this population is so small, no sampling occurred. A list of current information regarding chief state school officers was obtained from the Honorable Vern Duncan, Superintendent of Public Instruction, Oregon State Department of Education.

\section{Data Collection}

The survey instrument was first mailed to all chief state school officers on september 30,1983 . Subsequent 
requests were mailed at monthly intervals through February, 1984. The first three mailings yielded approximately $80 \%$ of the responses. The remaining respondents were contacted by phone and through additional mail inquiries. Responses were eventually received from each SEA and/or each chief state school officer.

All responses were collected utilizing the survey tool with the exception of Florida and Maryland. These two surveys were conducted through telephone interviews at the request of the respondents. In those cases, the survey tool was used as an interview schedule. One state, Nebraska, indicated that staff and budget reductions in the multicultural area of the state department made response to the survey impossible. Any questions regarding the accuracy or interpretation of the data were answered through legal research or additional inquiries by telephone or mail, thus strengthening the reliability of the answers.

\section{Data Analysis}

The general data from this study is summarized and displayed in Chapter IV using tables and narrative discussion. Qualitative and descriptive evaluation techniques were employed as well as the chi square test. Yates' correction for chi-square was employed when the expected cell values were less than five and the model had one degree of 
freedom (Hales, 1980, p. 12-19). Percentages and other descriptive statistical evaluations were also employed as necessary.

Many respondents forwarded copies of legal documents and other materials to further explain their state's position regarding multicultural programming. These documents were used in verifications and in qualitative analysis.

\section{Summary}

In summary, after defining the research problem, this chapter examined similar national studies and concluded the nature of the study necessitated the utilization of survey research methodology. This chapter then reviewed critical and supportive literature in the field of survey methodology to assist in the research design plan. The survey instrument developed with the assistance of Dr. John Heflin and Dr. Loyde Hales was described in this chapter as well as its usage in data collection. Data analysis procedures are also described. 


\begin{abstract}
CHAPTER IV
PRESENTATION AND ANALYSIS OF THE DATA
\end{abstract}

Introduction

The purpose of this chapter is to present and analyze the data resulting from the investigation. The results of Part I and Part II of the survey instrument will be presented, followed by an analysis of the interaction of the data from those two parts. The results of Part I will also be compared with earlier policy studies.

The data collected from the inquiries regarding multicultural programming numbers in the thousands of pages, mostly due to enclosures forwarded with each state's survey response. A brief presentation of a representative sample of the enclsoures is presented in each category of investigation. From these pages and the 250 pages of data from the survey, much can be gleaned about multicultural education programming across the states.

\title{
State Level Mandates Regarding
}

Multicultural Programs

The data presented in this chapter is based upon the responses from state education agency personnel and chief states school officers. All states responded in some man- 
ner to the survey instrument. However, Nebraska's resoonse was limited to a phone conversation with the office of the Honorable Joe Lutjeharms, Ed.D. (CSSO for the state of Nebraska) on January 27, 1984, in which it was made clear that due to severe budget cuts in the multicultural areas, none of the requested information was available. However, this investigator believes that the cut made by the Nebraska state Department of Education in the area of multicultural programming speaks for itself and is a significant finding in itself. Nebraska's cutbacks are blamed on the state's economic depression according to Dr. Lutjeharm's office. Therefore, the data in this study is based upon the other forty-nine responses.

\section{Multicultural/Multiethnic Education}

While policy would seem to be an important prerequisite step in the development of multicultural education (Blumenberg, 1981), it does not seem to be evident. While only nine states have mandated multicultural/ multiethnic programs, as many as 23 states have widespread programs, but no mandated policy (See Table IV). Only one state, Minnesota, had a policy on multicultural education which was pending governmental action. States responding yes to the question of mandated multicultural/multiethnic education were: California, Colorado, Iowa, Illinois, New York, Maryland, Pennsylvania, Ohio, and West Virginia. 
All but one of the responding states provided citations or copies of their respective policies. These citations ranged from mandated state curriculum guides to brief passages in policy documents.

TABLE IV

MANDATED MULTICULTURAL/MULTIETHNIC EDUCATION POLICY, 1984

Educational Level Frequency $\mathrm{Y} N \mathrm{NR}$ $\frac{\text { Percent }}{N}$ NR

Secondary

Mandated

Pending Governmental Action

Not Mandated, but Widespread Practice $21 \quad 10 \quad 19$

$\begin{array}{lll}18 & 68 & 14\end{array}$

$\begin{array}{lll}9 & 34 & 7\end{array}$

$2 \quad 36 \quad 62$

Junior High/Middle School

Mandated

Pending Governmental Action

$\begin{array}{lll}9 & 34 & 7\end{array}$

$\begin{array}{lll}18 & 68 & 14\end{array}$

Not Mandated, but

$\begin{array}{lll}1 & 18 & 31\end{array}$

$\begin{array}{lll}2 & 36 & 62\end{array}$

Widespread Practice

$\begin{array}{lll}20 & 11 & 19\end{array}$

$\begin{array}{lll}40 & 22 & 38\end{array}$

Elementary

Mandated

Pending Governmental Action

$\begin{array}{lll}9 & 34 & 7\end{array}$

$\begin{array}{lll}18 & 68 & 14\end{array}$

Not Mandated, but

$\begin{array}{lll}1 & 18 & 31\end{array}$

$\begin{array}{lll}2 & 36 & 62\end{array}$

Widespread Practice

$\begin{array}{lll}23 & 8 & 19\end{array}$

$\begin{array}{lll}46 \quad 16 & 38\end{array}$

Note: $Y$, yes; $N$, no; NR, No Response 
The state of Maryland forwarded Guidelines for Multicultural

Education (1980) in which the state mandate is quoted. Maryland Bylaw 325 (now numbered 13.03.02.05) states:

All public schools shall include in their programs of studies, either as a part of current curricular offerings or as separate courses, appropriate instruction for developing understanding and appreciation of ethnic and cultural minorities ( $p$. 1).

Maryland also requires LEAs to report to the SEA on the implementation of the programming on a biennial basis.

While Illinois has a mandated multicultural program as described by Chapter 122, School Code 27-21, The Goals of the Illinois State Board of Education (1981) also address multicultural education.

What is a high quality fully integrated system? The board believes it is one in which there is accountability for the resources allocated for education. It is one in which all persons, regardless of race, creed, sex, ethnic origin, age, or. handicap, have equal opportunity and can work harmoniously together. It is one in which segregated pockets are eliminated, and it is a system which provides multicultural programs which are based on the ethnic heritages of our people (The School Code of Illinois, 1981, p. 2).

New York State Board of Regents developed an action plan to improve the state's elementary and secondary schools. In the goal statements in the action plan several subgoals and one of the ten goal statements address multicultural issues. Goal statement six states: 
Each student will develop the ability to understand, respect and accept people of different race, sex, ability, cultural heritage, national origin, religion, and political, economic, social background, and their values, beliefs and attitudes. (Action Plan to Improve Elementary and Secondary Education Results in New York, 1983, p. 7)

These states (Maryland, Illinois, and New York) and their previously cited policies are representative of the materials enclosed with survey responses from states with mandated multicultural programs.

A few of the 23 states without mandated programs, but in which multicultural education was a widespread practice, forwarded excellent materials useu by state education agencies to assist in the development of multicultural/ multiethnic programs at local school district level. Washington is one such state, under the direction of Warren Burton, Director of the Office for Multicultural and Equity Education, this agency has developed Guidelines for multicultural Education, The Multicultural Education Quick Assessment Test and Evaluating the School for MulticulturalEducation. Brower (1984), with the Florida state Education Department, indicated that while there is not a mandated program, "a grassroots movement for multicultural education is alive and well in this state." Brower indicated that a state level policy may follow. Those states indicating a mandated program in multicultural/multiethnic education were asked to respond 
positively or negatively to the employment of certain administrative practices in implementing the policy mandate. The nine common administrative practices to which the participants responded were in the categories of: 1) planning/ assessment, 2) organization/development, 3) supervision/ technical assistance, and 4) evaluation/review (See Table V). The average of the responses reveal that evalation/ review is the least practiced of all administrative process categories. Only three states with mandated programs implemented any of the evaluation/review administrative process of statewide evaluation, evaluation for program modification or compliance review of LEAs. Table $\mathrm{V}$ shows the responses to the categories of administrative practice, and Table VI presents the responses to each item under those categories.

TABLE V

ADMINISTRATIVE PRACTICES OF STATE EDUCATION AGENCIES WITH MANDATED POLICY FOR MULTICULTURAL/ MULTIETHNIC EDUCATION

\begin{tabular}{|c|c|c|c|c|}
\hline \multirow[b]{3}{*}{$\begin{array}{l}\text { Category of } \\
\text { Administrative Practice }\end{array}$} & \multicolumn{4}{|c|}{ Practiced? } \\
\hline & Yes & & No & \\
\hline & $\begin{array}{l}\text { Arerage } \\
\text { Frequency }\end{array}$ & 8 & $\begin{array}{l}\text { Average } \\
\text { Frequency }\end{array}$ & 8 \\
\hline Planning/Assessment & 6 & 67 & 3 & 33 \\
\hline Organization/Development & 7.5 & 83 & 1.5 & 17 \\
\hline $\begin{array}{l}\text { Supervision/Technical } \\
\text { Assistance }\end{array}$ & 6.5 & 72 & 2.5 & 28 \\
\hline Evaluation/Review & 3 & 33 & 6 & 67 \\
\hline
\end{tabular}


TABLE VI

ADMINISTRATIVE PRACTICES EMPLOYED BY STATE EDUCATIONAL AGENCIES IN IMPLEMENTING MANDATED MLLTICULTURAL/MULIETHNIC POLICIES

Frequency $\frac{\text { Percent }}{\text { Ves No }}$

PLANNING/ASSESSMENT

1. Needs assessment have been conducted at the state level.

$4 \quad 5 \quad 44 \quad 56$

2. Students, teachers, community members and administrators have been involved in planning for multicultural education at the state level.

$8 \quad 1 \quad 39 \quad 11$

ORGANIZATION/DEVELOPMENT

3. Statewide specific goals and objectives for the multicultural/multlethnic programs do exist.

$\begin{array}{llll}7 & 2 & 78 & 22\end{array}$

4. Multicultural education is evident in state education agency (SEA) organizational structure and stafing patterns.

$\begin{array}{llll}5 & 1 & 89 & 11\end{array}$

SUPERVISION/TECHNICAL ASSISTANCE

5. Specific SEA personnel have been designated responsible for multicultural/multiethnic education.

$\begin{array}{llll}3 & 1 & 89 & 11\end{array}$

6. Staff development programs are or have been conducted in multicultural/multethnic education for SEA personnel

$5 \quad 4 \quad 56 \quad 44$

\section{EVALUATION/REVIEW}

7. A formal state level evaluation of the multicultural/ $\begin{array}{llllll}\text { multiethnic education program has been conducted. } & 3 & 6 & 83 & 67\end{array}$

8. Evaluation has resulted in modifications to the multicultural/multiethnic program to improve its effect Iveness.

$\begin{array}{llll}3 & 6 & 33 & 67\end{array}$

9. Compliance or standardization relews have been conducted in school districts.

$\begin{array}{llll}3 & 6 & 33 & 67\end{array}$


Only nine states reported mandated policies in multicultural/multiethnic educations and therefore only nine states responded to the use of the administrative processes. Three processes $(2,4,5)$ appear to be widely accepted and implemented practices among the mandated states. These practices are related to involvement in planning, to the organizational structure of the SEA, and to the assignment of multicultural responsibilities to specific SEA personnel. The next most frequently implemented administrative process was that of developing statewide goals in multicultural education. Again, evaluation and review processes appear to be implemented by only one-third of the states with mandated policies.

\section{Bilingual Education}

Bilingual education appears to be a more frequently mandated program than multicultural/multiethnic education. Sixteen states mandated bilingual education as compared to nine with a mandated programs in multicultural education. Those states with mandated programs in bilingual education are: Connecticut, Oregon, Pennsylvania, Washington, Massachusetts, Illinois, Michigan, Wisconsin, New Jersey, Alaska, Indiana, Texas, New York, California, Colorado, and Iowa. Any state which responded negatively to the question of mandated programs, but cited or submitted a policy supporting a mandate required further investigation. Utah, 
Pennsylvania, and Minnesota fit such a category. An exanination of their policies revealed a permissive program in "English as A Second Language" (ESL) or bilingual education. The data indicates (See Table VII) that 16 states have mandated bilingual education programs. Eighteen of the remaining states have widespread, nonmandated bilingual education programs.

TABLE VII

MANDATED BILINGUAL EDUCATION POLICY, 1984

Educational Level $\frac{\text { Frequency }}{\mathrm{Y} \frac{\mathrm{N}}{\mathrm{N} R}} \quad \mathrm{Y} \frac{\text { Percent }}{\mathrm{N}}$

Secondary

Mandated

Pending Governmental

Action

$13 \quad 31 \quad 26$

$\begin{array}{lll}26 & 62 & 12\end{array}$

Not Mandated, but

Widespread Practice

$\begin{array}{lll}0 & 19 & 31\end{array}$

$0 \quad 38 \quad 62$

$\begin{array}{lll}15 & 14 & 21\end{array}$

$30 \quad 28 \quad 42$

Junior High/Middle School

Mandated

Penciing Governmental Action Not Mandated, but

Widespread Practice $15 \quad 14 \quad 21$

Elementary

Mandated

Pending Governmental Action

Not Mandated, but

Widespread Practice $\begin{array}{lll}13 & 21 \quad 5\end{array}$

$\begin{array}{lll}0 & 21 & 29\end{array}$

$15-14-21$

$\begin{array}{lll}16 & 24 & 10\end{array}$

$\begin{array}{lll}0 & 19 & 31\end{array}$

$18 \quad 10 \quad 22$ $\begin{array}{lll}26 & 64 & 10\end{array}$

$\begin{array}{lll}0 & 42 & 58\end{array}$

$\begin{array}{lll}30 & 28 & 42\end{array}$ $\ln$ 
Bilingual education programs can be categorized into three types of programs 1) maintenance, 2) transitional, or 3) enrichment. Since enrichment programming is widely practiced, the researcher is primarily interested in the substance of maintenance and transitional programs. The data indicates that 23 states have transitional bilingual education programs, while 16 states have maintenance programs. Eleven states failed to respond to this survey item. While not all states have a mandated or widely practiced non mandated program, it is interesting to note that 41 states cited specfic SEA personnel responsible for bilingual education programs. This frequency, is higher than all other investigated areas (multicultural/multiethnic education, ethnic studies, affirmative action, textbook selection, and inservice training). The personnel charged with bilingual education ranged from bilingual ESL specialists to foreign language specialists or Equal Educational Opportunity officers.

Bilingual. education is an important aspect of a total multicultural program. In terms of mandated programming, it ranks second in frequency behind affirmative action according to the survey data. It is also important to note that unlike multicultural/multiethnic education, there appears a small difference in implementation at the various educational levels, with elementary education having the highest 
frequencies in the mandated and the nonmandated, but widespread practice categories.

Along with the survey response, The Commonwealth of Massachusetts included a copy of the Transitional Bilingual Education Law Chapter 71A. Section one of the law states:

[Added. 1971, ch. 1005, sect. 1 and sect. 2] Section 1. Declaration of policy. The General Court finds that there are large number of children in the commonwealth who come from environments where the primary language is other than English. Experience has shown that public school classes in which instruction is given only in English are often inadequate for the education of children whose native tongue is another language. The General Court believes that a compensatory program of transitional bilingual education can meet the needs of these children and facilitate their integration into the regular public school curriculum. Therefore, pursuant to the policy of the commonwealth to insure equal educational opportunity to every child, and in recognition of the needs of children of limited English-speaking ability, it is the purpose of this act to provide for the establishment of transitional bilingual education programs in the public schools, and to provide supplemental financial assistance to help local school districts to meet the extra costs of such programs.

While each state law is different, Massachusetts is cited because it is representative of bilingual policy materials enclosed with the survey responses and because most bilingual education programs are transitional in nature. All of the bilingual education policies or plans enclosed with the survey responses appeared to have these common characteristics: 1) program definition, 2) specifications for the target population, and 3) curriculum guidelines. 


\section{Ethic Studies}

Ethnic studies is the third area of inquiry in the survey of multicultural programming. The data reveals that Eive states (Maryland, Hawaii, Pennsylvania, New York, and Illinois) have mandated ethnic studies programs (See Table VIII)

TABLE VIII

MANDATED ETHNIC STUDIES POLICY, 1984

Educational Level

$\underline{\text { Secondary }}$

Mandated

Pending Governmental Action Not Mandated, but Widespread Practice

$\frac{\text { Frequency }}{\mathrm{Y}} \mathrm{N}$ NR

$\begin{array}{lll}4 & 36 & 9\end{array}$

$\begin{array}{lll}1 & 23 & 24\end{array}$

$17 \quad 18 \quad 15$

Junior High/Middle School
Mandated

Pending Governmental

Action Not Mandated, but

widespread Practice

$\begin{array}{lll}4 & 38 & 8\end{array}$

$124 \quad 25$

$\begin{array}{lll}14 & 22 & 14\end{array}$

Elementary

Mandated

Pending Governmental

Action

Not Mandated, but

$\begin{array}{llll}\text { Widespread Practice } & 14 & 22 & 13\end{array}$
$Y \frac{\text { Percent }}{\mathrm{N} N R}$ 
The survey data also suggests that certain ethnic groups were targeted for study in both mandated and non-mandated programs. The survey question presented was: "If ethnic studies do exist in your state, what ethnic group or groups are targeted for study?". Twenty-three states responded to this item. This represents $46 \%$ of the states. of those responding, 648 cited Blacks as a targeted ethnic group. Other responses included: Hispanics (558), Native Anerican (55\%), Asians (43\%), and Europeans (34\%). Hawaii's ethnic studies is a mandated program in Hawaiian studies. The state of Iowa responded that all their earlier ethnic programs had now been incorporated into the multicultural program which corresponds to the developmental nature of multicultural as expressed by Banks and others.

Texas reports pending governmental action on mandating ethnic studies at the junior high/middle schools and high school levels. Ethnic studies is a widespread practice at those levels in the state of Texas according to the survey data.

Ethnic studies is a vaiable component of multicultural programming and is viewed by some scholars as a developmental stage towards multicultural programming. While only five have mandated programs, 17 states have ethnic studies programs that are widespread. 
As might be expected due to the low frequency of mandated programs in ethnic studies, few materials were enclosed with the survey response. However, New York enclosed a syllabus for ethnic studies with a cultural anthropology perspective. The guide focuses on the Italo-American culture and was published by the Bureau of General Education Curriculum Development, New York State Education Department.

\section{Affirmative Action Plans}

Affirmative action is another area of inquiry included in this study. Twenty-six states have mandated affirmative action programs as shown in Table IX. Wisconsin is the state with an affirmative action policy pending governmental action at this time. Affirmative action plans are the most frequently mandated program of all the categories of multicultural programming included in this study. It is also important to note that only eight states have widespread affirmative action programs which are not state mandated. Many states enclosed materials relating to affirmative action plans. The documents ranged from pamphlets to copies of legal citations. A representation of the documents are discussed and cited below.

All the plans which were submitted, focused on implementation and procedures with varying degrees of specificity. All plans made specific reference to personnel with specific responsibility for the enforcement of the plan. 
TABLE IX

MANDATED AFFIRMATIVE ACTION POLICY, 1984

\begin{tabular}{|c|c|c|c|c|c|c|}
\hline \multirow[t]{2}{*}{ Policy } & \multicolumn{3}{|c|}{ Frequency } & \multicolumn{3}{|c|}{ Percent } \\
\hline & $\bar{Y}$ & $\mathbf{N}$ & $\sqrt{R}$ & $\bar{Y}$ & $\overline{\mathrm{N}}$ & NP \\
\hline Mandated & 26 & 11 & 13 & 52 & 22 & 25 \\
\hline $\begin{array}{l}\text { Pending Government } \\
\text { Action }\end{array}$ & 1 & 12 & 37 & 2 & 24 & 74 \\
\hline $\begin{array}{l}\text { Not Mandated, } \\
\text { But Widespread }\end{array}$ & 8 & 7 & 35 & 16 & 14 & 70 \\
\hline
\end{tabular}

Note: $\mathrm{Y}$, yes; N, No; NR, No Response. 
Several of the plans included monitoring regulations and review procedures for LEAS to use in reporting to the SEAS.

West Virginia's Equal Employment Opportunity Plan

(1981) is representative of the goals of all the plans:

The Department's specific program goals are as

follows :

1. To develop a profile and analyze the department's work force in terms of the total number of employees and their race and sex.

2. To insure compliance with the Governor's executive order prohibiting denial of employment of persons solely because of their race, color, religion, national origin, political affiliation, handicap, sex or age.

3. To increase the representation of women, ethnic minorities and handicapped persons in the composition of the staff of the department.

4. To insure that the appointment and promotion actions of assistant state superintendents reflect the department's commitment to equal employment opportunity.

5. To develop a full understanding of the EEO plan and related policies among all employees.

6. To develop an audit procedure which measures the effectiveness of the EEO plan, indicates needed remedial action, and determines the degree to which goals and objectives have been attained. (p. 4) 


\section{Textbook Selection Process}

Textbook selection processes are integral to establishing an effective multicultural/multiethnic program. Therefore, this study investigated the frequency of mandated policy in this area. Nine states (See Table $X$ ) have mandated textbook selection processes which require texts to reflect the cultural pluralism found in the American population. Texas is the only state in which such a policy is pending governmental action. Next to affiramtive action plans, a multicultural texthook selection process is the least frequently practiced multicultural program (in a widespread manner) without a state level mandate. Only 16 states have non-mandated, but widespread programs.

Several states (both mandated and non-mandated) enclosed descriptive materials relating to the textbook selection process. The range of materials sent included just policy statements to detailed description of procedures with evaluation worksheets. Representative of the forwarded material are the reviews and citations below.

The South Dakota State Department of Education produces a handbook providing direction for LEAs in the selection of instructional materials. The major criteria mentioned in the document are: readability, social fairness, content, and physical qualities. The social fairness aspect 
TABLE $X$

MANDATED TEXTBOOR SELECTION POLICY, 1984

\begin{tabular}{|c|c|c|c|c|c|c|}
\hline \multirow{3}{*}{$\begin{array}{l}\text { Policy } \\
\text { Mandated }\end{array}$} & \multicolumn{3}{|c|}{ Frequency } & \multicolumn{3}{|c|}{ Percent } \\
\hline & $\bar{Y}$ & $\mathrm{~N}$ & $\overline{N R}$ & $\bar{Y}$ & $\mathrm{~N}$ & $\mathrm{NP}$ \\
\hline & 9 & 30 & 11 & 18 & 60 & 22 \\
\hline $\begin{array}{l}\text { Pending Government } \\
\text { Action }\end{array}$ & 1 & 23 & 26 & 2 & 46 & 52 \\
\hline $\begin{array}{l}\text { Not Mandated, } \\
\text { But Widespread }\end{array}$ & 16 & 16 & 18 & 32 & 32 & 36 \\
\hline
\end{tabular}

Note: $\mathrm{Y}$, yes; $N$, No; NR, No Response. 
is related to the research thrust of this study. Subcriteria under social fairness include:

1) numerical representation of sexes, races, and cultures and classes of people;

2) consideration of the effects of the book on the child's self image and self esteem;

3) work roles of people;

$4)$ Iifestyles of people; and

5) language bias" (South Dakota, 1980, p. 16)

The South Dakota handbook is very complete in its description of social fairness, even including percentage figures for proportions of protected classes for use in text evaluation.

Rentucky operates a State Textbook Commission and the policy statement includes the following citation:

Textbooks that recognize that America's peoples take pride in their race, religion, and social backgrounds. Textbooks that portray prejudice, perpetuate stereotypes, or fail to recognize the talents, contributions, or aspirations of any segment of American people are not acceptable in the public schools. The Commission must choose textbooks that engender human dignity, humaneness, and understanding of the points of view of all Americans. Textbooks listed shall not include blatantly offensive language or illustrations. Violence, if it appears in textbook content, shall be treated in context of cause and consequence; it shall not appear for reasons for unwholesome excitement, sensationalism, or as an excuse for relevance. (Rentucky, no date, p. 3)

This citation addresses other issues beyond the multicultural scope and the policy statement was not accompanied by any implementation materials, but such materials may exist. 


\section{Inservice Training or Technical Assistance}

Training is important in the implementation of any educational program. Multicultural/multiethnic programming is no exception. As shown in Table XI, seven states have mandated inservice training or technical assistance programs in multicultural/multiethnic education. It is also a widespread practice in 18 states.

Table XI reflects the current status of inservice and technical assistance programs, but the enclosures with the survey responses provide a sampling of the composition of those programs. The California State Department of Education forwarded a copy of School staff preparation in the History, Culture, and Current Problems of Diverse Ethnic Groups. The program described therein is for teacher voluntary participation or mandated participation if the school where the teacher is employed has 258 or more of the students are from diverse ethnic backgrounds as mandated by the Education Code, Section 44560 . The program format is entirely the choice of the LEA, but all programs must be submitted to the Department of Education for Approval. The program goals are:

a. To develop respect for minority-group and other ethnic cultural traditions and for the aspiration of children and families of every group present in the community and in the nation;

b. To develop understanding of special problems of learning and behavior in schools of mixed or predominantly minority ethnic composition; 
TABLE XI

MANDATED POLICY FOR INSERVICE TRAINING OR TECHNICAL ASSISTANCE IN MULTICULTURAL/MULTIETHNIC EDUCATION, 1984

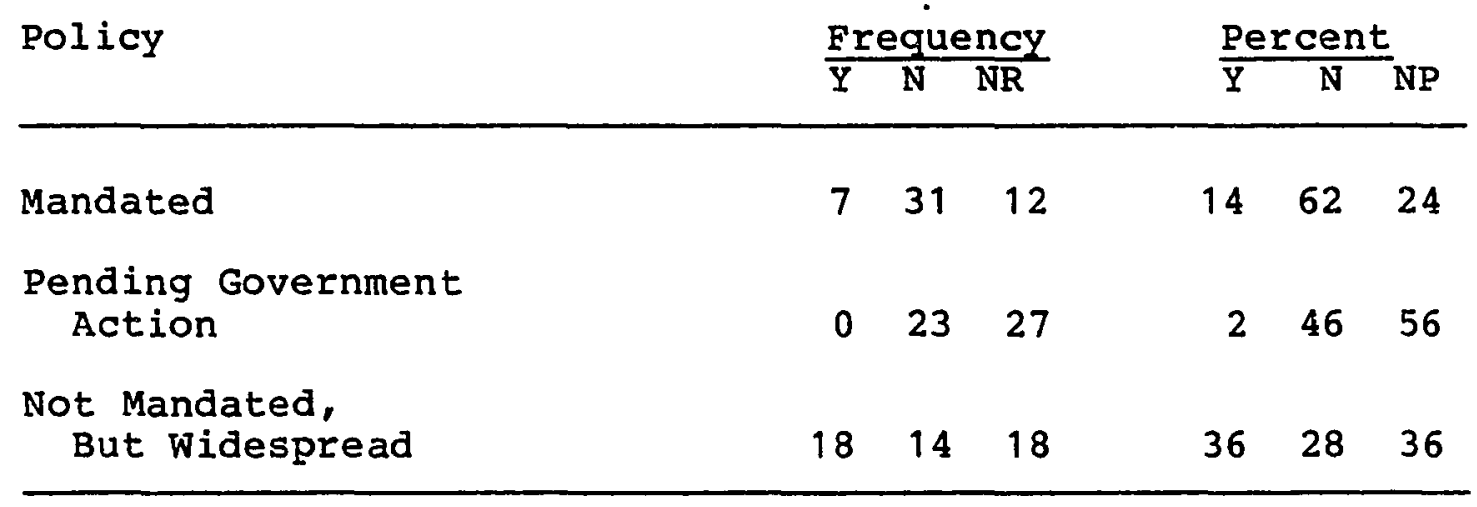

Note: $Y$, yes; $N$, No; NR, No Response. 
c. To help teachers and other staff to improve the quality of their relationships with students and the quality of relationships among students of diverse racial, ethnic, national origin, cultural, and religious heritage;

d. To promote higher expectations of educational achievement and of career and vocational preparation by students of every group;

e. To increase knowledge of available resources and of instructional strategies appropriate to schools of mixed or predominantly minority ethnic composition. (California, 1978, p. 3)

Washington state enclosed a copy of the document Competencies for Teaching Multiculturally. In the document there is a listing of 31 competencies for teachers. Also, the School Laws of West Virginia (1981) provides inservice education that is multicultural on an annual basis. Selection 18-5-15a states:

County boards of education shall annually provide a program, during at least one noninstructional day of the school term, for the study of multicultural education for all school personnel as definea in subsection (a), section one [18A-1-1(a)], article one, chapter eighteen-A of this Code. The study provided shall be in compliance with regulations to be developed by the state board of education.

As used in this section, multicultural education means the study of the pluralistic nature of American society, including its values, institutions, organizations, groups, status positions and social roles. $(1981, \mathrm{c}, 82$.$) (p. 17)$

These three documents (California, Washington, West Virignia) are typical of the program descriptions and policies (related to teacher inservice and technical assistance.) received during the execution of this study. 
Multicultural Programs Across the States

The previously discussed programs, which are integral parts of any effort to provide an education that is multicultural, have been presented in isolation, without much effort to relate or compare the programs one to another. Table XII provides a cumulative picture for this portion of the study and reveals further information about multicultural programming across the states. The highest frequency of mandated programming occurs in the area of affirmative action plans. The least frequently mandated program is ethnic studies. The multicultural programs in order of most to least frequently mandated are: affirmative action (26), bilingual education (16), multicultural/multiethnic education (9), textbook selection process (8), inservice/ technical assistance (7), and ethnic studies (5). The multicultural programs presented in order from most to least frequent which are not mandated, but are widespread practice are: multicultural education (23), bilingual education (18), inservice/technical assistance (18), ethnic studies (17), textbook selection (16), and affirmative action (8). Multicultural/multiethnic education is ranked third in mandated programs, but first in programs that are not mandated, but widespread. 
TABLE XII

MANDATED MULTICULTURAL PROGRAMMING, 1984

\begin{tabular}{lccc}
\hline & Mandated & $\begin{array}{c}\text { Pending } \\
\text { Government } \\
\text { Action }\end{array}$ & $\begin{array}{l}\text { Not Mandated, } \\
\text { But Widespread } \\
\text { Practice }\end{array}$ \\
\hline $\begin{array}{l}\text { Multicultural/ } \\
\text { multiethnic }\end{array}$ & 9 & 1 & 23 \\
$\begin{array}{l}\text { Bilingual } \\
\text { Education }\end{array}$ & 16 & 0 & 18 \\
$\begin{array}{l}\text { Ethnic Studies } \\
\begin{array}{l}\text { Affirmative } \\
\text { Action }\end{array}\end{array}$ & 5 & 1 & 17 \\
$\begin{array}{l}\text { Textbook } \\
\text { Selection Process }\end{array}$ & 8 & 1 & 8 \\
$\begin{array}{l}\text { Inservice/Technical } \\
\text { Assistance }\end{array}$ & 7 & 1 & 16 \\
\begin{tabular}{l} 
Total \\
\hline
\end{tabular} & 71 & 0 & 18 \\
\hline
\end{tabular}

A review of the data indicates that some type of multicultural programming is mandated in 33 states (See Table XIII). There are 16 states without any mandated program. Of those 16,11 states have one or more multicultural program which is not mandated, but is a wide-spread practice. Therefore, 44 states are involved in some aspects of multicultural programming through state mandate or nonmandated, but widespread practice.

Thirty-three states also have widespread multicultural programs without policy, the remaining 16 have at least one 
program with a policy or no programs at all either mandated or not.

TABLE XIII

FREQUENCIES OF STATE WITH/WITHOUT

MULTICULTURAL PROGRAMMING, 1984

\begin{tabular}{lc}
\hline Policy Requirement & Frequency \\
\hline $\begin{array}{l}\text { States with at least one mandated } \\
\text { Multicultural Program }\end{array}$ & 33 \\
$\begin{array}{l}\text { States with No Mandated } \\
\text { Multicultural Programs }\end{array}$ & 16 \\
\hline
\end{tabular}

Chief States school officers Perception

of the Impact of Multicultural Education

at the Statewide Ievel

This section of the survey data analysis focuses upon the impact of multicultural education within each state as perceived by the respective chief state school officer (CSSO). The cSSOs responded to ten statements regarding multicultural education recording their perceptions on a five point Likert Scale. Forty-three CSSOs responded to this portion of the questionnaire. The results are presented below in Table XIV. The frequency of response is shown as well as the percentage based on the total number of responses for that item.

While a survey response was received from each state, seven CsSOs (including Nebraska) elected not to respond to 
TABLE XIV

CHIEF STATE SCOOL OFFICER'S PERCEPTIONS OF THE IMPACT OF MULTICULTURAL EOUCATION AT TH STATEWIDE LEVEL

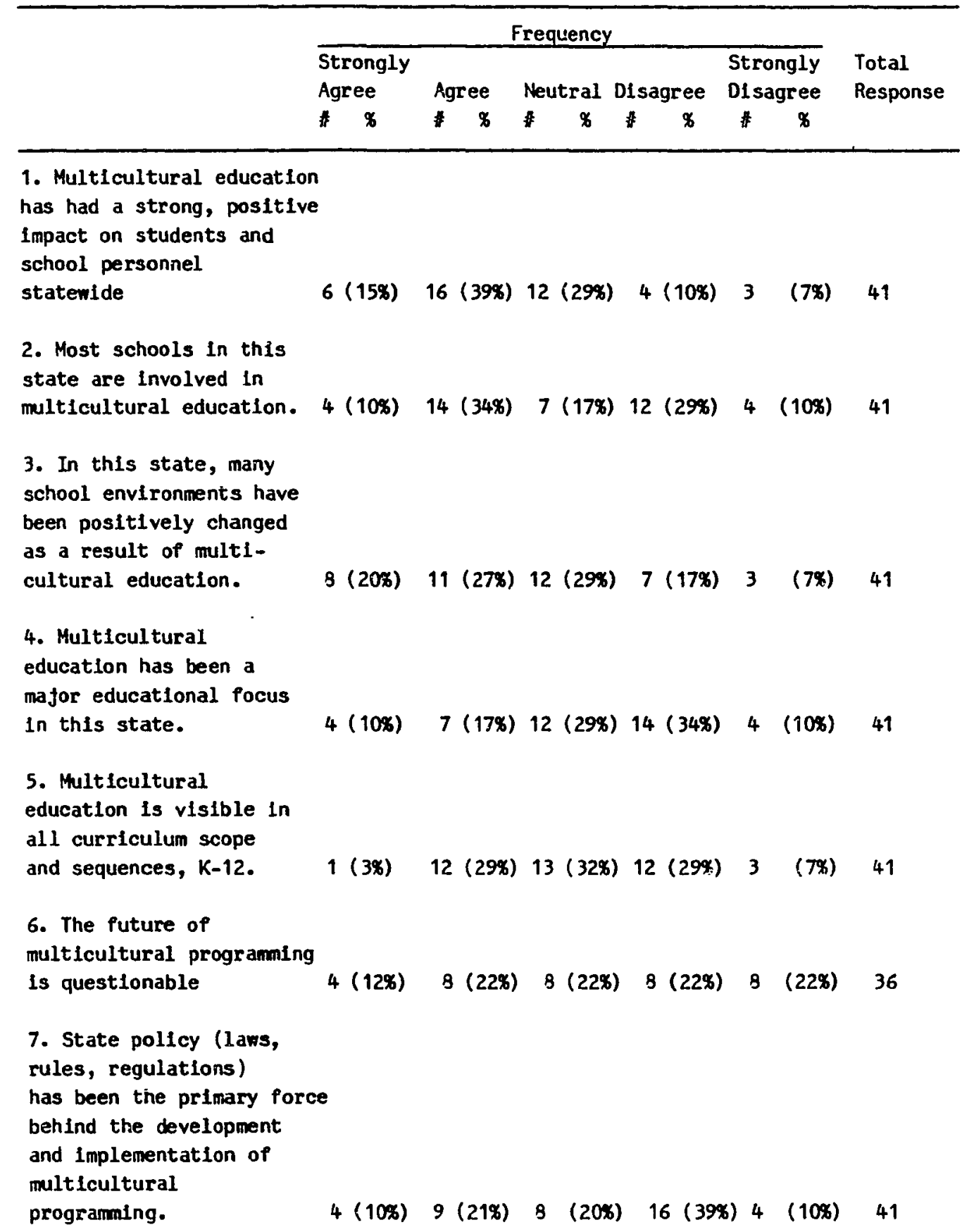


TABLE XIV continued

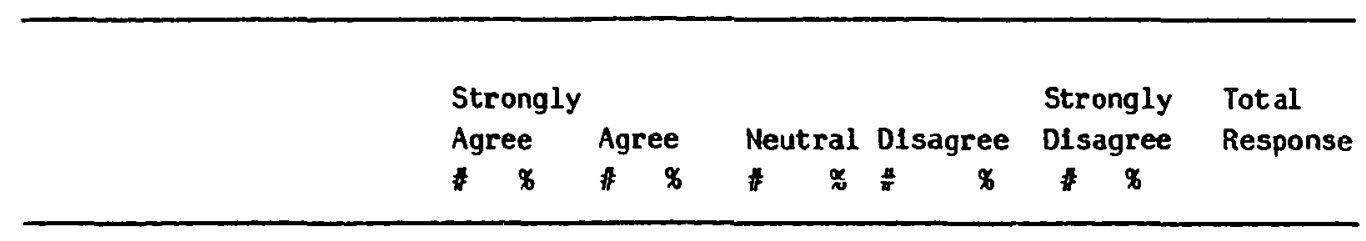

8. Other educational priorities are negatively affecting the development and Impact of mult 1cultural programing
$1(4 \%)$
B (20\%)
$13(32 \%)$
(34\%) 4
(108) 41

14

9. The varlous ethnic communitles have been supportive and involved In multicultural

programs.

$12(29 \%) 20(498) \quad 5 \quad(12 \%) \quad \& \quad(10 \%) \quad 0 \quad(0 x) \quad 41$

10. State educational agencles have been active in multicultural programing at the local level. 
any item on this portion of the questionnaire. Two CSSOs returned the survey, but did not respond because their respective states had no significant multicultural programming and felt that any response was inappropriate.

The data on CsSo's perceptions reveal some valuable findings. It is important to remember, however, that the data is based on 43 cssos perceptions.

Statements one and three (see Table XIV) address the impact of an involvement in multicultural programing. By collapsing the response categories on either side of neutral, one finds that 548 of the respondents to item one agree with the positive influence of multicultural programming, as reflected in statement one. Statement three shows 478 of the respondents to the item attesting to the impact of multicultural education in producing positive change in school environments.

Statements two, four and five (See Table XIV) deal with the extent of the implementation of multicultural education at the statewide level. Again, collapsing the data collapsed on either side of neutral, we find that 448 of the cssos responding to item two agree that most schools in their states are involved in multicultural education, (statement 2) however, only 278 of those responding to item four thought multicultural education to be a major focus (statement 4). Forty-four CSSOs disagreed with ranking multicultural education as a major focus. This would tend 
to indicate that most states are not extensively involved in multicultural education. Multicultural education's visibility in curriculum documents across the states is somewhat evenly divided according to the data from statement five, with 32 percent of the responding cssos affirming its visibility and 36 percent aligned with the position of minimal or no visibility.

Therefore, from the data in statements 1-5, it appears that multicultural education is having a positive impact, but it is not as strongly implemented as it could be. Statements six and eight (See Table XIV) focus on the future of multicultural programming. In statement six, the responses are fairly evenly distributed over all response choices. Clearly, there is no clear collective perception regarding the future of multicultural programming.

An examination of solicited comments as to why the future of multicultural education might be questionable proauces no clearer picture of the future, but the data for statement six clearly points to the fact that from a national perspective multicultural education is at the crossroads. The nation's cSSOs are collectively unsure about multicultural education's future as indicated by the fairly even distribution of responses to question six. The comments regarding statement six are found below in categories corresponding to the responses of the cssos on the likert scale. These comments are made in response to the statement 
six, "The future of multicultural education is questionable, why or why not?" Those cssos responding in the strongly agree/agree category of the Likert scale made the following comments:

"Poor initial conceptualization -- often not integrated with regular curriculum"

"English as a Second Language has been the emphasis"

"A smail percentage of the total population representing other than caucasion [sic]."

"Cut in Title IV money -- inability to obtain state money."

"Availability of funds"

"It has not been given a high priority status in terms of budget or other services."

"Federal funds support multicultural education."

Those CSSOs responding in the category of strongly disagree/ disagree made the following comments:

"Despite modest percentages, there is a commitment to multicultural education"

"Priority has been established"

"much of it is now institutionalized"

"Very necessary program to prepare our young persons for the future, but funding is always a problem."

"Because of program emphasis and implementation efforts"

"Disagree because financial support and sympathy for multicultural education remains strong." 
The comments are taken directly from item six of the survey instrument. Those CSSOs with neutral responses to statement six made no comments as to why multicultural programming might be questionable.

Statement eight also deals with the future of multicultural education. The responses to this item indicate that other educational priorities are not negatively affecting the development or impact of multicultural education in at least 18 states, while 9 states CSSOs perceive negative impact from other priorities on multicultural programing. Some cSSOs attempted to further clarify their responses with comments or by listing the other educational priorities negatively impacting multicultural programming. From the comments to statement eight of the following educational priorities are cited as negatively affecting the development of multicultural programming:

1) Basic Skills

2) Back to Basic Movement

3) Excellence in Education has tended at times to ignore equity

4) Emphasis on basics which are interpreted to be reading and mathematics

5) Emphasis on talented and gifted program

6) The need for funds to provide for regular educational needs

7) Finances

8) Awareness of need

9) State policy of local control

10) Lack of funding, time and staff

11) Computer Literacy

12) Natural Disasters

13) Excellerce in Education. This effort should reinforce the need for multicultural education

statements seven, nine and ten (See Table XIV) probe issues surrounding the impetus behind implementation or the 
"how" of implementation. In other words, was it state policy which was the primary force behind the development of multicultural programming (statement 7) and were various minority groups (statement 9) and state education agencies involved policy and/or program in implementation (statement 10). From the csso's percep-tions, it appears as though various ethnic groups as well as state educational agencies have been advocates for implementing multicultural education. Of less significance in facilitating multicultural education has been state level policy. In fact, 498 of those CSSOs responding to item seven find disagreement with the statement that state policy has been primary force behind the formation and implementation of multicultural education policy.

In summary, from the examination of the cssos responses to the ten statements about their perception of multicultural education, the following observations may be offered :

1) Multicultural education is a positive force in most schools in which it has been implemented.

2) Multicultural education has not been implemented in a majority of schools throughout the nation.

3) Ethnic communities and state educational agencies have been instrumental in developing multicultural programming. 
4) CSSOs are uncertain about the future of multicultural programing.

5) Policy has not been viewed as the primary impetus behind the development of multicultural programs.

\section{Analysis of the Data}

The focus of this section of the chapter is: 1) a comparison of the data in Part I and Part II of the survey results, 2) a comparison of the data with this researcher's 1980 study, and 3) a general discussion of this study's results.

In comparing the data from Part I and Part II, the question comes to mind as to whether Csso's with mandated policies responded differently to Part II than do CSSO's without mandated policies. From Part $I$, we find that multicultural education is mandated in nine states and that at least 34 states do not have a mandated program. Of those, 8 of the mandated states and 33 of the non-mandated states responded to the survey. The likert response frequencies as displayed in Table XIV were collapsed in two categories to perform a chi-square test with Yate's correction. The collapsing of the five response categories into two respose categories was necessary due to the small frequency of states with mandated policies in multicultural education. The strongly agree and agree categories were collapsed into one category, while neutral, disagree and strongly disagree 
were considered the other category. This process was reversed for items six and eight due to the directionality of the statement. The two new categories we labeled: positive and negative. The chi-square test was applied to each item to determine if response patterns differ according to the policy mandate variable. The collapsed frequencies and observed variables are displayed in Table $\mathrm{XV}$.

TABLE XV

A COMPARISON OF THE CSSO'S PERCEPTUAL RESPONSE AND THE POLICY MANDATE VARIABLE

\begin{tabular}{lllll}
\hline Statement & Mandated & \multicolumn{2}{l}{ Non-Mandated } & \multirow{2}{*}{ Obs } \\
& Pos. Neg. & Pos. Neg. & $x^{2}$ obs \\
\hline
\end{tabular}

1. Multicultural educa-

tion has had a strong, positive impact on students and school personnel statewide

$\begin{array}{lllll}6 & 2 & 16 & 17 & 3.0429\end{array}$

2. Most schools in this state are involved in multicultural education.

$\begin{array}{lllll}7 & 1 & 11 & 22 & 10.028 *\end{array}$

3. In this state, many school environments have been positively changed as a result of multicultural education.

4. Multicultural education has been a major educational focus in this state.

5. Multicultural education is visible in all curriculum scope and sequences, $\mathrm{R}-12$.

6. The future of multicultural programming

is questionable

. 
TABLE XV Continued

\begin{tabular}{lllll}
\hline Statement & Mandated & Non-Mandated \\
& Pos. Neg. & Pos. Neg. & $\mathrm{x}^{2}$ Obs \\
\hline
\end{tabular}

7. State policy (laws, rules, regulations) has been the primary force behind the development and implementation of multi$\begin{array}{llllll}\text { cultural programming. } & 8 & 0 & 5 & 28 & 25.506 \text { * }\end{array}$

8. Other educational priorities are negatively affecting the development and impact of multicultural programming.

$\begin{array}{lllll}5 & 3 & 13 & 20 & 2.491\end{array}$

9. The various ethnic communities have been supportive and involved in multicultural programs.

10. State educational agencies have been active in multicultural programming at the local level. $8 \quad 0 \quad 21 \quad 10 \quad 5.368$ *

*Significant at .05 level, $\mathrm{x}^{2}$ critical $=3.841$.

From Table XV, one can observe that responses to six of the ten items are distributed differently (in a statistically significant manner) on the policy mandate variable. The variable impacts statements two, three, four, five, seven and ten.

As mentioned earlier in the chapter, statements two, four, and five are related to the extent of the implementation of multicultural education. The policy variable appears to impact the extent of implementation. 
Statements one and three deal with the perceived impact of multicultural education. While statement one is not statistically significant of the .05 level, it is approaching statistical significance and statement three is statistically significant. This evidence again tends to support the importance of the policy variable.

state policy is the focus of statement seven and as might be expected, the policy variable appears to be important in impacting the csso's responses.

Statements six and eight address the future of multicultural education. The policy variable appears to have no significance in the responses of the cssos. But, the frequencies show a clear alignment of policy mandates with positive responses and the non-mandated frequencies align with the negative side.

Statements nine and ten focus on the groups and agencies involved in the planning, support and implementation of multicultural education. Statement nine is not statistically significant while statement 10 is statistically significant. When the ferquencies are examined, one can observe that the responses in both the mandated and non-mandated categories tend toward the positive with statement ten showing that tendency the strongest. Statements nine and ten are the only two statements in which this tendency is displayed. 
An examination of the data suggests that the policy variable appears to be important in impacting the responses to the cssos on the ten statements.

As mentioned in Chapters I and II, contemporary scholars are concerned about multicultural education's survival in the $1980^{\prime} \mathrm{s}$. The rebirth of this educational reform occurred three decades ago with the Brown (1954) decision. This year, many reports will be issued speculating about the success or failure of multicultural programming as a by product of early attempts at school desegregation. Perhaps some inferences can be drawn about the future of multicultural education by analyzing the growth of policy mandates across the states during the last several years.

TABLE XVI

MULTICULTURAL PROGRAMMING POLICY MANDATES 1980-1984

\begin{tabular}{|c|c|c|c|c|}
\hline \multirow{2}{*}{ Policy Mandated In: } & \multicolumn{2}{|c|}{1980} & \multicolumn{2}{|c|}{1984} \\
\hline & Ereq. & $\overline{8}$ & Freq. & $\frac{9}{8}$ \\
\hline $\begin{array}{l}\text { Bilingual Education } \\
\text { Multicultural/Multiethnic Education } \\
\text { Ethnic studies } \\
\text { Affirmative Action Programs } \\
\text { Textbook Selection Process } \\
\text { Inservice Training or Technical } \\
\text { Assistance in Multicultural } \\
\text { Education } \\
\text { Total }\end{array}$ & $\begin{array}{l}20 \\
10 \\
11 \\
26 \\
17\end{array}$ & $\begin{array}{l}40 \\
20 \\
22 \\
54 \\
34\end{array}$ & $\begin{array}{r}16 \\
9 \\
5 \\
26 \\
8\end{array}$ & $\begin{array}{l}32 \\
18 \\
10 \\
52 \\
18\end{array}$ \\
\hline
\end{tabular}

Observed $x^{2}=34.705 ;$ critical $x^{2}=11.07 ;$ df $=5 j d=.05$ 
In 1980, this researcher conducted a similar study anticipating a longitudinal comparison. Four years have witnessed a reduction in the frequency of state policy mandates for multicultural educaton (See Table XVI).

A chi square was conducted on the two frequency distributions (1980 and 1984). The calculated chi square was 34.705; the statistical hypothesis was rejected at the .05 level. A statistically significant downward trend in the frequency of policy mandates in multicultural programming between 1980 and 1984 occurred.

An examination of the data in Table XVI reveals that the most stability over the last four years in frequency count appeared in the two categories of multicultural education and affirmative action. Other areas fluctuated by at least four frequencies.

Other policy studies in this area were mentioned in Chapter II (Marconnit, 1968; Buffington, 1974; AACTE, 1978). While these studies are similar, this researcher felt statistical comparisons were not appropriate based on the variances in operational definitions, etc. However, the frequencies from these previous studies are presented in Table XVII. 
TABLE XVII

COMPARATIVE GROWTH OF STATE MANDATED PROGRAMS, 1974-1984

\begin{tabular}{|c|c|c|c|c|}
\hline Multicultural Programming & $\begin{array}{c}1974^{\mathrm{Mu}} \\
\text { (Buff-- } \\
\text { ington) }\end{array}$ & $\begin{array}{l}\text { States } W \\
\text { iticultu } \\
1978 \\
(\text { AACTE })\end{array}$ & $\begin{array}{l}\text { th Mandat } \\
\frac{\text { al Progr }}{1980} \\
\text { (Greene) }\end{array}$ & $\begin{array}{l}\frac{\text { amming }}{1984} \\
\text { (Greene) }\end{array}$ \\
\hline Bilingual Education & 13 & 23 & 20 & 15 \\
\hline $\begin{array}{l}\text { Multicultural/Multiethnic } \\
\text { Education }\end{array}$ & 8 & 33 & 10 & 9 \\
\hline $\begin{array}{l}\text { Textbook Selection Process } \\
\text { Addressing }\end{array}$ & 6 & 15 & 17 & 8 \\
\hline $\begin{array}{l}\text { Teacher Training/Technical } \\
\text { Assistance in Multicultur } \\
\text { Programming }\end{array}$ & al & 15 & 17 & 7 \\
\hline Total & 31 & 86 & 64 & 39 \\
\hline
\end{tabular}

From examining the frequencies presented in Table XVII

growth in programming continues through 1978. This comparison must be made with reservation. The AACTE (1978) study defined states with mandated multicultural education differently from all the other studes. The AACTE used multicultural education much the way the term multicultural education programming was used in. this study. This explains the high frequency of mandated multicultural program found in 1978. 
TABLE XVIII

PERCENT OF STATES WITH AT LEAST ONE MANDATED

MULTICULTURAL PROGRAM, 1968-1984

\begin{tabular}{lccccc}
\hline & 1968 & 1974 & 1978 & 1980 & 1984 \\
\hline $\begin{array}{l}\text { Percent of states with } \\
\text { at least one multi- } \\
\text { cultural program }\end{array}$ & 28 & 488 & 668 & 768 & 668 \\
\hline
\end{tabular}

Marconnit, 1968; Buffington, 1974; AACTE, 1978; Greene, 1980.

The percentage figures of states with at least one mandate indicate a downward trend between 1980 and 1984 just as the earlier statistical anlaysis on the frequency of the occurrence of policy mandates.

\section{Summary}

This chapter has presented the data from Part I and Part II and examined the significance of the policy mandate variable on the responses of CsSos. The longitudinal aspect of the study was also examined and discussed.

The findings regarding policy status are summarized by the observation that nine states have mandated programs in multicultural/multiethnic education, 16 states have mandated bilingual education programs, five states have mandated ethnic studies programs, 26 states have mandated affirmative action programs, nine states have mandated textbook 
selection policies, and seven states with mandated inservice training and technical assistance.

Implementation was addressed through the study of nine administrative processes in four major categories. The administrative process category consistently rating the lowest in frequency of usage was evaluation and review. An additional finding presented in this chapter is that the policy mandate variable effects the csso's, perception of multicultural education's impact, the extent of the implementation of multicultural education and the role of policy in promoting multicultural education. Also, the data reveals that since 1980 there has been a downward trend in the frequency of mandates as well as the percentage of states with at least one multicultural policy mandate. 
CHAFTER $\vee$

SUMMARY, CONCLUSIONS AND RECOMMENDATIONS

\section{Introduction}

This chapter will present a brief summary of the study, conclusions resulting from the findings, and recommendations for further research.

\section{Summary of the study}

America's population is diverse in ethnic and cultural composition. This wealth of diversity has been viewed as a positive attribute, but has also resulted in prejudice, discrimination and intergroup tension. Efforts to deal with this social problem have ranged from philosophical rhetoric to government funded programs. One recent phenomena has been the rise of the multicultural education movement.

This study addresses the growth of this movement through a policy analysis paradigm. Policy analysis has been viewed by Boyan (1981) as a conceptual framework for examining the practice of educational administration. This study focuses on the growth of multicultural education through policy formation, the administration of 
multicultural education through policy implementation and the effects impact of multiculutral education through policy impact analysis.

The focus of the study centers around these basic questions related to the policy analysis paradigms presented by Jones (1977) and Heflin (1981):

1) What is the current status of multicultural education programming policy mandates at the state level?

2) Have certain administrative practices been employed by the state education agencies in implementing multicultural programming?

3) What are the perceptions of chief state school officers (CSSO) as to the effectiveness and status of multicultural programming in their state?

To obtain data in response to those questions, a survey was mailed to all fifty chief state school officers inquiring about policy mandates and administrative practices. In addition, responses were solicited from CSSO's regarding perceptual statements about multicultural education.

In general, this study was in response to evidence in the professional literature indicating that multicultural education might be at the crossroads. Since the 1954 Brown Decision, three decades have passed and the 
progress and success of multicultural education is in question. The desegregation movement, sparked by the Brown decision, is now viewed as one aspect of the multicultural movement. Those three decades have given birth to other aspects of the multicultural movement as well. Ethnic studies, affirmative action, bilingual education, textbook selection, and teacher training have been influenced by the Brown doctrine during the past three decades. All of these institutional programs coupled with a general social awareness have resulted in improved educational opportunities for many of America's students (Clayton, 1984). Randolph, an educator in Charlotte-Mecklenburg School District (the nation's 30 th largest) claims that the multicultural movement including desegregation and other multicultural/multiethnic programs has been successful. He states:

Desegregation does work! It has made so many good things possible in our community. Just a little more than a third of our city is Black, yet Blacks serve at every level of government. We recently elected a Black mayor. Neighborhoods have significantly integrated.

'The schools,' says Randolph, 'have brought people
together in a way that no other institution in
society could have.' (Clayton, 1984, p. 5)

While successes have been noted, others claim we have not arrived at educational and social equality. Now, in a time of relatively reduced ethnic tension, is not a time to abandon multicultural educational practices in favor of 
other priorities and this concern is noted by Banks (1983). Banks' observation provided this researcher with incentive to provide some empirical data upon which professional educators might assess the degree of severity of Banks' concern.

\section{Policy Formation Conclusions}

The current status of state-level policy mandates related to multicultural programming is as follows. There are :

1) Nine states with mandated programs in multicultural education.

2) Sixteen states with mandated programs in bilingual education.

3) Five states with mandated programs in ethnic studies.

4) Twenty-six states with mandated affirmative action plans.

5) Eight states with mandated multicultural textbook selection processes.

6) Seven states with mandated multicultural inservice or technical assistance programs. Thirty-three states have at least one mandated multicultural program and 33 states have at least one statewide, non mandated program. 
In regards to the status of state-level policy mandates for multicultural education programming, the findings indicate an overall decrease in the frequency of states with policy mandates since 1980. This research documents that fewer policy formulation efforts aimed at developing multicultural programming have resulted in policy mandates. However, one cannot infer that the year 1984 has resulted in less interest and practice of multicultural education because an examination of the frequencies of standard practice (non-mandated) in the 1980 and 1984 studies reveals a distinct increase. In 1980, only 52 states responded in that manner while 1984 resulted in 95 incidences of widespread, but not mandated multicultural programming. The percentage of states with at least one mandated program in multicultural education also decreased of $10 \%$ over the last four years. Therefore, one can conclude that legitinzied policy frequencies have decreased over the last four years, but that conclusion may not reflect the complete activity in multicultural programming.

In general, the current status of multicultural education programing policy at the state level has decreased over the last four years, but the widespread practice of multicultural programming has increased; however, mandated policy may be an important factor in the program's perceived success. The literature related to multicultural 
education refers to the important role of policy in facilitaling its implementation. Blumenberg (Banks, 1981) stresses policy as vital to a successful program and GolInick (1983) underscores its importance as "institutional support." Certainly Gollnick is including staff, and financial support in the phrase "institutional support," but she is also referring to policy. Policy provides direction in any organizational environment undergoing any type of change. Unfortunately, policy legitimization appears to be on the downward trend. The data might suggest that the "crossroads" have been passed and multicultural education is no longer an important focus. This study also discovered an increase in its widespread practice which provides encouraging evidence for the advocacy of multicultural programming.

\section{Policy Implementation Corclusions}

The second focus of the study was to determine if any particular administrative practices were commonly used by SEAs in the implementation of multicultural education policy. Since only nine states have mandated programs in multicultural education, the findings are not conclusive. Drawing generalizations about all 50 states based upon nine is a dangerous practice, but looking at the findings regarding the nine states yields some descriptive datạ. 
Three administrative practices are common to the nine states.

They are:

1) The involvement of students, teachers, administrators and community members in planning for multicultural education at the state level.

2) Staffing patterns and organizational structure of the SEA indicate an evidence of multicultural education.

3) Specific personnel are assigned the responsibility for multicultural education.

None of the other administrative practices show such strong commonality of usage, but it is interesting to observe the obvious low frequencies in the area of evaluation and review. All other categories of administrative practices investigated had at least $67 \%$ claimed usage while only $33 \%$ of the nine states made use of any of the evaluation practices. This finding supports some professional literature which points to the lagging of public agencies behind private industry in practicing effective evaluation. (Buchele, 1977)

This researcher concludes that the policies mandating multicultural education do not address the implementation (administrative procedures). Implementation appears to be left to the professional SEA administrator. The frequency in which multicultural education is assigned to 
specific personnel is significant and tends to support this researchers conclusions. Those personnel and their functions are then reflected on the SEA's organizational chart. The data reflects this correspondence and supports the notion that multicultural education policy implementation generally rests with specific SEA personnel. The findings indicate that those SEA administrators may then turn to a task force or advisory board composed of community members, students, teachers and administrators.

\section{Policy Impact Conclusions}

The third focus of his study was to examine the impact of multicultural education through the opinions of the chief state school officers. Those opinions are based on the CSSO's responses to ten value statements. While the specific findings are presented in Chapter IV, the following generalizations are based on the data.

1) Multicultural education is viewed as a positive idea and its implementation has resulted in some successes.

2) Multicultural education is not a major focus and its implementation has not been accomplished in a majority of schools across the nation.

3) The future of multicultural education is questionable. The cSsos provide mixed signals about the future of such programming. However, other educational priorities are not negatively 
affecting multicultural education's development, according to the cssos.

4) Multicultural education as we know it today is probably the result of a grassroots effort from ethnic communities for such an innovation rather than an internal policy decision. SEAs have responded in attempts to implement such programs, but policy formulation and adoption has not been one of the initial forces behind implementaton, nor for that matter, the end result.

However, in analyzing the data from Part I and Part II of the survey instrument, it appears that policy directives impact chief states school officer's perception of the success of the mandated multicultural programming. Those Csso's with mandated policies tended to respond more favorably to the perceptual statements. Therefore, policy plays an important role in the implementation and success of programming at least for the eight states with mandated programs.

Multicultural education has had a national impact. It appears to be an increasing practice, but not formalized at the policy level. While cssos view the impact of multicultural education as positive, it is not fully implemented at this point, nor are we sure exactly what has been implemented. We are not sure of its future, but 
we do know that it is being supported by ethnic community groups and that SEAs are heavily involved in its implementation. Other educational priorities (finances, excellence endeavors, basic skills) appear to only have a modest negative impact on multicultural education. Multicultural education has evolved through conceptual changes and its implementation has been varied, but it has had an impact on the nation's schools.

After examining the data from of this study, it seems appropriate to attempt to respond to the observation which to some extent inspired this study. Banks (1983) asserts that multicultural/multiethnic education is at the crossroads. He is implying that its time is now, or it may never be realized as conceived. Gay also emphasizes that the critical time is now. What is its status and future of multicultural education?

The multicultural education movement is strong where America's cultural diversity is present. New York and California are prime examples. These states strongly reflect America's diversity and have multicultural policies and programs and the ethnic community and involvement. Policy adoption and existence has decreased, at least the awareness of policy existence has diminished in the last four years, yet the widespread practice of various multicultural programs has increased. The "conservative reentrenchment" Gay (1983) has warned about is educationally 
evident in such programs as basic skills, yet many cssos perceive no negative affect of such programs on the development of multicultural education. Fositive results are happening as a result of multicultural programming as well as an increase in its practice. So is multicultural education at the crossroads where one turn results in continued survival and another turn results in an educational grave? This study supports Banks' assertion. The data also tends to support this conclusion. The multicultural education movement appears to be typical of an evolving developmental program, formed in a crisis reactive time with only a recent development of the conceptual and theoretical framework. It is also typical of a program in which there is a lack of a research base. While this study has resulted in some indicators, further research in the field is necessary.

\section{Suggested Further Research}

The field of research in multicultural education is limitless. For this writer, some immediate research issues come to mind as a result of this project.

The policy mandates identified in this study frequently result in program development. One such mandated program is in the area of inservice education. In order to assess the effectiveness of inservice education programs and determine levels of multicultural competence in 
teachers, a reliable assessment tool needs to be developed. This assessment tool could have broad application in pre and post settings or for use in needs assessment projects. Indirectly, the use of this tool would then be one factor used in evaluating the impact of a policy mandate. The assessment tool could be composed of attitudinal and factual items. An attitudinal and factual scale might assess the level of multicultural competency of the individual. The scale results might be developed and presented around Banks models of developmental levels of multiculturalism (1981).

While such an assessment instrument would be of value to those working with adults in the area of multicultural education an elementary version of the instrument would serve all the same purposes previously mentioned for adults and it would give school administrators and teachers information for program development and evaluation. Such an instrument would serve to focus importance on this area of affective education in an educational climate that is so focused on student cognitive outcomes. of particular interest to this researcher, would be the examination of the policy mandates in multicultural education documented in this study. A content analysis of the policy combined with the policy development history might unearth some interesting similarities or parallels and be of interest to policy scholars. 
Also, to study the implementation of the documented policy mandates in this research would be of interest and value. An examination of the educational implementation of the policy mandate through the conceptual framework of policy implementation analysis would serve to further the advocacy of policy analysis as a framework for studying administration.

These suggested research endeavors would be timely and serve the needs of all humanity towards facilitating positive intergroup relations.

\section{Summary}

This chapter has provided a summary of the study and a discussion of the findings of the study in relation to the conceptual framework of policy analysis. The current legitimation of multicultural programming has been documented, the administrative practices involved in implementing multicultural education have been presented and the impact of multicultural educational policy has been discussed through the perceptions of the CSSOs. Further analysis of the data also provided in evidence which supports the position that the existence of a policy mandate may be an important variable in perceived program success. Also, the data verifies that multicultural policy mandates are less frequent in 1984 than in 1980. In conclusion, it appears that multicultural education is perceived as a positive force, yet it has not 
been a major focus in a majority of the states, and policy supporting multicultural programming is on the downward trend. Is multicultural education at the crossroads? Conflicting positive and negative data and the confusion of the CSSOs regarding multicultural education's future points to a program stopped at the intersection with a driver unsure of which way to turn. 


\section{Bibliography}

American Association of Colleges for Teacher Education, Commission on Multicultural Education. State legislation, provisions and practices related to multicultural education. Washington, D.C., 1978.

American Association of Colleges for Teacher Education, Commission on Multicultural Education. No one American model. Washington, D.C., 1972.

Backstrom, Charles H., Cesar-Hursh, Gerald. Survey research. New York: Wiley and Sons, 1981.

Baker, Gwendolyn C. The effects of trainisg in multiethnic education on preservice teachers' perceptions unpublished dissertation. The University of Michigan, 1972.

Baker, Gwendolyn C. Two preservice training approahces Journal of Teacher Education, 28, No. 3, May-June 1977, 31-33.

Baker, Gwendolyn C. Policy issues in multicultural education in the United States. Journal of Negro Education, $1979, \underline{48}, 253-266$.

Baker, Gwendolyn C. Motivating the culturally different Momentum, February, 1983, 45-46.

Baker, G. Multicultural imperatives for curriculum sevelopment in teacher education Journal of Research and Development in Education, $2,1977,70-83$.

Banks, James A. A response to Phillip Freedman. Phi Delta Kappan, 1977, 58, 695-697.

Banks, James A. Multicultural education at the crossroads," Phi Delta Kappan, 1983, 느, 559.

Banks, James A. Multiethnic education: Practices and promises. Bloomington, Indiana: The Phi Delta Kappa Foundation, 1977.

Banks, James A. Multiethnic education. Boston: Allyn and Bacon, Inc., 1981. 
Banks, James A. Keynote Address, Metropolitan Human Relations Commission, Portland, Oreqon, May, 1983.

Banks, James Ed., Education in the 80's: multiethnic education. Washington, D.C., NFA, 1981.

Babtiste, H. Pentrice, Jr. Multicultural education: a synopsis. Washington, D.C. University Press of America, Inc., 1979.

Baptiste, Prentice H. Tr.: Baptiste, Mira L.: Miott, Roosevelt. An analysis of upper elementary afroanglo-and mexican-american studies attitudes toward race related concepts" Journal of Research and Development in Education, Vol. 2, No. 1, November, 1977, 46-51.

Beckum, Leonard; Dasho, Stefan, Accommodatina diversity. San Francisco, CA: Far West Lab, April, 1981.

Bell, Derrich, Learning from our losses: is school. desegreqation still feasible in the 1980's?" Phi Delta Kappan, April, 1983.

Blumenbera, Eleanor, Multiethnic education in the 80s: an action aqenda plan in Banks, James. Ed, Education in the 80's: multiethnic education washington, D.C.: NEA, 1981 .

Bolmeier, Edward $C$. The School in the leqal structure. Cincinnati, OH: The W.H. Anderson Co., 1968.

Boyan, Norman Follow the leader: commentary on research in educational administration Educational Researcher, February 1981.

Boyd, W.L. and Immeaart, G.L. Fducation's turhulent environment and problem findina: 1 ines of convergence.". In G.L. Immegart and W.L. Boyd (Eds), Problem-Findina in Educational Administration: Trends in Research and Theory. Lexington, Mass.: D.C. Heath, 1979.

Brenbeck, Cole S. and Hill, Walker H. Cultural Challenqes to Education. Toronto Ontario, Canada: Lexington Books, 1973 .

Brouillet, Frank B, Guidelines for multicultural education. Washinaton state Department of Education, Olympia, WA: May, 1983.

Brouillet, Frank B. Evaluating the School for Multicultural Education, State of Washington, 1983 . 
Brower, Cathy Florida State Department of Education, telephone conversation, May, 1984.

Buchele, Robert $B$. The mangement of business and public orqanization. New York: McGraw-Hill Co., 1977.

Buffington, Lamont E. A survey of statutory provisions mandating multicultural education or training in interpersonal and intergroup relations. A Look at the Education of Teachers: Preservice and Inservice Training, Conference Proceedings, Program of Equal Educational Opportunity, School of Education, University of Michigan. Ann Arbor, 1974.

California State Department of Education, School staff preparation in the history, culture, and current problems of diverse ethnic groups. Office of Intergroup Relations, Revised 1978.

Campbell, Roald et al. The organization and control of american schools. Merrill Books, Inc., Columbus, Ohio, 1965 .

Campbell, Roald F. Public schools and the challenge of cultural pluralism. Theory into Practice, 1978, 15, 260-266.

Campbell, Roald, A critique of the educational administration quarterly. Educational Administration Quarterly, Vol. 15: Fall, 19 $\overline{79,1-19 .}$

Campbell, Roald F. and Sroufe, Gerald R. Toward a rationale for federal-state-local relations in education. Phi Delta Kappan, 1965, September, 1965, 2-7.

Clayton, H. 30 years after brown. NEA Touay, March, 1984.

Cole, Beverly P. The state of education for black americans. Education Digest, Dec. 1983, 28-32.

Commager, Henry S. Free public schools--a key to national unity, in Ehlers, Henry, ed. Critical Issues in Education. New York: Holt, Rinehart and Winston, 1969.

Commonwealth of Massachusetts. Transitional bilingual education law chapter 71A, $19 \overline{72 .}$

Cross, D.; Baker, G.C.; and stiles, L.J. Teaching in a multicultural society, New York: MacMillan Publishing Co., 1977.

Cuban, Larry, Ethnic content and white instruction, Kappan, January, 1972, 273 . 
Currie, walker, Cultural issues in education: a book of readings. Los Anqeles: National Dissemination and Assessment Center, California State University, 1978.

Dasho, stefan J. Responding to teachers' concerns with qualitative inquiry. San Francisco, CA: Far West Lab, March 1982 .

Dolce, C. J. Multicultural education. The Journal of Teacher Education 1973, 24, 282-28

Duet, Claude P. Trends in legislating curriculum, Educational Leadership, 1976, 33, 125-127.

Epps, Edgar G. Cultural Pluralism. Berkeley, California: McCuthan Publishing Corp., 1974.

Fox, David J. The research process in education. New York: Holt, Rinehart, Winston, 1969.

Freedman, P. Multiethnic studies: proceed with caution, Phi Delta Kappan, 1977, 58, 401-403

Gay, Geneva Racism in America: imperatives for teaching ethnic studies, in James A. Banks, ed., Teaching Ethnic studies: Concepts and strategies. Washington, D.C.: National Council for the Social studies, 1973.

Gay, Geneva, Retrospects and prospects of multicultural education. Momentum, February, 1983, 5.

Gay, Geneva, Why multicultural education in teacher preparation prourams, Contemporary Fducation, Vol. 54, No. 2, winter, 1983.

Gezi, Kal. Issues in multicultural education. Educational Research Quarterly, Fall, 1981, $6,5-13$.

Gibson, M. Approaches to multicultural education in the United States: some concepts and assumptions. Anthropology and Education Quarterly, 1976, 7(4), 7-18.

Glock, C. Y. (Ed.), Survey Research in the Social Sciences, New York: Russell Saqe Foundation, 1967.

Gollnick, Donna and Klassen, Frank. Pluralism and the american teacher, Washington D.C.: American Association of Colleges for Teacher Education, 1977.

Gollnick, Donna. Teacher education proqrams that have met the NCATE multicultural standard. Washington, DC: AACTE, unpublished report, 1983. 
Grant, Carl A. Multicultural education: commitments, issues, applications, Nashington, D.C. Association for Supervision and Curriculum Development, 1977.

Green, Thomas F. The Activities of Teachina. New York: McGraw-Hill, 1971.

Greene, Thomas G. A status report: statutory provisions mandating multicultural education in the fifty states. unpublished manuscript, 1980 .

Hackett, Gail. Survey research methods. The Personnel and Guidance Journal, Vol. 59:9, May 1981, 599-604.

Hales, Loyde, An introduction to nonparametric tests - $x^{2}$, unpublished manuscript, 1980.

Harris, Ben M.; McIntyre, Kenneth E.; Littleton, Vance C.; and Long, Daniel F. Personnel administration in education. Boston: Allyn and Bacon, 1979.

Hazard, William R. Education and the law (2nd Ed.). New York: The Free Press, 1978.

Heflin, John. Perspectives on educational policy research, paper presented at annual meeting of the american educational research association, San Francisco, California, Aoril 7, 1979

Heflin, John. Leadership training for integrated educationFinal Report on a staff Development Project to Supplement Portland Public School District's Comprehensive Desegregation Plan, Portland, Oregon, 1980.

Heflin, John. Perspectives on policy analysis. Paper presented at the annual retreat of ESEA Title I, technical assistance center: Northwest Regional Educational Laboratory, Newport, Oregon. July 1, 1981.

Heflin, John F.; Broussard, Camille; and Gudger, Gregory, A survey of multicultural teacher education in oregon higher education institutions. Metropolitan Human Relations Commission, Portland, Oregon. March 1983.

Hollins, W. E. Beyond multicultural education. The Negro Educational Review, 198\%, 33 140-145.

Hornbeck, David. Guidelines for multicultural education, Maryland state Department of Education, 1980 .

Ijaz, M. Ahmed. Study on ethnic attitudes of elementary school children toward blacks and east indians. A Report to the Scarborough Board of Education, ERIC Document, February, 1981. 
Illinois state Department of Education, School code of illinois, Illinois state Board of Education, 1981.

Kallen, Horace M. Democralcy versus the melting pot. Nation, February 18, 1915.

Innaccone, Lawrence. Politics in education. New York: The Center for Applied Research Research in Education, Inc., 1967.

Itzkoff, Seymour $w$. Cultural pluralism and americaneducation. Scranton, Pennsylvania: International Textbook Co.: 1969 .

Jones, Charles 0 . An introduction to the study of public policy. Duxbury Press, 1977.

Kentucky State Textbook Commission. Policy statement for textbook selection. State Department of Education, (no date).

Kerlinger, Fred, Foundations of behavioral research, (2nd. Ed). New York: Holt, Rinehart and Winston, Inc., 1973.

King, Edith and Milan, Marjorie, Identifying promising practices in teaching ethnically diverse children in elementary schools. ERIC, 1981.

Kirby, Douglas and Scales, Peter An analysis of state guidelines for sex education instruction in public schools. Family Relations, April 1981, 229-237.

Kirk, Diana and Goon, Susan. "Desegregation and the cultural deficit model: An examination of the literature," Review of Educational Research, 1975, 45, 4.

Kitano, Harry. Race relations. Englewood Cliffs: Prentice Hall, Inc., 1980 .

Klassen, Frank and Gollnick, Donna, Pluralism and theamerican teacher issue and case studies, washington, D.C. Ethnic Heritage Center for Teacher Education of the AACTE, 1977.

Krueger, Jack and Parish, Ralph Implementing New School programs. Education Digest, April, 1983.

Lehne, Richard. State government in education, Education digest, December, 1983, 40-45.

Livingston, Alexander. Evaluating attitudinal change in a multicultural setting. ERIC, 1978 . 
Mahan, James and Lacefield, Warren. Employability and multicultural teacher preparation," Education Research Quarterly, 1982, 7, 15-20.

Mahan, James and Boyle, Virginia. Multicultural teacher preparation: an attitudinal survey. Education Research Quarterly, 1981, 6, 22-24.

Marconnit, George D. State legislatures and the school curriculum. Phi Delta Kappan, 1968, 49, 269-272.

Milan, Marjorie and King, Edith. Promising practices in teaching ethnicaliy diverse children in elementary school. Research In Education, March, 1981.

Miskel, Cecil and Sandlin, Terry. Survey research in educational administration. Educational Administration Quarterly, Vol. 17, No. 4, Fall 1981, 1-20.

Mitchell, D.E. The emergence of multiple paradigms in the politics of education. unpublished paper presented at the annual meeting of the American Political Science Association, Washington, D.C. 1979.

Morrison, L. Trigo. Cultural Pluralism. The Clearinghouse, Vol. 55, December, 1981.

Motley, Constance Baker. The role of 1 aw in effecting social change. Crisis, 1978.

National Council for Accreditation of Teacher Education. Standards for accreditaion of teacher education, Washington, D.C., 1977.

National Institute for Education. Grants for research on law and government in education. U.S. Department of Health, Education and Welfare, 1979.

Neuman, william M. Is multicultural education a new attempt at acculturation? in Grant, Carl A., Multicultural Education: Commitments, Issues, and Applications, Washinaton, D.C., Association for Supervision and Curriculum Development, 1977.

New York State Department of Education, Action plan to improve elementary and secondary education results in new york. New York Board of Regents, 1983.

Novack, Michael. The rise of the unmeltable ethnics. New York: The MacMillan Co., 1971.

Obatala, J.K., Black studies: stop the shouting and go to work. Smithsonian, Dec. 1974, 47-53. 
Oqilvie, Barnetto s. The Multicultural Education Quick Assessment Test. Washinaton State Department of Fducation, July, 1983.

Pate, Glen and Garcia, Jesus. Multiethnic/multicultural education: A Review of proqrams The Clearing House, 1981, 55. 132-135.

Payne, Charles R. Multicultural education: a natural way to teach. Contemporary Education, winter 83, 54, 98-104.

Pipho, Chris. State legislatures and the schools. Fducational. Leadership, $1980,38,127$.

Pratte, Richard The public school movement: a critical study. New York, New York: McKay Publishina Co., 1973.

Rist, Ray, student social class and teacher expectations: the self-fulfillina prophecy in ahetto education. Harvard Education Review, 40, Auqust, 1970, 411-449

Rosenthal, Alan and Fuhrman, Susan. State leqislatures and education policy Education Diqest, April, 1983, 22 .

Simpson, Carl. Classroom orqanization and the qap between minority and non-minority student performance. levels. Educational Research Quarterly Vol. 6, No. 3, 1981 .

Sims, E. William. Preparina teachers for multicultural classrooms. Momentum, February, 1983, 7-8.

South Dakota state Department of Education. School. district handbook for selection of instructional materials, 1980 .

Stone, James C. and DeNevi, Donald P. Teaching multicultural populations. New York: Van Nostrand Reinhold C., 1971.

Valverde, Leonard A. Multicultural education: social and educaional justice. Educational Leadership, $1977, \underline{35}, 196-201$.

Washinqton State Department of Education. Comoetencies for teaching multiculturally, 1983 . 
Washington, Valora. Impact of antiracism/multicultural education training on elementary teachers' attitudes and classroom behavior. The Elementary School Journal, $1981,81,186-192$.

Washington, Talora. Implementing Multicultural Education. Peabody Journal of Education, April, 1982, 44-48.

Weible, Tom and Dumas, Nayne. Secondary teacher certification standards in fifty states. Journal of Teacher Education, 23, July-August $1982, \overline{22-3}$.

West Virginia Department of Education, Equal employment opportunity plan, 1981.

West Virginia Department of Educaton, School laws of west virginia, 1981.

Wirt, Frederick, What state laws say about local control. Phi Delta Kappan, April, 1978, 517-520.

Wirt, F. M. The uses of political science in study of educational administration. In G.L. Immerqart and W. L. Boyd (Eds), Problem-Finding in Educational Administration: Trends in Research and Theory, Lexington, Mass: D.C. Heath, 1979.

Yeakey, Carol, Emerging policy research in education research and decision-making. Review of Research in Education, 10, 1983. 
APPENDIX A 
September 30,1983

I am engaged in a longitudinal study at Portland state University in which I am examining statutory provisions mandating multicultural programs. There are a variety of multicultural programs (i.e. bilingual education, multicultural/multiethnic education, ethnic studies, affirmative action programs, teacher education programs, etc.) which have received national attention in the wake of increasing ethnic awareness, but I am particularly interested in the response of state government to such programming.

In 1979, your office responded to a survey examining statutory provisions for such programming in your state. I am now soliciting another response to a similar expanded questionnaire. In 1979, I x seived a 1008 return, which was greatly appreciated and $i$ anticipating such a response again.

This survey is divided into two parts:

Part I -- A SURVEY: STATE LEVEL MANDATES REGARDING MULTICULTURAL PROGRAMS

Part II - A SURVEY: CHIEF STATE SCHOOL OFFICER'S PERCEPTIONS OF THE IMPACT OF MULTICULTURAL EDUCATION AT THE STATF LEVEL

Part I may be completed by any official you delegate. However, I would greatly appreciate it if you would take the time to complete Part II yourself.

Your response to Part II will not be used or identified singly. The information you share in Part II will be used only collectively with the responses of your colleagues. Thus, your individual perceptions will remain anonym:us to all but myself. Your response will be considered consent to participate in the study. Your assistance will be greatly appreciated.

You may have read the April, 1983 issue of the Phi Delta Kappan in which James Banks points to the fact that multicultural education is at the crossroads. Hopefully, the data collected from this survey may serve to quantify the impact of state action in the areas of multicultural programming and help determine its future as it faces the crossroads in the 80 's. 
Thank you in advance for your time and participation. A self-addressed envelope is enclosed for your convenience. Please give this your prompt attention.

Thank you!

Sincerely,

Thomas G. Greene

Should you desire a summary of this study, the results will be available by January, 1984. You may receive your copy by enclosing this form with the completed questionnaire.

Mail to: 
APPENDIX B 
A SURVEY: STATE LEVEL MANDATES REGARDING MULTICULTURAL PROGRAMS

DOES THE STATE OF RULES/REGULATIONS MANDATING THE FOLLOWING:

HAVE STATUTORY PROVISIONS/ADMINISTRATIVE

I MULTICULTURAL/MULTIETHNIC EDUCATION In:
A) Elementary Schools
B) Jr. High/Middle Schools
C) Secondary Schools
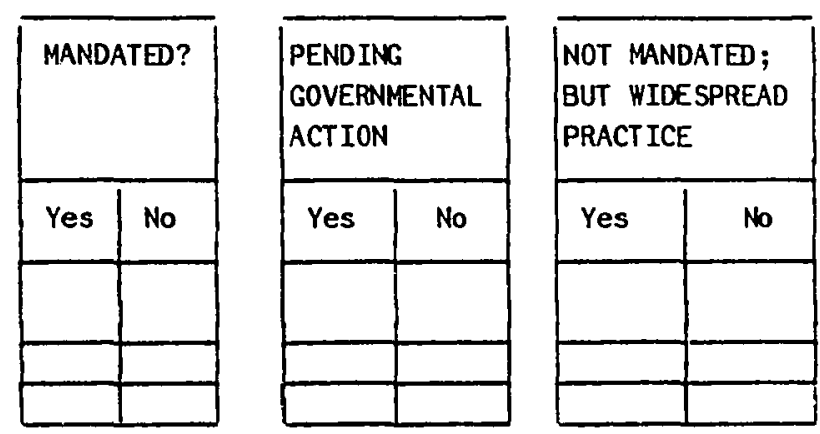

If your state does require multicultural/multiethric education, please respond to the following statements in relation to state department of education's activities.

\section{STATEMENTS}

RESPONSES

\section{PLANHING/ASSESSMENT}

1. Needs assessments have been conducted at the state level.

2. Students, teachers, community members and administrators have been involved in planning for multicultural education at the state level.

\section{ORGANIZATION/DEVELOPMENT}

3. Statewide specific goals and obfectives for the multicultural/mult ethnlc programs do exist.

4. Multicultural education is evident in state education agency (SEA) organizational structure and staffing patterns.

SUPERVISION/TECHNICAL ASSISTANCE

5. Specific SEA personnel have been designated responsible for mult 1cultural/multiethnic education.

6. Staff development programs are or have been conducted in multicultural/multiethric education for SEA personnel.

\section{EVALUATION/REVIEW}

7. A formal state level evaluation of the multicultural/multiethnic education program has been conducted. 
9. Evaluation has resulted in modiflcations to the multicultural/multiethnic program to improve its effectiveness.

9. Compliance or standardization reviews have been conducted in school districts.

Please clte or Include a copy of policy mandating multicultural education.

What SEA or specific personnel are responsible for implementing multicultural education?

OTHER PROGRAMS

II. BILINGUAL EDUCATION in

A) Elementary Schools

B) Jr. High/Middle Schools

C) Secondary Schools

\begin{tabular}{|l|l|}
\hline MANDATED? \\
\hline Yes & No \\
\hline & \\
\hline & \\
\hline & \\
\hline
\end{tabular}

\begin{tabular}{|l|l|}
\hline PENDING \\
GOVERNMENTAL \\
ACTION
\end{tabular}

NOT MANDATED;

BUT WIDESPREAD PRACT ICE

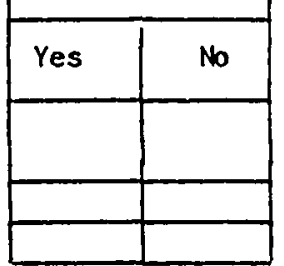

Is the bilingual program transitional or is it a program which helps students maintain the nat ive language?

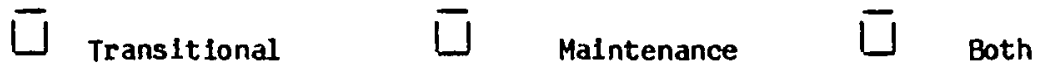

Please clte or Include a copy of pollcy mandating bllingual education.

What SEA or speciflc personnel are responsible for implementing bilingual education?

III. ETHNIC STUDIES in

A) Elementary Schools

B) Jr. High/Middle Schools

C) Secondary Schools

\begin{tabular}{|l|l|}
\hline MANDATED? \\
\hline Yes & No \\
\hline & \\
\hline & \\
\hline & \\
\hline
\end{tabular}

\begin{tabular}{|l|l|}
\hline $\begin{array}{l}\text { PENDING } \\
\text { GOVERNMENTAL } \\
\text { ACTION }\end{array}$ \\
\hline Yes & No \\
\hline & \\
\hline & \\
\hline & \\
\hline
\end{tabular}

\begin{tabular}{|l|l|}
\hline $\begin{array}{l}\text { NOT MANDATED; } \\
\text { BUT WIDESPREAD } \\
\text { PRACT ICE }\end{array}$ \\
\hline Yes & No \\
\hline & \\
\hline & \\
\hline & \\
\hline
\end{tabular}


If ethnic studies do exist in your state, what ethnlc group or groups are targeted for study?-

Please cite or Include a copy of policy mandating ethnic studies.

What SEA or specific personnel are responsible for implementing ethnic studies?

IV AFF IRMATIVE ACTION PROGRAMS

\begin{tabular}{|c|c|c|c|c|c|}
\hline \multicolumn{2}{|c|}{ MANDATED? } & \multicolumn{2}{|c|}{$\begin{array}{l}\text { PENDING } \\
\text { GOVERNMENTAL } \\
\text { ACTION }\end{array}$} & \multicolumn{2}{|c|}{$\begin{array}{l}\text { NOT MANDATED; } \\
\text { BUT WIDESPREAD } \\
\text { PRACTICE }\end{array}$} \\
\hline Yes & No & Yes & No & Yes ${ }^{\circ}$ & No \\
\hline & & & & & \\
\hline
\end{tabular}

Please cite or include a copy of pollcy mandating affirmative action.

What SEA or specific personnel are responsible for implementing affirmative Action?

V. TEXTBOOK SELECTION PROCESS which require that texts must reflect the cultural pluralism of the American population.

\begin{tabular}{|l|l|}
\hline MANDATED? \\
\hline Yes & No \\
\hline & \\
\hline
\end{tabular}

\begin{tabular}{|l|l|}
\hline PENDING \\
GOVERNMENTAL \\
ACTION \\
\hline Yes & No \\
\hline & \\
\hline
\end{tabular}

\begin{tabular}{|l|l|}
\hline NOT MANDATED; \\
BUT WIDESPREAD \\
PRACT ICE \\
\hline Yes & No \\
\hline & \\
\hline
\end{tabular}

Please cite or include a copy of policy mandating textbook selection.

What SEA or specific personnel are responsible for implementing textbook selection process?

VI INSERVICE TRAINING OR TECHNICAL ASSISTANCE in multicultural education.

\begin{tabular}{|l|l|}
\hline MANDATED? \\
\hline Yes & No \\
\hline & \\
\hline
\end{tabular}

\begin{tabular}{|l|l|}
\hline PENDING \\
GOVERNMENTAL \\
ACTION \\
\hline Yes & ino \\
\hline & \\
\hline
\end{tabular}

\begin{tabular}{|l|l|}
\hline NOT MANDATED; \\
BUT WIDESPREAD \\
PRACT ICE \\
\hline Yes & No \\
\hline & \\
\hline
\end{tabular}

Please cite or include a copy of policy mandating inservice training or technical assistance-

What SEA or specific personnel are responsible for implementing inservice training or technical assistance? 
APPENDIX C 


\section{A SURVEY: CHIEF STATE SCHOOL OFFICER'S PERCEPTIONS OF THE IMPACT OF MULTICULTURAL EDUCATION AT THE STATEHIDE LEVEL}

THIS IS THE RESFONSE FROH THE STATE OF

DIRECTIONS: Please respond to each statement with a check in the appropriate box.

\begin{tabular}{l|l|l|l|l|l|}
\cline { 2 - 5 } & $\begin{array}{l}\text { Strongly } \\
\text { Agree }\end{array}$ & Agree & Neutral & Disagree & $\begin{array}{l}\text { Strongly } \\
\text { Disagree }\end{array}$ \\
\hline 1. A. Multicultural education has had a \\
$\begin{array}{l}\text { strong, positive impact on students } \\
\text { and school personnel statewide. }\end{array}$ & & & & & \\
\hline
\end{tabular}

B. What percentage of students and school personnel have been impacted?

2 A. Most schools in this state are involved in multicultural education

\begin{tabular}{|l|l|l|}
\hline & & \\
\hline
\end{tabular}

B. What percentage of school are involved?

3. A. In this state, many school environments hiave been positively changed as a result of multicultural education.

B. Please cite one or more examples of school environments which have been positively changed.

4. A. Multicultural education has been a mafor educational focus in this state

\begin{tabular}{l|l|l|l}
1 & 1 \\
\hline
\end{tabular}

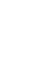


6. A The future of multicultural programing is questionable.

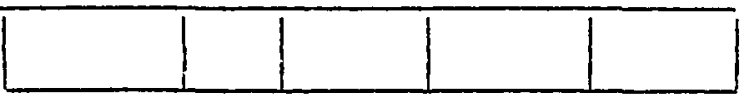

B. Why?

\begin{tabular}{l|l|l|l|l|l|}
\cline { 2 - 5 } & $\begin{array}{l}\text { Strongly } \\
\text { Agree }\end{array}$ & Agree & Neutral & Disagree & $\begin{array}{l}\text { Strongly } \\
\text { Disagree }\end{array}$ \\
\hline 7. A. State policy (laws, rules, regula- \\
$\begin{array}{l}\text { tions) has been the primary force } \\
\text { behind the development and imple- }\end{array}$
\end{tabular}
mentation of multicultural programing.

B. If so, what was the primary force behind passage of the law?

S A. Other educational priorities are negatively affecting the development

\begin{tabular}{|l|l|l|l|} 
& & & \\
\hline
\end{tabular}
and impact of multicultural programing.

B. If so, what other priorities are negatively affecting the development and impact of multicultural programs?

9. A. The varlous ethnic communities have been supportive and involved in multi-

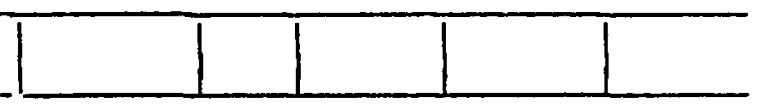
cultural programs.

B. What ethnic groups have been involved?

10. A. State educational agencies have been active In multicultural programing at the local level.

B. Please clte an example. 